\title{
EARTHQUAKE ENGINEERING RESEARCH AND PRACTICE IN MEXICO AFTER THE 1985 EARTHQUAKES
}

\author{
Luis Esteva*
}

\author{
This paper was presented as a keynote address at the Pacific \\ Conference on Earthquake Engineering, Wairakei, 5-8 August 1987.
}

\section{INTRODUCTION}

Before 1985, engineers and public in Mexico City knew that high intensity ground motion might occur on the surface of the soft soil formations spreading throughout a large portion of the Valley of Mexico, seat of the ancient Aztec capital of Tenochtitlan since 1325, of the capital of the Spanish colony since 1521 and of that of independent Mexico since 1821. However, both engineers and public were confident about the seismic safety of the city, on account of the use of reasonably up-to-date building codes and of the long experience of satisfactory performance of constructions when shaken by high intensity earthquakes. But the 1985 events showed that intensities might be much higher than those recorded in recent times, that the scarcity of information about extensive damage in ancient times did not suffice for reaching conclusions regarding risk to modern constructions and that the influence of repeated load cycles might make tall buildings significantly more vulnerable to long-duration narrow-band ground motion than was formerly believed, on the basis of laboratory tests and of observations of seismic response of structures built on firm ground.

A toll of several thousand lives lost, over 200 buildings partially or completely collapsed and about 1000 severely damaged makes the event of 19 September 1985 the largest disaster produced by an earthquake in a city built in accordance with reasonably modern structural safety regulations. This attracted many teams of engineers, seismologists, geologists, social scientists, emergency preparedness officers, among others, who came from every corner in the world, to observe the damage and to learn the lessons taught by that exceptional event. Many excellent reports describing types of damage, influence of local soil conditions and typical ground motion records were written, thus transmitting those lessons to the specialized international community.

This paper intends to describe the earthquake from the perspective of those who have followed the development of earthquake engineering practice in Mexico City prior to 1985 and who have been participating in the effort to learn from the earth-

Director and Professor, Institute of

Engineering, National University of Hexico quake and to tranform that learning into new design and construction regulations applicable to the immediate reconstruction process and to the long term revision of building codes. Writing of the paper has been feasible thanks to the kindness of several colleagues of the author, who have generously supplied him with their many results and pieces of information that he has tried to put together in order to describe in a few pages our attempts at learning from the earthquake and our efforts at revising our building codes.

\section{EARTHQUAKE ENGINEERING IN MEXICO CITY} BEFORE 1985

An account of the development of earthquake engineering practice in Mexico City was presented in Ref. 1. A summary of it follows.

Prior to 1985, the most severe earthquake since the advent of buildings of moderate height in the city took place in 1957, when an earthquake with magnitude 7.6 at $256 \mathrm{~km}$ of epicentral distance led to extensive damage, including the loss of nearly 100 lives and the collapse of a few buildings and structures of various types, most of which were in the aftermath discovered to bear blatant weaknesses. The distribution of damage called the attention to the influence of local soil conditions on the characteristics of earthquake ground motions, and this influence was taken into account, perhaps too timidly, in subsequent building codes. Widespread application of modern earthquake engineering in Mexico City starts right after this earthquake.

The seismic activity of the subduction zone in the southern coast of Mexico is among the highest in the world. Largemagnitude shocks generated in this region (Fig. 1) stand as the main contributors to seismic hazard on the soft soil area in Mexico City, although, as a consequence of the long epicentral distances involved, their intensities on the firm soil area in the city are usually very low, with peak ground accelerations only exceptionally above 4 percent of gravity. In addition, significant intra-plate activity and potential seismic sources capable of generating moderate magnitude shocks in the vicinity of Mexico City have been identified, but their relevance to seismic hazard in the city has not been assessed yet. 


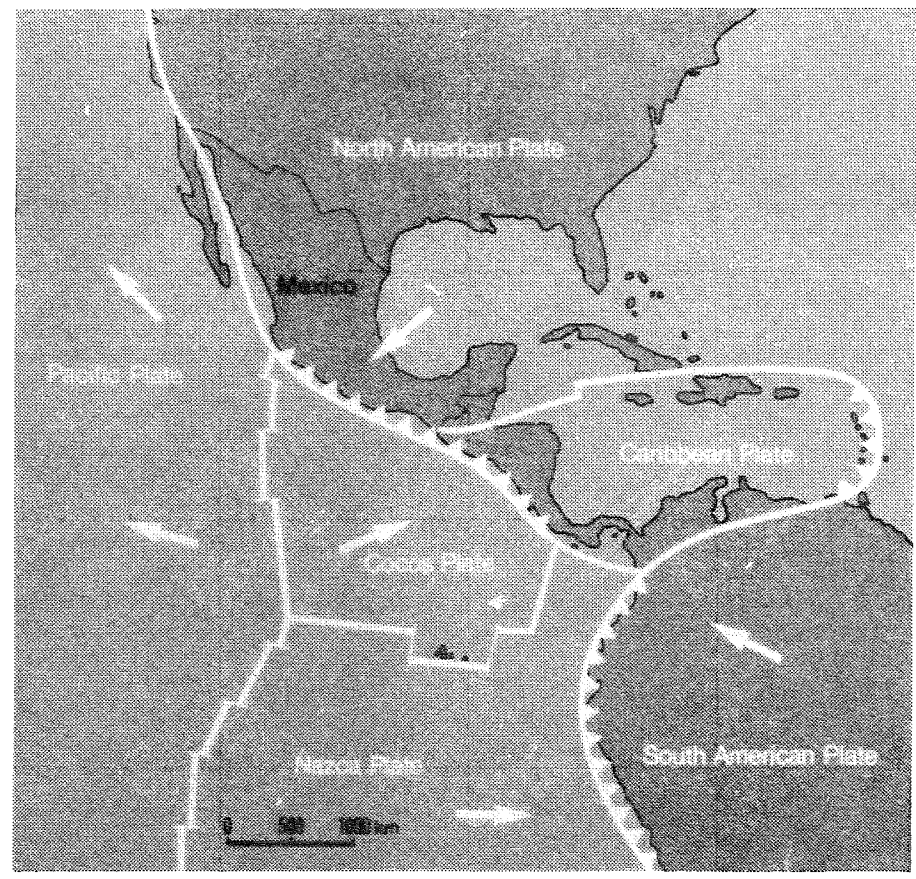

FIG. 1 - BOUNDARIES BETWEEN MAJOR CRUST PLATES IN THE REGION OF MEXICO AND CENTRAL AMERICA

The evolution of earthquake-resistantdesign codes in the city during the interval 1957-1985 was strongly influenced by the observations about structural performance during the 1957 event and during a number of moderate intensity shocks occurring every five years on the average. Mean rates of ground motion having mean accelerations in excess of given values were derived from records obtained at several locations on firm ground and soft soil in the Valley of Mexico during the interval 1959-1982 $(1,2)$. These rates are plotted in Fig. 2, adapted from Ref. 2. The highest acceleration recorded on soft soil during the observation interval nearly coincides with the value of 0.06 , estimated for the 1957 earthquake at the base of the Latin American Tower in downtown Mexico City. The latter value is about one third of that recorded in 1985 near the SCT building, within the area of highest intensity. Extrapolating the curves to long return intervals leads to the conclusion that peak ground accelerations in excess of $0.09 \mathrm{~g}$ and $0.14 \mathrm{~g}$ respectively may occur on firm ground and soft soil in the average once every 100 years. For 250 years the respective values are $0.14 \mathrm{~g}$ and $0.022 \mathrm{~g}$, approximately.

The design intensities proposed by the codes previous to 1985 were consistent with the experience described in the above paragraphs, although the intensity of the 1985 earthquake proved them to be excessively low. Historical information about previous earthquakes had not been carefully examined before 1985, and its interpretation is not free of difficulties, because the type of structures vulnerable in the face of lowacceleration long-period ground motion typical of the site -- that is, long-period frame buildings with moderate height -- did not exist in the city before the last few decades. The strongest earthquake previous to the one of 1985 for which a historical record is kept is perhaps that taking place in 1858, but the Aztec codices report a very large intensity in 1460

The highest intensity in Mexico City between 1858 and 1985 probably corresponds to the 1911 earthquake $(M=7.9$, originated at the same section of the subduction zone as the 1985 shock), when rails buckled, as they did in 1985. In 1932, a magnitude of 8.2, the largest since 1858, was generated on the coast at Jalisco, near the western end of the subduction zone, giving place to high intensity in Mexico City; however, damage was not particularly severe, oring to the large focal distance, relatively small population and absence of tall buildings. The largest intensity in the half century that followed took place in 1957. and only moderate intensities were observed from that time up to 1985 .

The code in force in Mexico City when the earthquake of 1957 took place had been promulgated in 1942, but it was often ignored or violated (in some occasions for the better), as it was deemed by engineers to be obsolete. The code called for base shear coefficients ranging up to $0.10 \mathrm{~g}$ depending on the importance of the structure, and permitted to increase by 33 percent the allowable stresses for the superposition of gravity and earthquake forces, with respect to those applicable to gravity loads alone. A uniform distribution of lateral force coefficients along the height of buildings was specified, but a triangular variation giving place to the same base shear was often adopted for the design 


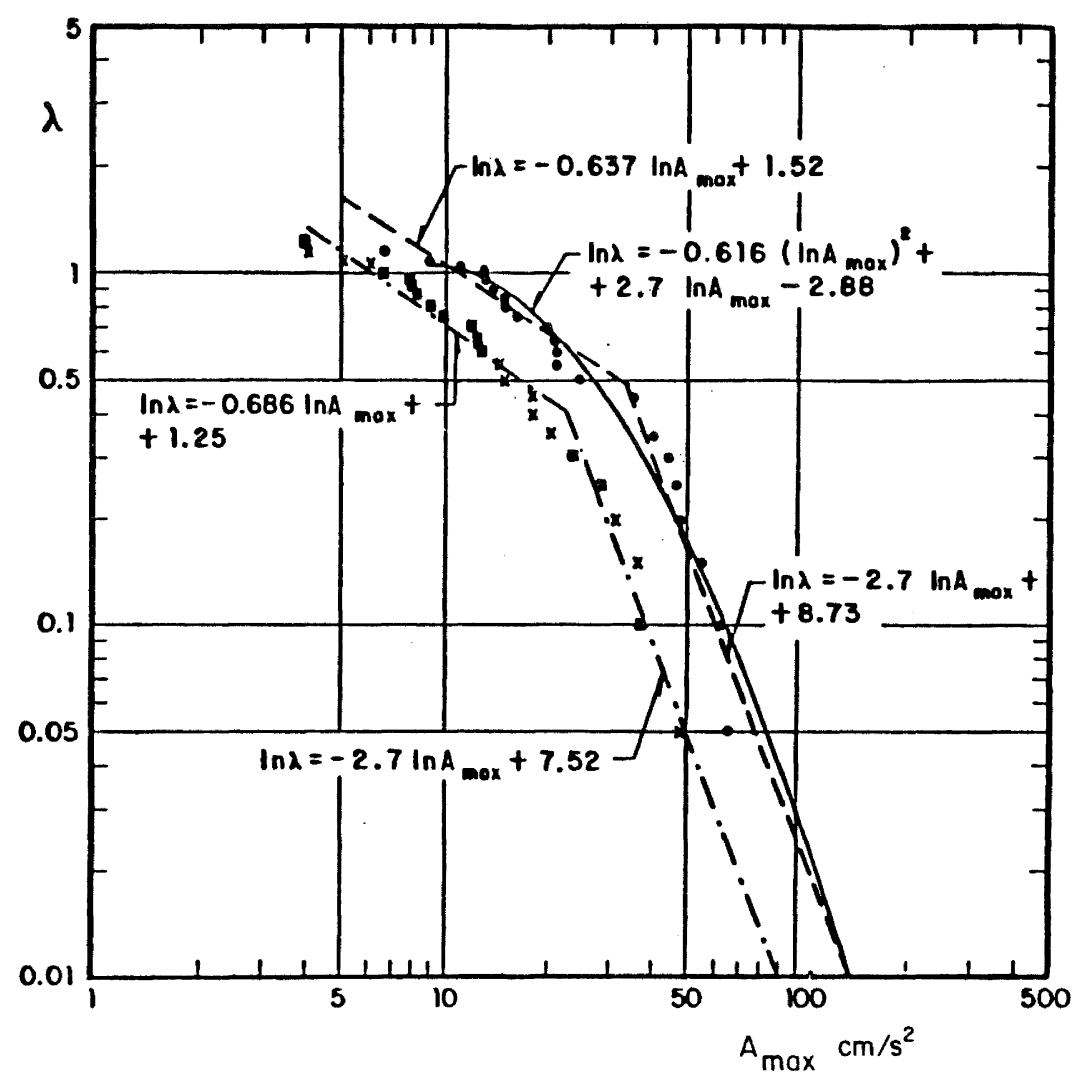

- Volues estimated on soft soil

$x$ Values estimated on hard soil

- Values estimated on hard soil

FIG. 2 - RATES OF EXCEEDENCE OF GROUND ACCELERATIONS IN THE VALLEY OF MEXICO (REF. 2)

of moderately tall buildings. Office and apartment buildings should be designed for $0.025 \mathrm{~g}$ and structures lower than $16 \mathrm{~m}$ did not require seismic design. There were not provisions on story torsion, or about the influence of masonry walls and partitions on the response. The possibility of dynamic analysis was ignored. The significance of relative rigidities to the distribution of story shears among resisting elements was ordinarily ignored.

The observations about the peformance of structures during the 1957 earthquake led engineers to recognize that ground accelerations substantially higher than those foreseen in the past could occur at return intervals of about 50 years, and that drastic increments in ground motion intensity and duration might result from the filtering of the seismic waves through the soft clay formations found over a large part of the city. Damage to specific buildings was largely ascribed to deficiencies in structural analysis, such as neglect of story torsions and relative values of member stiffnesses when distributing story shears among resisting elements.

A few weeks after the earthquake an emergency code was enforced. According to local soil conditions, the city was divided in three zones: soft, transition and firm ground (Fig. 3). Base shear coefficients were raised up to values of 0.05 to 0.10 for ordinary buildings, according to location, and a linear variation of acceleration along the building height was stipulated. Torsional moments at stories should be computed on the basis of eccentricities obtained as the superposition of a static nominal value multiplied by an amplification factor intended to cover dynamic effects and an accidential contribution intended to cover uncertainties about relative stiffnesses and live-load distribution. The stiffnesses supplied by plain unreinforced masonry panels, either confined by pilasters and bond beams or as infills of structural frames, should be explicitly incorporated when computing story torsions. An upper bound to allowable story drift, computed on the basis of the linear response to the design lateral forces, was specified equal to 0.002 of story height.

In 1959 the time was ripe for a thorough revision of the city building code, after the experiences from the 1957 shock had been assimilated. Because damage was largely ascribed to noor construction practices and oversimplifications in analysis 


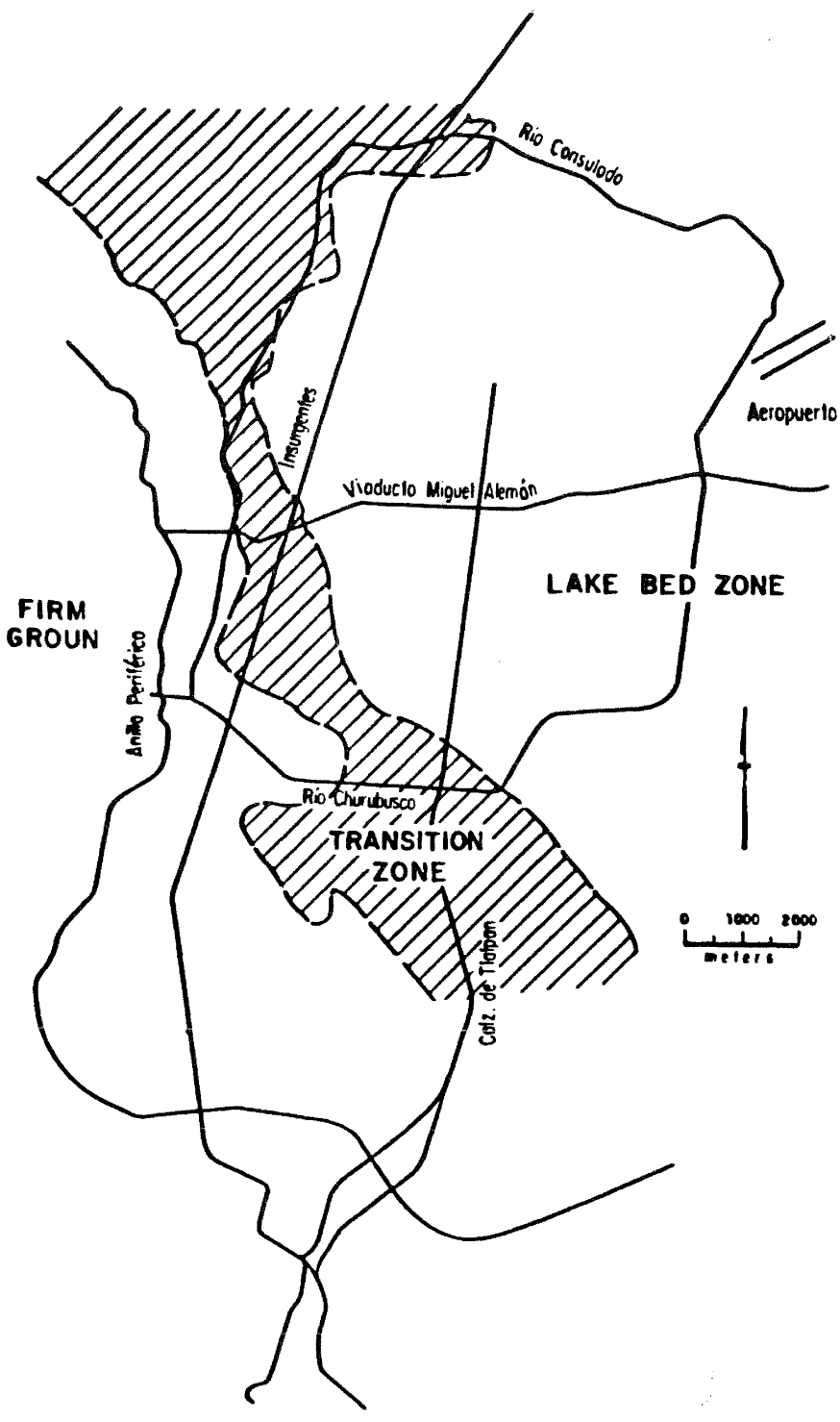

FIG. 3 - SEISMIC MICROZONATION OF MEXICO CITY (REF. 3)

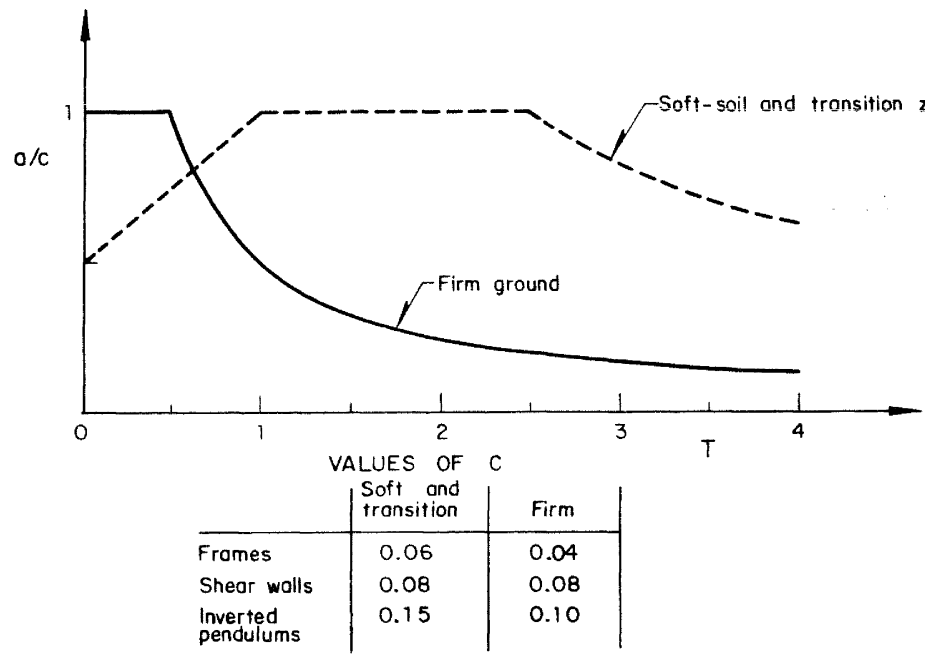

FIG. 4 - DESIGN SPECTRA ACCORDING TO 1966 BUILDING CODE and design, it was concluded that the 1957 emergency code was penalizing many structures excessively, only because some atypical or poorly built structures had performed badly.

The revision ended in 1966. Seismic microzonation of the city was simplified, incorporating the transition zone into the soft soil zone. According to their use, structures were classified into three groups: very important, ordinary and low risk structures. According to structural characteristics, three types were proposed: type 1 included frame structures and some combinations of frames with shear walls or bracing systems; type 2 included shear wall systems and braced systems while type 3 covered inverted pendulums and similar structures. Base shear coefficients for ordinary structures on firm ground ranged from 0.06 for type 1 buildings to 0.15 for type 3 systems. For static analysis the code specified linear variation of acceleration along the building height. Because of the prevalence of long ground motion periods, the influence of higher vibration modes on the shears at the upper portions of tall buildings is deemed insignificant, and no provision is made to include a force concentrated at the top, as done in other codes. For the first time, acceleration design spectra for firm ground and soft soil are specified (Fig. 4). Each of them has a plateau with an ordinate equal to the base shear coefficient that corresponds to the structural type and local ground conditions. That plateau extends from 0 to $0.5 \mathrm{sec}$ and from 1 to $2.5 \mathrm{sec}$ of natural period for firm ground and soft soil, respectively. Beyond the upper limits, spectral ordinates decay with power -1 of the natural periods, but a lower bound of 60 percent of the static forces is established for design. This limitation intends to cover uncertainties in natural periods, second order effects and the possibility of failure in a large number of modes.

The 1966 code sets allowable story drift limits of 0.002 , save where elements that do not form integral parts of the structure are adequately isolated from the deformations of the latter. Then the limit changes to 0.003 in the soft soil zone and to 0.004 in the rest of the city. Clear spacing between a face of a building and the boundary of the neighbouring plot of land is stipulated at a minimum of $3 \mathrm{~cm}$, but not less than the computed displacement at the top increased by 0.006 times the building height in the soft soil zone or by 0.004 of that height at other locations.

In 1971 the code revision started in 1959 was deemed too aged. A new revision culminates with the 1976 code, which intends to deal as explicitly and as openly as possible with concepts of structural safety and performance. Thus, linear response spectra are proposed as design targets and reductions of lateral forces are permitted provided several requirements oriented to attain local and 


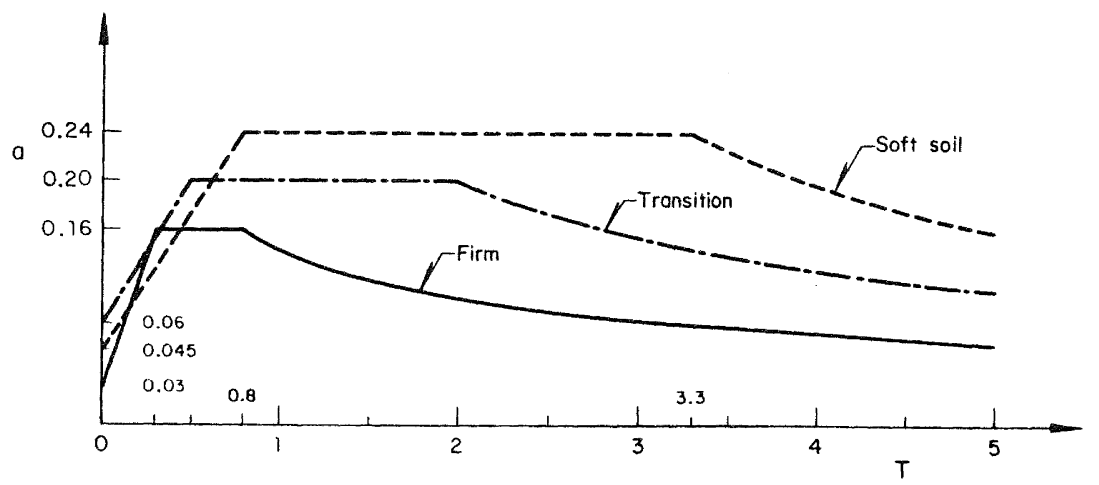

FIG. 5 - DESIGN SPECTRA UNREDUCED BY DUCTILITY ACCORDING TO 1976 BUILDING CODE

global ductility are met (Fig. 5). The reduction factor $Q$, defined as the ratio between the maximum ordinates of the linear and of the corresponding reduced nonlinear acceleration response spectra are made to depend on structural type, materials and several concepts related to design criteria and construction details. Q can be taken as 6 for reinforced concrete and steel frame buildings that satisfy a set of special requirements intended to prevent brittle failure, local buckling and deterioration of force-displacement curves. For ordinary reinforced concrete and steel frame buildings, $Q$ is taken as 4 , and for structures resisting lateral forces mainly by means of reinforced concrete or confined plain masonry walls, $Q$ is taken as 2 . In order to restrict uncertainties arising from non-uniform distribution of safety factors along the building height, adoption of ductility factors of 4 and 6 is conditioned to the requirement that the minimum ratio of the strength of a story (computed design strength that takes into account all elements which can contribute to lateral resistance) to the design action at that story does not differ in more than 35 and 20 percent, respectively for $Q=4$ and $Q=$ 6 , from the average of such ratios for all the stories. Some of the special requirements established to adopt $Q=6$ were as a rule considered too complicated by engineers, who preferred to omit them, everi at the expense of not being allowed to take $Q$ greater than 4. With few exceptions, the requirements specified to take $Q$ equal to 4 did not differ from those applicable to design for gravity loads.

The widths of the design response spectra are intended to cover uncertainties on response arising from uncertainties on natural periods of structures. For long periods the spectral ordinates decay with powers $1,0.67$ and 0.5 of $T$ on the soft soil, transition and firm ground zones, respectively. These rates of decay are substantially slower than those observed in spectra obtained from records. They are intended to account for uncertainties arising from second order effects and possibility of occurrence of a large number of failure modes.

The analysis and design of flat slabs is based on distinguishing central and column strips. Positive bending moments at midspan are distributed between central and column strips in the ratios 0.4 and 0.6 , respectively, while for negative moments at supports these ratios are 0.25 and 0.75 ; these coefficients are applied to vertical as well as to lateral loads. At least 25 percent of the column strip reinforcement must lie within the column width plus one effective depth to each side. The last requirement was often disregarded in practice.

Displacements must be computed as the product of the assumed ductility factor by the displacements corresponding to the linear response of the structure under the action of the reduced seismic forces. Allowable limits to relative lateral displacements computed in this manner are set at 0.016 times the corresponding differences in elevation, where the elements not forming an integral part of the structure are attached to it in such a manner as not to be damaged by the deformation of the latter, and at 0.008 for other cases. Second order effects must be explicitly included in the analysis when the relative lateral displacement of a story divided by its height is equal to 0.08 times the ratio of the shear at that story to the sum of the vertical loads above it. In order to avoid impact between neighbouring constructions, the distance from each of them to the edge of the plot of land next to it should not be smaller than the computed displacement at the top increased by $0.001,0.0015$ and 0.002 of its height, for the firm ground, transition and soft soil zones, respectively. This requirement was often ignored by contractors.

\section{5: LESSONS LEARNED AND QUESTIONS RAISED}

The paragraphs that follow are largely based on the summary of lessons and questions presented by the writer in Ref. 1.

The first lesson learned was that intensities much in excess of what was deemed likely before 1985 have occurred in the past and have a non negligible probability of recurring in moderately long time intervals. The severity and extent of damage are largely a consequence of the 
TABLE 1 - STATISTICAL SUMMARY OF DAMAGE TO BUILDINGS*

\begin{tabular}{|c|c|c|c|c|c|c|c|c|c|}
\hline \multirow[t]{2}{*}{ Type of Structure } & \multirow{2}{*}{$\begin{array}{l}\text { Extent of } \\
\text { damage }\end{array}$} & \multicolumn{3}{|c|}{ Year when built } & \multicolumn{4}{|c|}{ Number of stories } & \multirow{2}{*}{ Total } \\
\hline & & $<1957$ & $57-76$ & $>1976$ & $<5$ & $6-10$ & $11-15$ & $>6$ & \\
\hline Steel frame & $\begin{array}{l}\text { collapse } \\
\text { severe }\end{array}$ & $\begin{array}{l}7 \\
1\end{array}$ & $\begin{array}{l}3 \\
1\end{array}$ & $\begin{array}{l}0 \\
0\end{array}$ & $\begin{array}{l}4 \\
0\end{array}$ & $\begin{array}{l}3 \\
0\end{array}$ & $\begin{array}{l}1 \\
2\end{array}$ & $\begin{array}{l}2 \\
0\end{array}$ & $\begin{array}{r}10 \\
0\end{array}$ \\
\hline R C frame & $\begin{array}{l}\text { collapse } \\
\text { severe }\end{array}$ & $\begin{array}{l}27 \\
16\end{array}$ & $\begin{array}{l}51 \\
23\end{array}$ & $\begin{array}{l}4 \\
6\end{array}$ & $\begin{array}{l}27 \\
10\end{array}$ & $\begin{array}{l}46 \\
28\end{array}$ & $\begin{array}{l}8 \\
6\end{array}$ & $\begin{array}{l}1 \\
1\end{array}$ & $\begin{array}{l}82 \\
45\end{array}$ \\
\hline Waffle dab & $\begin{array}{l}\text { collapse } \\
\text { severe }\end{array}$ & $\begin{array}{l}8 \\
4\end{array}$ & $\begin{array}{l}62 \\
22\end{array}$ & $\begin{array}{l}21 \\
18\end{array}$ & $\begin{array}{r}36 \\
5\end{array}$ & $\begin{array}{l}49 \\
26\end{array}$ & $\begin{array}{r}5 \\
12\end{array}$ & $\begin{array}{l}1 \\
1\end{array}$ & $\begin{array}{l}91 \\
44\end{array}$ \\
\hline $\begin{array}{l}\text { Masonry bearing } \\
\text { walls }\end{array}$ & $\begin{array}{l}\text { Collapse } \\
\text { severe }\end{array}$ & $\begin{array}{l}6 \\
9\end{array}$ & $\begin{array}{r}5 \\
13\end{array}$ & $\begin{array}{l}2 \\
1\end{array}$ & $\begin{array}{l}11 \\
22\end{array}$ & $\begin{array}{l}2 \\
1\end{array}$ & $\begin{array}{l}0 \\
0\end{array}$ & $\begin{array}{l}0 \\
0 .\end{array}$ & $\begin{array}{l}13 \\
23\end{array}$ \\
\hline Other. & $\begin{array}{l}\text { Collapse } \\
\text { severe }\end{array}$ & $\begin{array}{l}4 \\
0\end{array}$ & $\begin{array}{l}8 \\
4\end{array}$ & $\begin{array}{l}2 \\
2\end{array}$ & $\begin{array}{r}12 \\
2\end{array}$ & $\begin{array}{l}2 \\
4\end{array}$ & $\begin{array}{l}0 \\
0\end{array}$ & $\begin{array}{l}0 \\
0\end{array}$ & $\begin{array}{r}14 \\
6\end{array}$ \\
\hline Total & $\begin{array}{l}\text { collapse } \\
\text { and severe }\end{array}$ & 82 & 192 & 56 & 129 & 161 & 34 & 6 & 330 \\
\hline
\end{tabular}

* After Reference 4.

TABLE 2 - PERCENTAGES OF COLLAPSE OR SEVERE DAMAGE*

TABLE 3 - CAUSES OF FAILURE*

\begin{tabular}{|c|c|}
\hline $\begin{array}{l}\text { Number of } \\
\text { Stories }\end{array}$ & $\begin{array}{l}\text { Percent of cases of } \\
\text { collapse or severe } \\
\text { damage }\end{array}$ \\
\hline $1-2$ & $0.9 \%$ \\
$3-5$ & 1.3 \\
$6-8$ & 8.4 \\
$9-12$ & 13.6 \\
12 & 10.5 \\
\hline Total & 1.4 \\
\hline
\end{tabular}

* After Reference 4

discrepancies between the intensity of the ground motion and the value implicit in earthquake resistant design codes and construction practice. A statistical summary of damage is given in Table $1-3$, taken from Ref. 3. Table 1 contains numbers of buildings of different types which suffered collapse or severe damage, while Table 2 gives percentages of cases of collapse or severe damage in terms of the number of stories. These percentages are referred to the population of damaged buildings surveyed by the team of the Institute of Engineering of the National University of Mexico immediately after the earthquake (4). Table 3 classifies failure or damage according to its causes.

It is well known that the ground motion records obtained at the parking lot of the office building of the Ministry of Communications and Transportation (Secretaria de Comunicaciones y Transporte, SCT) give place to a response spectrum of accelerations with ordinates near $1 \mathrm{~g}$ for 5 percent of critical damping and for a range of natural periods near $2 \mathrm{sec}(6)$. On the other hand, in the soft soil area the codes from 1959 to 1985 asked for design base

\begin{tabular}{|l|c|}
\hline \multicolumn{1}{|c|}{ Characteristic observed } & $\begin{array}{c}\text { Percent } \\
\text { of cases }\end{array}$ \\
\hline Pronounced asymmetry of stiffness & $15 \%$ \\
Corner building & 42 \\
Weak first story & 8 \\
Short columns & 3 \\
Excessive mass & 9 \\
Previous differential settlement & 2 \\
Unsatisfactory foundation & 13 \\
Pounding performance & 15 \\
Previous earthquake damage & 5 \\
Punching in waffle slabs & 4 \\
Upper story failure & 38 \\
Intermediate story failure & 40 \\
\hline
\end{tabular}

* After Reference 4

shear coefficients not much larger than 0.06 for ordinary frame structures. Thus, not much doubt is left at ascribing the widespread occurrence of structural damage to the insufficiency of code prescriptions to protect structures against the intensity observed. That insufficiency refers to both the low values of the coefficients used and the poor requirements related with construction details oriented to ensure ductile behaviour. Given the overwhelming difference between intensity and design capacity, the stability of constructions rested mainly on the reserves derived from the strength of elements not accounted for in the design as well as on the energy dissipation capacity of the latter elements and of the structural members. Therefore, for the purpose of improving the technical basis for earthquake engineering, explaining the survival of so many structures in 
Mexico City in 1985 is at least as important as finding causes for the failures observed.

Because a large portion of the structures that failed were characterized by significant irregularities in the distribution of strengths and stiffnesses, it was concluded that those irregularities can enhance the uncertainties that arise from the practice of establishing design responses on the basis of linear methods of dynamic analysis, in spite of the high nonlinearities to be expected in the seismic response of actual systems under the action of high intensity earthquakes. Conspicuous representatives of those irregularities are buildings with weak ground floor (that is, where the ground floor story has a safety factor with respect to shear significantly lower than the rest of the stories, either because the ground floor story is too weak or because the others are too strong) or with large torsional eccentricities.

Questions were raised as to what extent the appearance of the mentioned irregularities should be banned or restricted and how should their influence on response be taken into account when designing. The 1976 building code included some prescriptions oriented to preventing the use of weak ground floors or to reduce their vulnerability by requiring their design for higher story shear coefficients, but those prescriptions were often disregarded. On the other hand, attention was usually paid to the prescriptions relative to torsional response which had been in force, with a few changes, since 1957. As mentioned above, these prescriptions included an amplification factor to cover dynamic response effects and an accidental eccentricity, aimed at covering uncertainties about relative values of stiffnesses of structural members, spatial distribution of live loads and ground rotations.

The high level of safety with respect to collapse observed during all intense earthquakes occurred during the last half century had fostered a sense of confidence, now proved to possess no firm basis, relative to the adequacy of construction practices and details. As a result, Mexican engineers had consciously set aside some conclusions of code writing bodies in countries such as Japan, New Zealand and the United States, which in the last two decades incorporated into their practice the use of strict criteria for the design of construction details oriented at attaining adequate energy-dissipation capacities of steel and reinforced concrete structures. The earthquake showed that the adoption of a similar practice may be even more important in Mexico City than at other sites, as a consequence of the large number of high amplitude cycles to be expected of the response of structures subjected to long and nearly monochromatic ground motion time histories. A shocking evidence of this is the large number of columns failed, where many unfavourable features coincided, leading to drastic degradation of strength and stiffness: influence of axial loads, increased by large overturning effects probably augmented by foundation rocking; low weight of concrete aggregates, leading to low tensile concrete strength and therefore to higher proneness to degradation; poor confining capacity of typical reinforcement details; high bond stresses and poor restriction to buckling of longitudinal reinforcement in columns as a consequence of the use of bundles of bars. $\mathrm{p}-\Delta$ effects, initiated by stiffness degradation, may have significantly contributed to collapse, as evidenced by the many cases of large story drift and tilting visible after the earthquake.

About 40 percent of the cases of partial or total collapse involved failure of one or more stories in the upper third of the height of the structure. In many of those cases, pounding between adjacent structures was decisive. The others were ascribed to drastic changes in structural solution or in capacities of structural members; to inadequate splicing of vertical reinforcement; to the lack of capacity of small width columns to provide sufficient bond development lengths to permit the stresses on the longitudinal reinforcement of concurrent beams to change from yield stress in tension to yield stress in compression from one face of the column to the other; or to the rapid increase in response amplitude owing to base rocking caused by soil-structure interaction. Later on, the latter assumption was dismissed as a result of theoretical studies described below.

Because of the lack of records of previous differential settlement or tilting of buildings it is difficult to assess the relation between those variables and the structural damage produced by the earthquake. In Mexico City, accounting for these effects may have more than academic interest, as evidenced by the results of the theoretical response studies of tilting structures described below.

Most cases of inadequate performance not covered by the paragraphs above can be ascribed to blatant violations of the regulations or to evident gaps in them Instances of the former are the excessive live loads in some buildings, the disregard for limitations relative to allowable drift, to separation between adjacent buildings or to uniformity of safety factors along the height of a building. The design and construction of waffle slabs were plagued with deficiencies arising from both groups of concepts.

The geographical distribution of damage posed many questions relative to the variability of intensities along the soft soil area: how wide the variability really was? what portion of it is systematic and how much of it may have significantly different distributions in earthquakes with different origins, mechanisms, paths and energy distribution between different types of waves? How significant may have been the presence of archaeologic remains or buried structures, the effects of structure-soil-structure interaction or the modification of soil properties resulting from large excavations near a structure of interest? Finally, the cases of generalized foundation failure by exceedence of 
the soil bearing capacity called the attention to the need for studying how the deformations of the foundation can affect the overall system response and how safe are present criteria for design of friction piles, regarding the degree of protection they provide against the consequences of the deterioration of bond between soil and pile. Many cases of excessive differential settlements have been identified after the earthquake, and the potential significance of those settlements to the development of extensive damage in the rest of the structure has been recognized.

\section{EMERGENCY CODE}

Immediately after the earthquakes an ad-hoc committee was formed with the responsibility of updating Mexico City building code. This committe undertook also the job of coordinating research work relevant to code revision. It also formulated the required code updating in two steps: a long term (about one year) thorough revision and a nearly immediate emergency code. The latter was promulgated five weeks after the earthquake; its main concepts were supported by the immediate conclusions of damage surveys.

The emergency code establishes the obligation of repairing structures that suffered significant structural damage so as to comply with the new requirements. On the basis of the large amount of damage observed, but also of the many cases of satisfactory performance, base shear coefficients were raised in 67 percent for the soft zone and 33 percent for the transition zone. Strength reduction factors (to be applied to nominal values of ultimate capacities) suffered reductions ranging from 18 to 33 percent for brittle failure modes of reinforced concrete and steel structures; more drastic reductions were applied to bond between soil and friction piles. Design values of live loads in office buildings were raised and the obligation to fix in each story of a building a plate showing the maximum allowable live load was stressed.

The possibility of assuming ductility reduction factors of 6 was eliminated. For $Q=4$, the requirements for detailing of reinforced concrete structures are stricter than those formerly stipulated for $Q=6$. Among the new requirements, are noteworthy those intending to improve concrete confinement, for instance: tied columns must have thicknesses equal to or greater than $30 \mathrm{~cm}$; longitudinal bars cannot be spaced more than $30 \mathrm{~cm}$; at least one out of two bars has to lie on the corner of a tie; a longitudinal bar not restricted against lateral displacement cannot be more than $15 \mathrm{~cm}$ apart from one provided with that restriction; ties must not be smaller than No. 3 and must not be spaced more than $20 \mathrm{~cm}$ or $700 \mathrm{~d} / \sqrt{\mathrm{f}}$, except at the end quarters of columns, where they should lie at half these distances; reinforcement of shear walls projected to resist the combination of bending moments and axial forces must be concentrated at the ends, and for steel percentages greater than 0.0075 placing of that reinforcement must satisfy the same requirements applicable to columns.

Adoption of $Q=4$ is limited to frame structures and to those possessing reinforced concrete shear walls, provided that at every story the lateral capacity of the frames is at least equal to half of the total. It is also required that the minimum ratio of the strength of a story to the design action at the story does not differ in more than 30 percent from the average of such ratios for all the stories.

For flat slabs, the allowable ductility factor was downgraded to 3 , and a number of requirements related with placing of reinforcement were established. For instance, it is now required that 75 percent of the reinforcement necessary to resist seismic forces goes through the column cross section; the rest must lie within 1.5 times the slab effective depth from the column face. For the purpose of improving concrete confinement, stirrups must be spaced at distances not greater than one third the effective depth. There must exist a solid area, extending at least as far as 2 times the slab depth from the column faces. In addition, for the purpose of estimating lateral deflections the slab must be replaced with a beam having an effective width equal to that of the column increased by three times the slab thickness.

Structures giving place at any story to torsional eccentricities in excess of 20 percent of the width of that story in the direction of the eccentricity are not accepted.

The influence of damage due to previous differential settlements above allowable values set by the code must be explicitly taken into account, and the lateral capacity of the structures must be reduced in accordance with it.

The code calls for the participation of a supervisor independent from the contractor for all constructions from group $A$ and $B$ taller than $15 \mathrm{~m}$ or having an area larger than $3000 \mathrm{~m}^{2}$. Finally, change of occupancy of a construction will require the approval by the city authorities of a detailed study made by a registered engineer, stating that safety conditions will not be lower than those corresponding to the former occupancy.

\section{LOCAL DISTRIBUTION OF INTENSITIES}

When the zone of highest concentration of damage in 1985 was compared with those corresponding to the earthquakes of 1957 and 1979 the coincidence was deemed nearly perfect, although some deviations were clearly identified and worries were expressed about the need to understand how the ground motion varies throughout the valley as a function of the types of waves arriving from the source.

The records obtained from strongmotion instruments on September 19, 1985 showed the variation of intensities to be much more pronounced than that implied by 
the microzoning map in Fig. 3, which is strongly tied to the local thicknesses of the soft clay formation. A look at the records and response spectra of Refs. 5 and 6 confirms this statement. Shortly after the earthquake it was shown that the peculiarities of accelerograms and spectra at various locations in the valley of Mexico could not be explained in all cases in terms of the simple uni-dimensional vertically-travelling shear waves model: the contribution of surface waves should not be neglected, with all its implications regarding the possibility of constructive or destructive interference of waves at different regions in the valley.

In the absence of enough instrumental records, two complementary approaches were suggested and are being pursued: one consists in formulating a mathematical model of the Valley of Mexico and the region in its vicinity and studying how different wave trains are amplified at different points in the ground surface throughout the valley, and the other consists in attempting an interpretation of the observed damage at each point as a measure of local intensity. The former approach demands extremely large efforts, both in the exploration oriented to determine the geotechnical characteristics of the valley and in the formulation of sufficiently detailed mathematical models, capable of reproducing the complex patterns of amplification suggested by the instrumental records and the distribution of damage. In spite of the size of the effort, studies along this line are successfully being carried out, but the results obtained up to now are mainly related to building the models and developing the computational tools rather than to quantitative representations of amplification patterns. The rest of this section is devoted to describing the use of damage information to obtain a map of intensities.

Reference 7 describes the work of a large group of students and engineers, headed by J. Iglesias, from the the Universidad Autónoma Metropolitana in Mexico City, who analyzed the information about damage to buildings, transformed it into intensities, obtained a map showing the variation of intensities and related that variation to a description of the local soil properties substantially more detailed than had previously been considered. In the first stage of the study, they started expressing intensity by the "density" of the population of damaged buildings not taller than four stories. The density mentioned above was defined as the ratio of the number of damaged buildings in the group considered to the surface area covered by the buildings in the same group. Several shortcomings of this approach are obvious, but only one will be discussed here: because the strengths of the buildings included in the sample are not taken into account, the zones of highest intensities that result coincide with those where are located the oldest constructions, with the highest degree of decay. Therefore, this method was superseded by that explained in the following paragraphs.

In the second stage, earthquake inten- sity was measured by the strengths of structures that suffered severe damage. In order to implement a procedure based on this idea, two groups of concepts had to be developed: the first included a set of criteria to classify damage in several levels and the second coped with the problem of estimating seismic strength of existing buildings. The former set of criteria led to classifying damage in four levels, 0 to 3 , where level 0 means only non-structural damage, and level 3 means severe structural damage, including, for instance, cracks thicker than $1 \mathrm{~mm}$ in reinforced concrete members; opening of gaps in masonry walls; spalling of concrete cover in columns; crushing of concrete, breaking of ties and buckling of reinforcement in beams, columns and walls; cracking of capitals; tilting of columns or of buildings as a whole, when it exceeds 1 percent of the corresponding height; and large settlements. Level 2 corresponds to substantial structural damage and includes, for instance, cracks between $0.5 \mathrm{~mm}$ and $1 \mathrm{~mm}$ in thickness in reinforced concrete members or $3 \mathrm{~mm}$ to $10 \mathrm{~mm}$ thick in masonry walls. Unfortunately, no indications are given regarding the extension of the foregoing types of damage throughout the structure.

A simplified approach to estimate the seismic strength of existing structures is presented in Ref. 7, together with its calibration with respect to a detailed criterion. Both approaches aim at determining the base shear that a given building can resist when its stories are permitted to reach their nominal ultimate capacities. The detailed criterion estimates story shears by means of modal analysis and obtains story capacities through methods of limit analysis of framed structures. The simplified approach assumed that the variation of story shears follows a configuration of the type used for conventional seismic static analysis and obtains story capacities adding up rough estimates of the contributions of the various structural members involved, each of those contributions multiplied by a participation factor smaller than unity, in order to account for the fact that stress-strain curves of those members are not elasto-plastic and that their maxima are not reached simultaneously.

The simplified criterion was applied to a sample of 162 buildings, resulting from two sub-samples: one includes buildings for which repair permits had been filed with the city authorities, and the other was obtained from a list of buildings reported as damaged to the same authorities. The numbers of buildings initially surveyed were very high, but after the lists were revised in order to include only those buildings not taller than 10 stories for which the information necessary to apply the simplified method was complete and reliable, the numbers of buildings remaining in the first sub-sample were 54 with level-3 damage, 7 with level-2 damage and one with lower damage. For the second subsample the numbers were 20,9 and 71 , respectively. The nominal strengths of buildings with level-3 damage were used to define a map of intensities; those corresponding to other damage levels were used to 
suggest new seismic design coefficients.

Expressed as fractions of gravity. the strengths of the buildings with level3 damage had a mean value of 0.122 and a variation coefficient of 0.33 . When the nominal strengths are reduced by a correction factor intended to cover irregularity, initial tilting and aging, the mean becomes 0.088 and the variation coefficient 0.30 . If waffle-slab systems and beam-and-column reinforced concrete frames are taken separately, the means are 0.091 and 0.087 , respectively. For buildings with nonsevere damage, the mean is 0.166 and the variation coefficient 0.40 .

The strengths obtained as described above are shown by circled numbers in Fig. 6. Absence of circles in some areas does not necessarily imply a low intensity, but it may result from absence of vulnerable buildings. A map of intensities in the downtown area and neighbouring districts was prepared using the circled values (Fig. 7). In the southern end of the city a few buildings suffered collapse or level-3 damage, but due to the low density of vulnerable buildings in that area the local sample was too small as to permit plotting such a detailed set of curves as for the downtown area. Therefore, the intensity zones shown in the map of Fig. 7 in the southern end of the city were plotted taking into account previous knowledge about soil properties in that zone. in addition to intensities derived from the strengths of severely damaged buildings. Contrary to previous conceptions, intensities change very fast within the

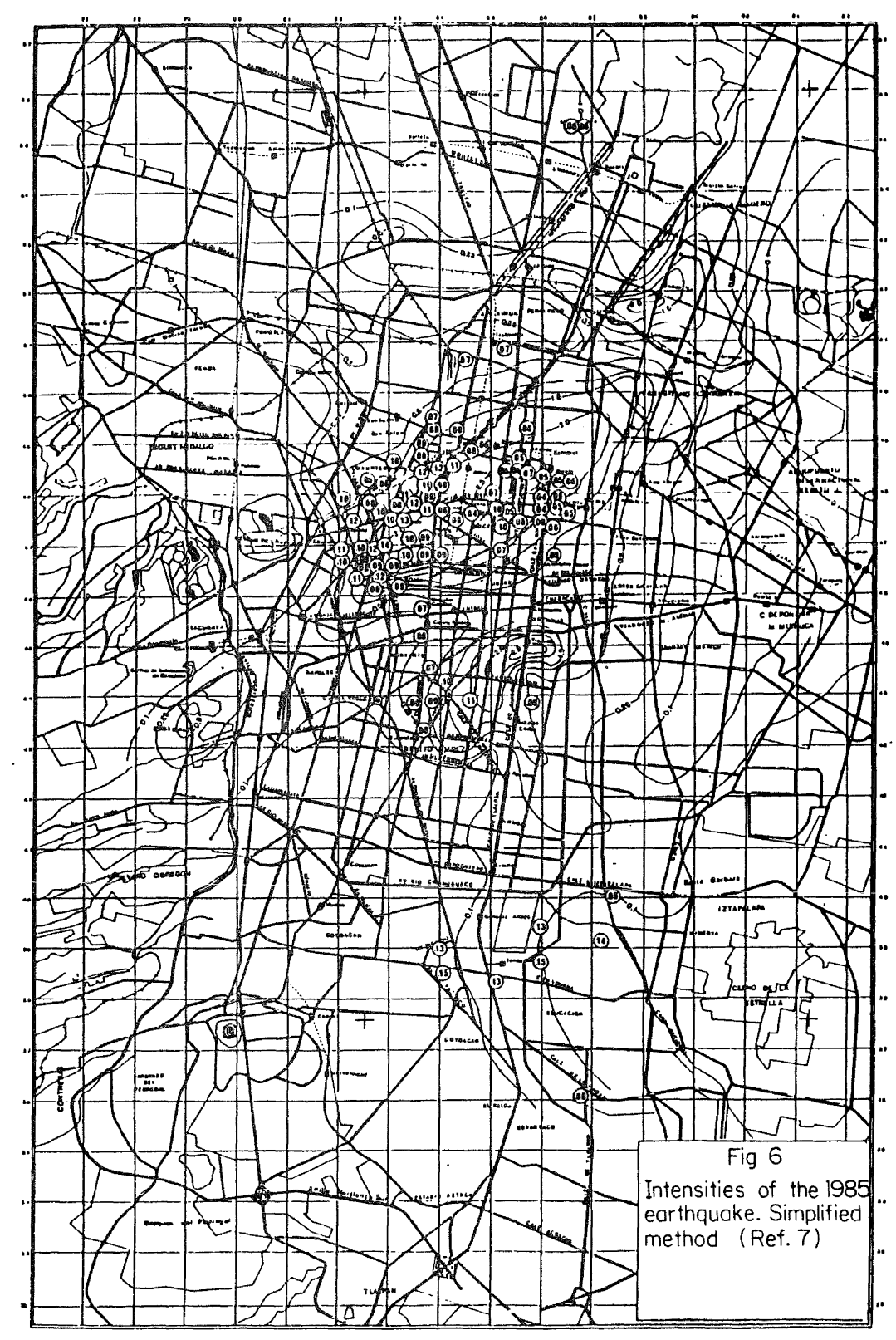

FIG. 6 - INTENSITIES OF THE 1985 EARTHQUAKE. SIMPLIFIED METHOD (REF. 7) 


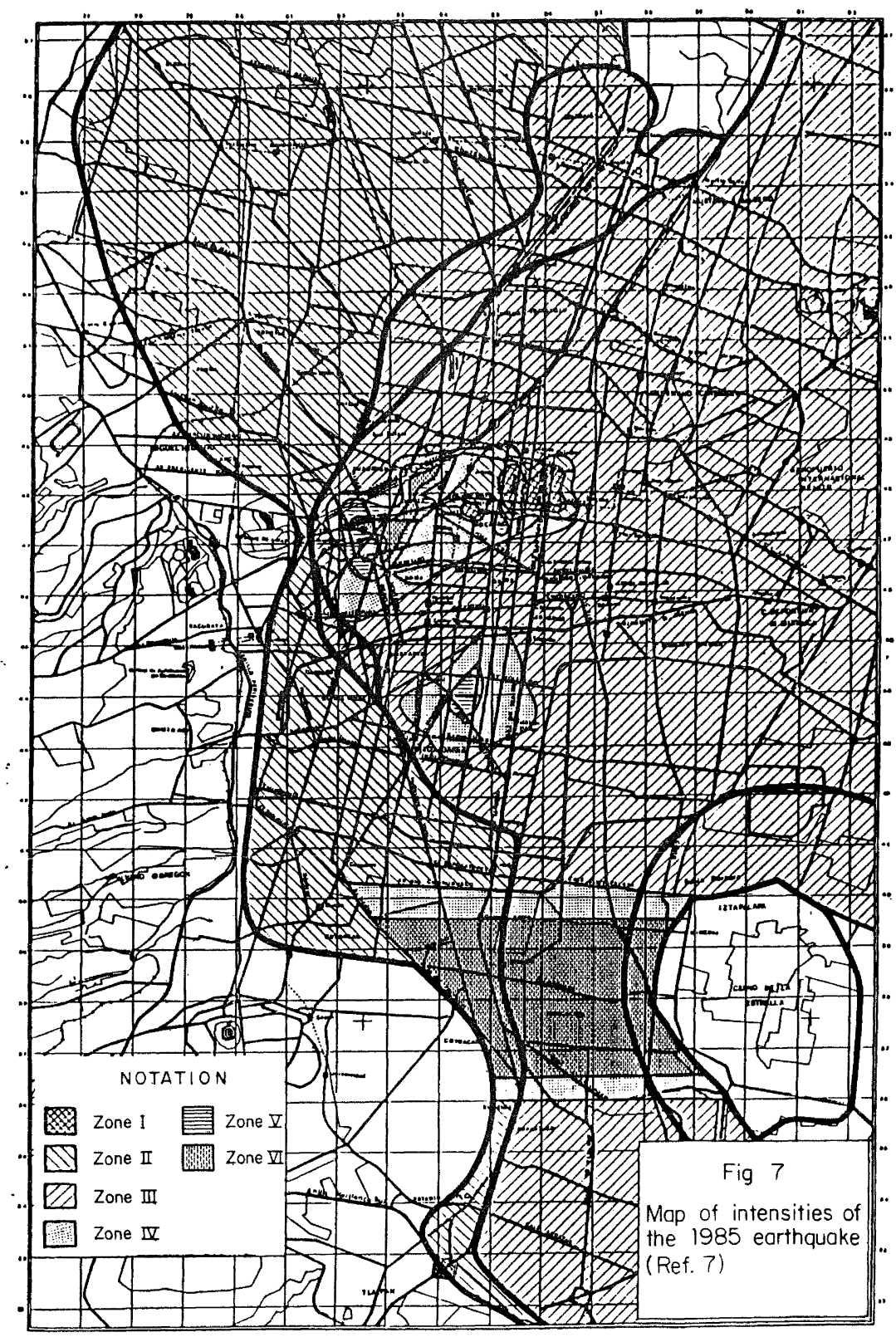

FIG. 7 - MAP OF INTENSITIES OF THE 1985 EARTHQUAKE (REF. 7)

downtown area. A spot of abornally low intensities coincides with the area originally covered by the ancient Aztec city and later on by the Spanish city of the colonial times. The presence of harder soil, including a thick layer of consolidated archaeological fill, has been advanced as a reason for the existence of this low-intensity spot. Within a zone limited at the West by the transition zone and at the East by the low intensity downtown area, intensities are significantly higher than at other areas with similar local soil conditions. Another high intensity spot is observed directly to the south of the downtown area, between the latter and the high intensity area at the southern end.
A look at the location of the three high intensity areas in Fig. 7 shows that they are limited at their East and west ends either by the areas covered by ancient towns (Fig. 8), where local soil is now known to be stiffer than in the parts of the city around them. Consequently, it has been speculated that the high intensity spots may have been the result of surface waves reflecting back and forth at the East and West ends of these spots.

Finally, the microzonation map in Fig. 9 was prepared on the basis of the intensity maps in Fig. 7. It differs from Fig. 3 in that the soft-soil zone is divided through portions of the former 


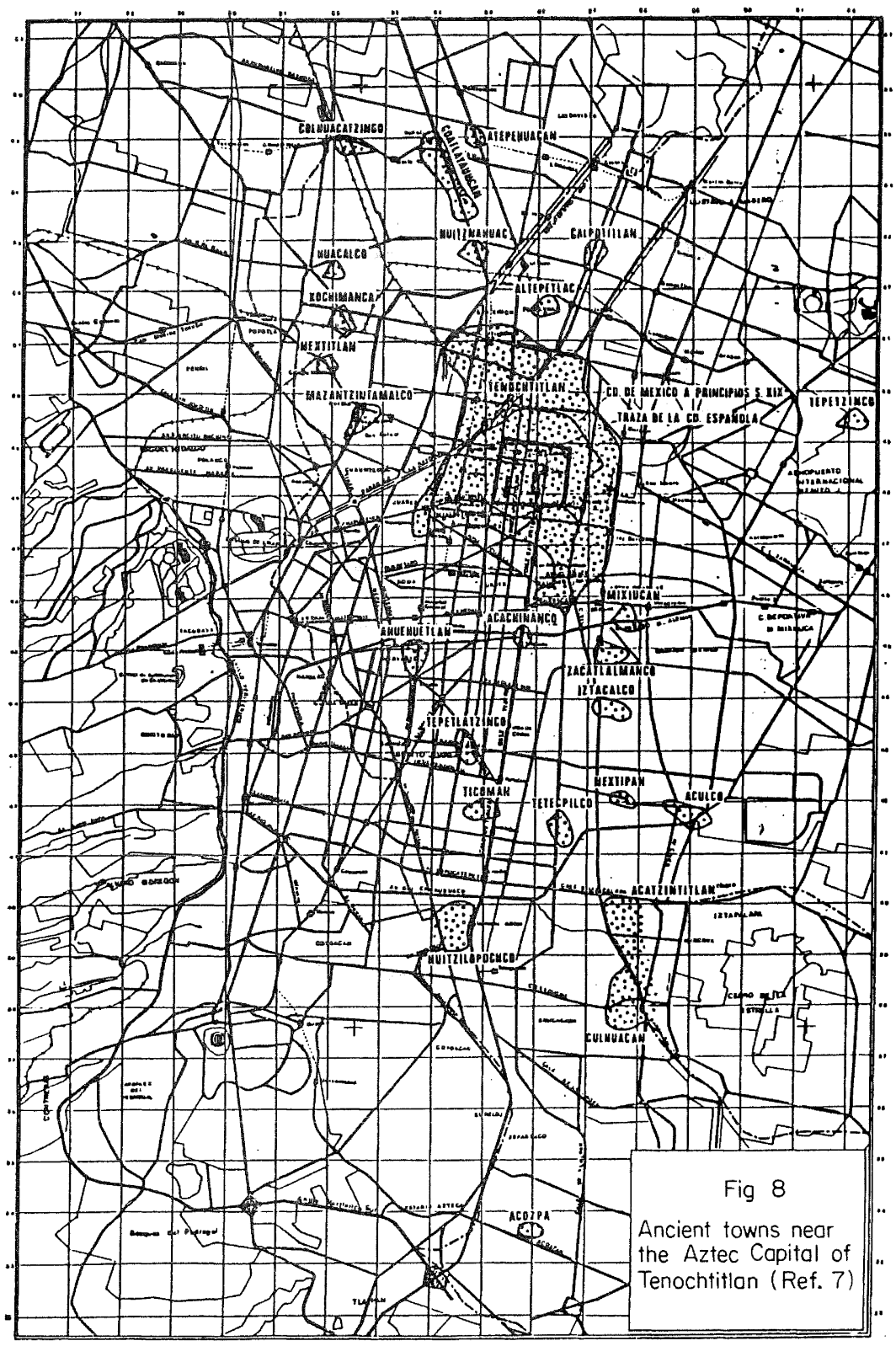

FIG. 8 - ANCIENT TOWNS NEAR THE AZTEC CAPITAL OF TENOCHTItLAN (REF. 7)

transition zone at some locations.

COMPARISON OF PREDICTED RESPONSE AND OBSERVED BEHAVIOUR

The feasibility of establishing optimum realiability design rules for structures subjected to earthquakes depends strongly, among other things, on our capability for making consistent probabilistic predictions of the response of those structures to ground motion excitation. In general, this entails defining accurate mathematical models of complex nonlinear systems. Thanks to the spectacular progress of computing equipment and tools, our capability for handling sophisticated models of complex nonlinear systems is by far more advanced than our knowledge about the dynamic properties of the systems to be modelled. Hence the importance of calibrating those models with the responses of actual systems.

Unfortunately, no strong motion instruments had been installed on the upper stories of buildings in Mexico City before September 1985. Therefore, our information about the amplitude of structural response of specific buildings is limited to descriptions of the type and intensity of damage. Detailed studies about the response of specific buildings during the 1985 earthquake are being carried out in Mexico as 


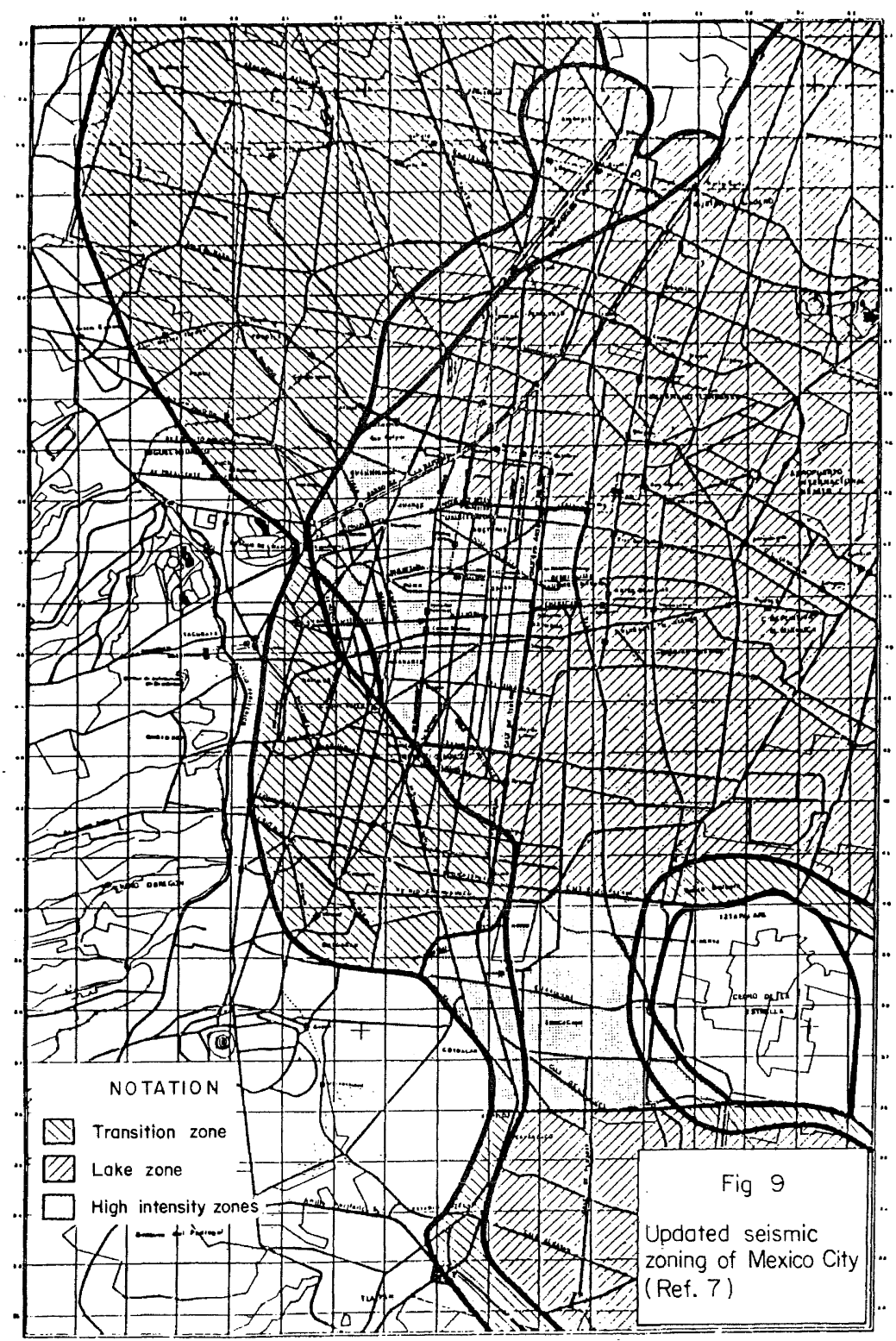

FIG. 9 - UPDATED SEISMIC ZONING OF MEXICO CITY (REF. 7)

well as in other countries, aiming at comparing predicted with observed response. The writer has had access only to those in progress at the Institute of Engineering of the National University of Mexico. An example of them is described in the following (8).

The building which houses the administrative offices of the Collective Transportation System (Metro) is a reinforced concrete structure built around 1970. It has ten stories above the ground, a basement and a two-floor appendage for machinery. Its plan is rectangular, $36 \mathrm{~m}$ by $18 \mathrm{~m}$ (Fig. 10), with four nine-metre spans in the longitudinal direction and three six-metre spans in the transverse direction. The structural system consists of rigid frames in both directions, but two frame-wall systems parallel to the transverse direction are

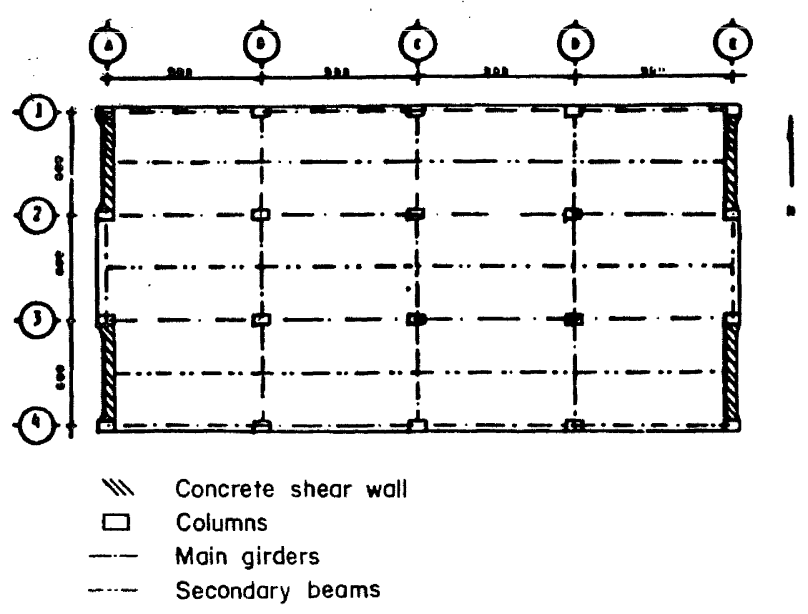

FIG. 10 - PLAN OF STC BUILDING 
located at both ends of the building. The floor system consists of monolithically cast beams and slabs; the latter are $10 \mathrm{~cm}$ deep. The building is founded on friction piles, $22 \mathrm{~m}$ long, which receive the loads from the structure through a rigid reinforced concrete box system, 3m deep, located underneath the basement.

The structure was designed for a base shear coefficient of 0.06 , in accordance with the 1966 building code. The nominal cyclinder strength of concrete is $f^{\prime}=3400$ psi and the reinforcement consists of cold twisted bars with a nominal yield strength of 57000 psi, but some beams show both this type of steel and untwisted bars, which probably results from a modification to the construction specifications in the original project. Typical cross-section dimensions of columns are $50 \times 90 \mathrm{~cm}$ in the lowest stories and $50 \times 60$ or $50 \times 90$ at the top. With some exceptions, beams are $40 \mathrm{~cm}$ wide and $90 \mathrm{~cm}$ deep. Th thickness of shear walls varies from $40 \mathrm{~cm}$ to $25 \mathrm{~cm}$. Reinforcement details are care- fully planned and built both at structural members and at joints. Typical cross sections of columns and shear walls are shown in Figs. 11 and 12. Reinforcement ratios ranged from 1 to 4.5 percent. Ties were No. 3 or 4 bars at 30 or $40 \mathrm{~cm}$, with half of this distance near the column ends. Typical reinforcement of longitudinal beams is shown in Fig. 13 .

In the transverse direction the building remained virtually undamaged. Concrete spalling appears at many beam ends, on the lower surface, next to the column face. At some locations, steel bars lost their cover or underwent local buckling. Some columns at stories 4 and 6 suffered diagonal cracking and ground floor columns show traces of hinging at their bottom, corresponding in all cases to shear forces parallel to the longitudinal direction of the building. Concrete spalling and reinforcement buckling occurred at the bottom of the corner columns which constitute the vertical edges of the shear walls.

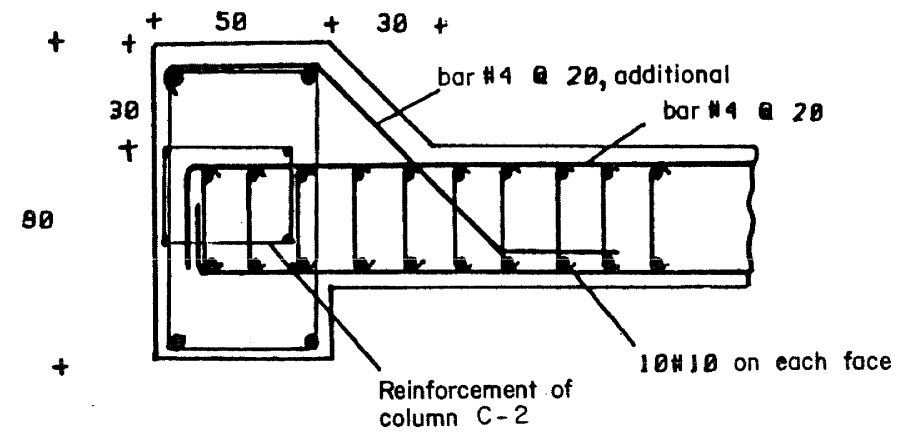

FIG. 12 - REINFORCEMENT OF SHEAR WALLS IN STC BUILDING (REF. 8)
FIG. 11 - REINFORCEMENT DETAILS OF COLUMNS IN STC BUILDING (REF. 8)
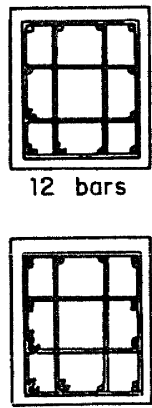

20 bars

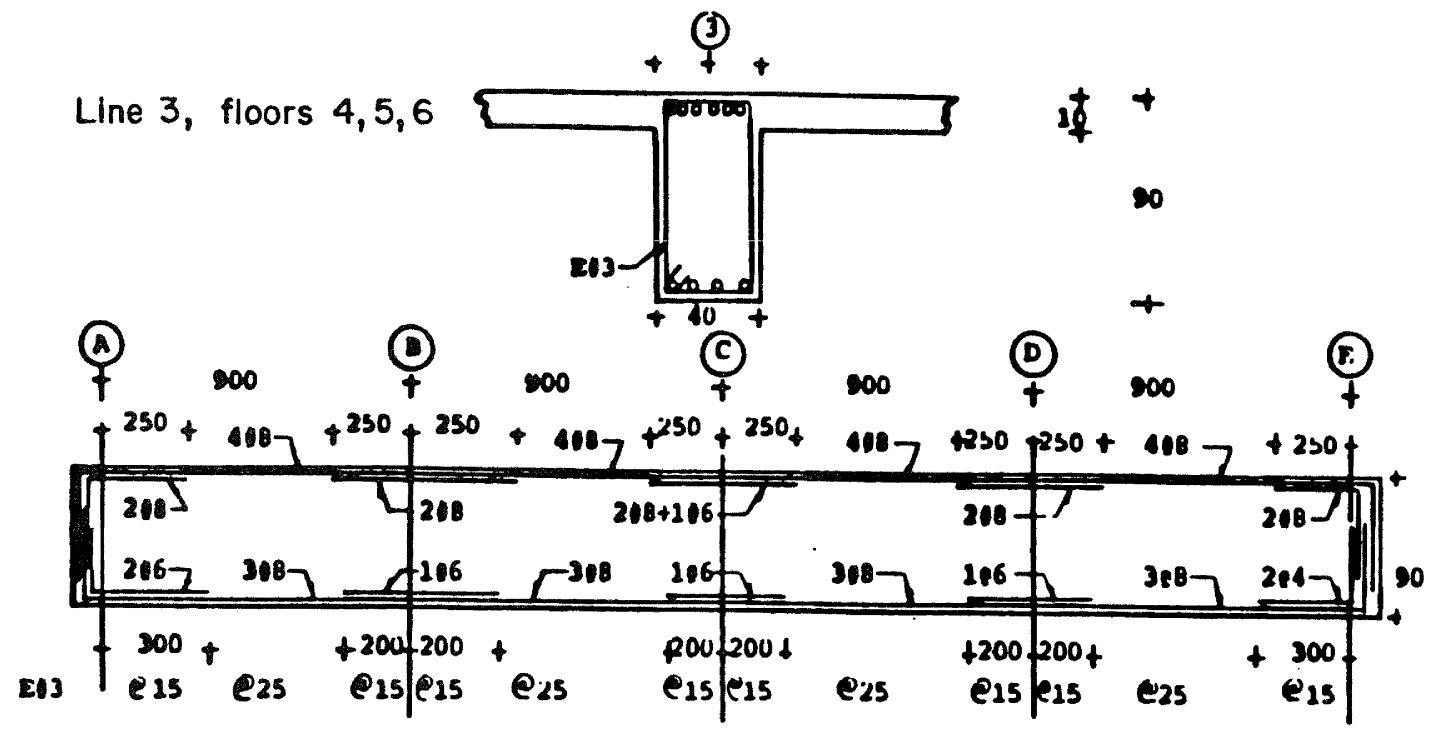

FIG. 13 - TYPICAL REINFORCEMENT OF MAIN GIRDERS AT STC BUILDING 
Fundamental vibration periods in the two principal orthogonal directions of the building were determined after the earthquake, using for this purpose the response to ambient ground vibrations. When the observations were made the building was practically empty, reinforcement cover had been stripped off at several columns and false ceilings had been removed at several locations. Measured periods were 1.3 in the transverse direction and 2.1 in the longitudinal direction, to be compared to the calculated values for the undamaged structure, equal to 0.96 and 1.59 , respectively.

Efforts oriented to computing structural response followed two lines: one intends to calibrate the requirements of the 1966 building code (the one applied to the design of the structure of interest) and of the 1985 emergency regulations with the observed behaviour, while the other aims at assessing the capability of nonlinear response analysis methods for predicting structural performance. Following the first line, the action/capacity ratio, that is the ratio of nominal acting internal force at a critical section to the corresponding nominal capacity of the critical section was determined by means of modal dynamic response analysis complying with the requirements of the mentioned codes. Ranges of values of the mentioned ratio for columns, walls and beams when the forces specified by the 1966 and the 1985 codes were assumed to act are shown in the following table. capacity ratios of the foregoing table can also be used to obtain the "available" base shear capacity such that internal forces derived from linear structural response analysis do not exceed critical section capacities anywhere in the structure. For the ground motion component acting in the longitudinal direction, the available base shear coefficient is 0.100 or 0.110 , according to whether one estimates that coefficient on the basis of action/capacity ratios in beams or columns. In the transverse direction, the resulting figures are 0.073 and 0.190 , for compression-flexure and shear in walls, respectively. The coefficients aimed for in the design were 0.078 and 0.104 in the directions mentioned above.

In order to make more refined comparisons between predicted response and observed performance, the response of a nonlinear model of one of the longitudinal frames of the building to the EW component of the ground motion record obtained at the ACT site on September 19, 1985 (6) was calculated by means of the program DRAIN-2D, assuming elastoplastic non-degrading behaviour of plastic hinges at the ends of the frame members and incorporating P-delta effects. The masses associated with the floors of the frame studied were obtained so as to lead to the same three lowest natural frequencies and to the same linear dynamic response configuration as those of the whole building in the same direction. The studies aimed at predicting the locations of the regions where

RANGES OF ACTION/CAPACITY RATIOS

\begin{tabular}{|l|c|c|c|}
\hline MEMBERS & ACTION & 1966 CODE & $\begin{array}{c}1985 \text { EMERGENCY } \\
\text { CODE }\end{array}$ \\
\hline \multirow{2}{*}{ COLUMNS } & $\begin{array}{c}\text { AXIAL FORCE } \\
\text { BENDING MOMENT } \\
\text { SHEAR FORCE }\end{array}$ & $\begin{array}{c}0.57-0.72 \\
0.56-0.72 \\
0.32-0.41\end{array}$ & $\begin{array}{c}1.85-2.23 \\
1.91-2.21 \\
1.14-1.36\end{array}$ \\
\hline SHEAR WALL & AXIAL FORCE & 0.97 & 1.75 \\
(BOTTOM END) & BENDING MOMENT & 1.03 & 2.56 \\
& SHEAR FORCE & 0.41 & 1.05 \\
\hline BEAMS & BENDING MOMENT (+) & $0.54-0.65$ & $1.96-2.38$ \\
& BENDING MOMENT (-) & $0.56-0.65$ & $1.45-1.79$ \\
& SHEAR FORCE & $0.36-0.43$ & $0.86-1.10$ \\
\hline
\end{tabular}

According to this table, the structure complies with the 1966 code, but is unsafe according to the 1985 emergency code. It can be seen that the values of the action/ capacity ratios for bending moments at the bottom ends of shear wall are the largest, which is not consistent with the observation that these elements remained unscathed after the earthquake. This apparent inconsistency can be explained very easily: bending moments at the lower portions of shear walls are usually much smaller than those computed under the assumption of fixed-end support. This also means that the contributions of slender shear walls to stiffening structures and to increasing lateral strength of the lowest stories can be significantly lower than those derived from the mentioned assumption.

The information that led to the action/ significant nonlinear behaviour would occur and to compare the calculated local ductility demands with the type and severity of local damage. The dead weights, live loads and member strengths assumed for the models of the structure were nominal values of those variables, and did not include any load factor or strength reducing factor as applied to structural design specifications.

The system studied was subjected to the portion of ground motion record within the time interval $30-80 \mathrm{~s}$, which includes the highest-amplitude cycles. Step-bystep dynamic response studies were carried out successively for three different assumptions: linear behaviour, nonlinear behaviour concentrated at plastic hinges on beams, with columns remaining linear, and nonlinear behaviour including plastic 
hinges on beams and columns. In the sequel, these types of behaviour will be designated as $L, N L B$ and NLBC, respectively. In all cases, viscous damping is taken as 5 percent of critical, referred to the small amplitude natural periods.

Time histories of the displacements at the roof show that the amplitudes for the three types of behaviour considered are only slightly different, with the peak value being highest $(42 \mathrm{~cm})$ for the NLBC system. These values correspond to average sway angles of 0.011 and 0.0095 , respectively, which are smaller than the value of 0.012 allowed by the 1987 building code for the cases when non-structural elements are isolated from the structure and larger than 0.006 , allowed by the same code for other cases. P-delta effects were found to be of small significance.

Fig. 14 shows the locations of some critical sections for which time-histories of shear forces and local ductility demands were obtained. For the purpose of calculating these demands, the following variables are introduced:

$\begin{array}{ll}\text { yield curvature }: & \Phi_{y}=\frac{M_{y}}{E I} \\ \text { plastic curvature : } & \Phi_{p}=\frac{{ }^{\theta} p}{l_{p}} \\ \text { local ductility }: & \mu_{L}=\frac{\Phi^{+} \Phi_{p}}{\Phi_{y}}\end{array}$

In these equations, $\mathrm{M}_{\mathrm{Y}}$ is the yield moment, $\mathrm{E}$ and I are modulus of elasticity and moment of inertia of the cross section, $\theta_{p}$ is plastic rotation at a plastic hinge, and $\ell_{p}$ is the corresponding hinge length. In the case of columns, $\mathrm{N}_{\mathrm{y}}$ is a function of the axial load, as given by the corresponding interaction diagram. Details of

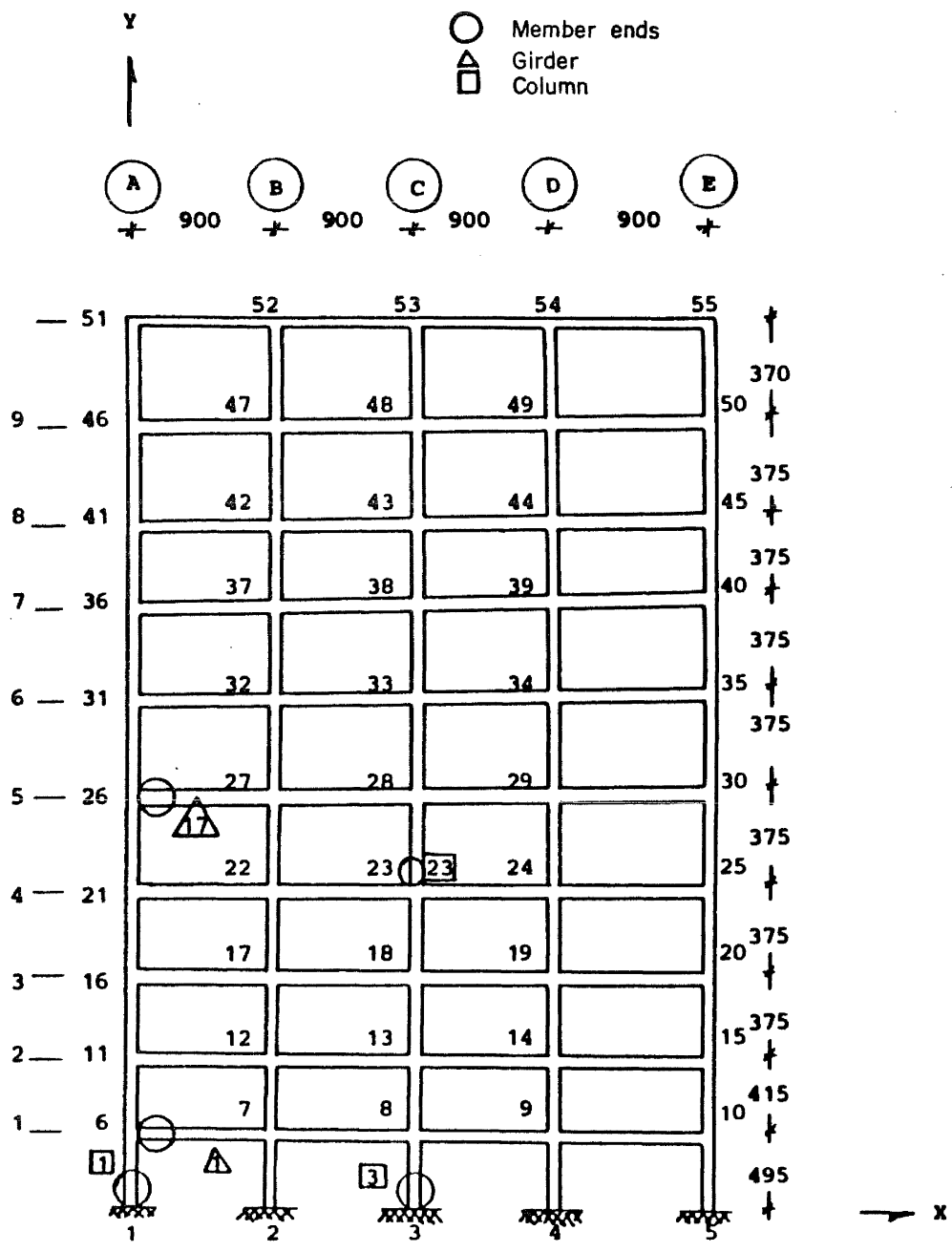

FIG. 14 - SECTIONS STUDIED, STC BUILDING (REF. 8) 
response studies and their comparison with observed performance are presented in the following, making reference to Fig. 14.

Column section 1 . This corresponds to the bottom end of an exterior ground floor

column. Axial loads fluctuate between 200 and 500 ton, and the resulting yield moments at both ends of that interval are

130 and 120 ton. m, approximately * (Fig.15). The maximum plastic rotation is 0.015 radians, which corresponds to local ductility values of 7.55 and 14.06 , depending on whether $h_{p}$ is taken as the column depth or half of that value when applying Eq. 2 . Damage at the corresponding location consists of only traces of plastic hinging, a fact which speaks well of the degree of confinement provided by the transverse reinforcement.

* 1 ton $=1000 \mathrm{~kg}=2200 \mathrm{lb}$
Time histories for the shear force acting on the section are shown in Fig. 16 for behaviour models NLB and NLBC. As expected, the possibility of hinging at the column ends reduces the shear forces, but the difference from the case NLB is not very important. The capacity of the section, $V_{R}$, is barely exceeded in two occasions. This is in agreement with the reported absence of diagonal cracking in members similar to this.

Column section 3. This is an interior ground floor column. Plastic hinge rotations, safety factors with respect to shear and types and severity of damage are similar to those reported for column section 1 .

Column section 23. This is an interior

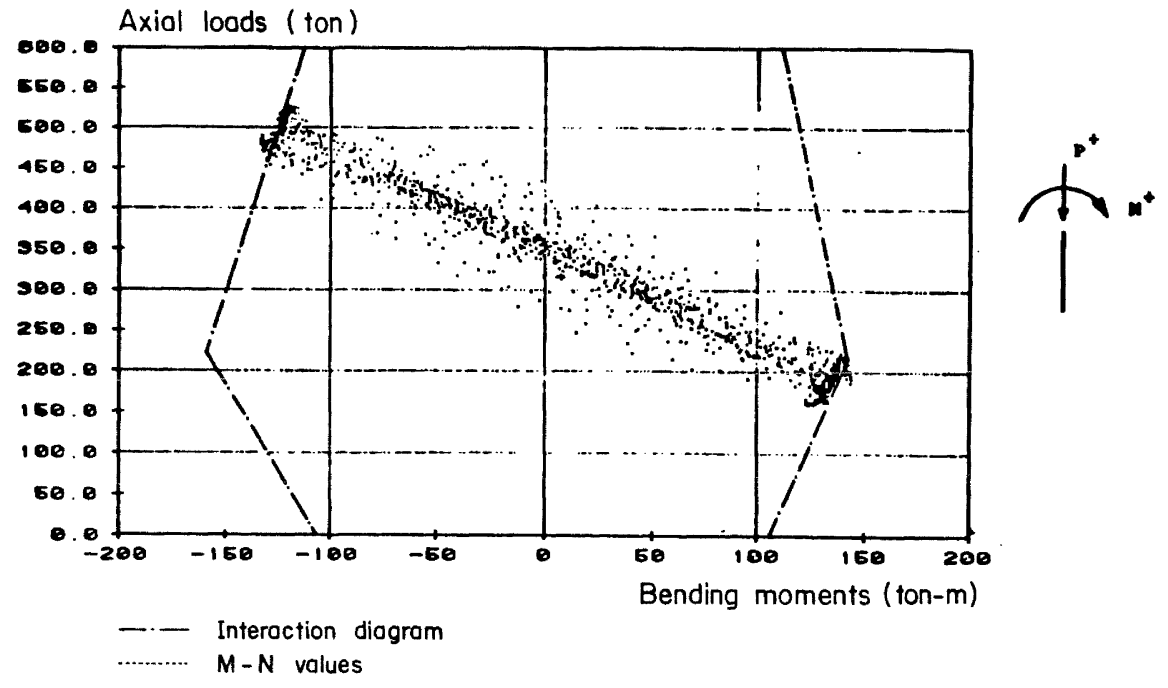

FIG. 15 - M-N VALUES AT COLUMN SECTION 1 (REF. 8)

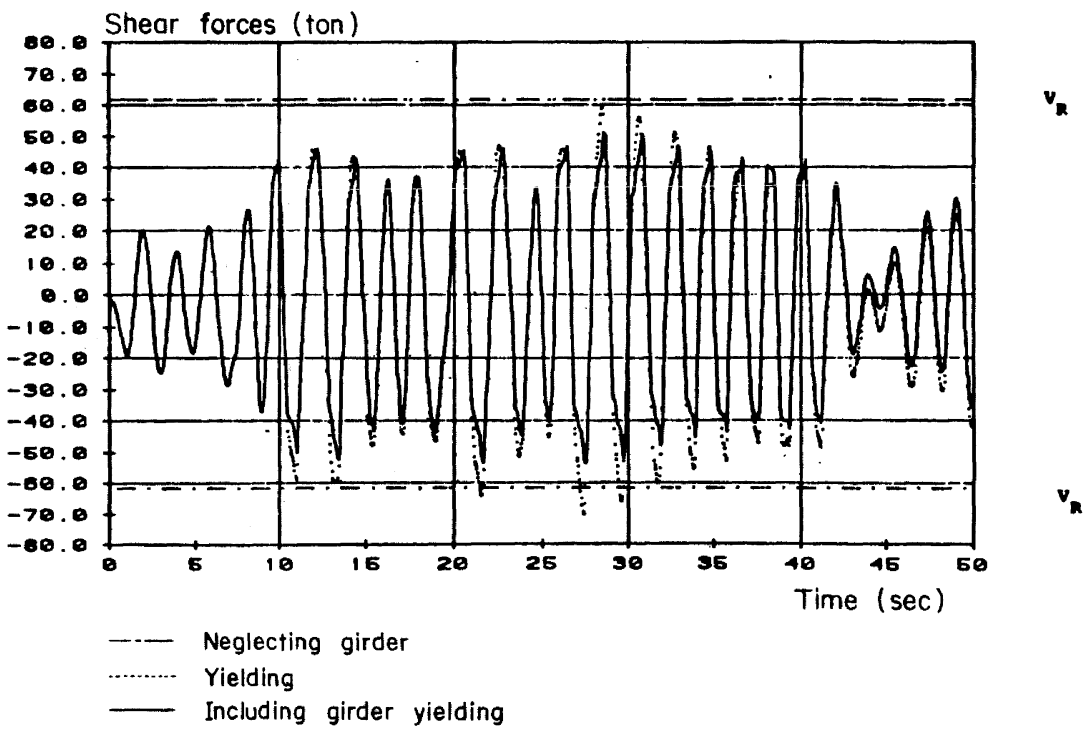

FIG. 16 - TIME HISTORY OF SHEAR FORCES, COLUMN SECTION 1 (REF. 8) 
column located at the fifth story. The response histories shown in Figs. 17 and 18 correspond to case NLBC. It is observed that the bending moment capacity is far from being reached, but the shear capacity $V_{R}$ is reached (but not exceeded) several times. Damage reports mention the occurrence of diagonal cracking at this section.

Beam section 1. This section is located at the first floor, next to an exterior column. Ductility demands of the order of 10 or 20 are developed according to

whether $l_{p}$ is taken as the beam's depth or half of it (Figs. 19 and 20). Shear forces are much smaller than $V_{R}$. Concrete spalling and local buckling of reinforcment at the hinge are consistent with the predicted ductility demands.

Beam section 17. This is an exterior end of a beam located at the fifth floor.

Ductility demands for the case NLBC reached values of 13 for $l_{p}$ equal to one half of the beam's depth. Shear forces are significantly smaller than $\mathrm{V}_{\mathrm{R}}$. The observed behaviour is similar to that of beam section 1 .

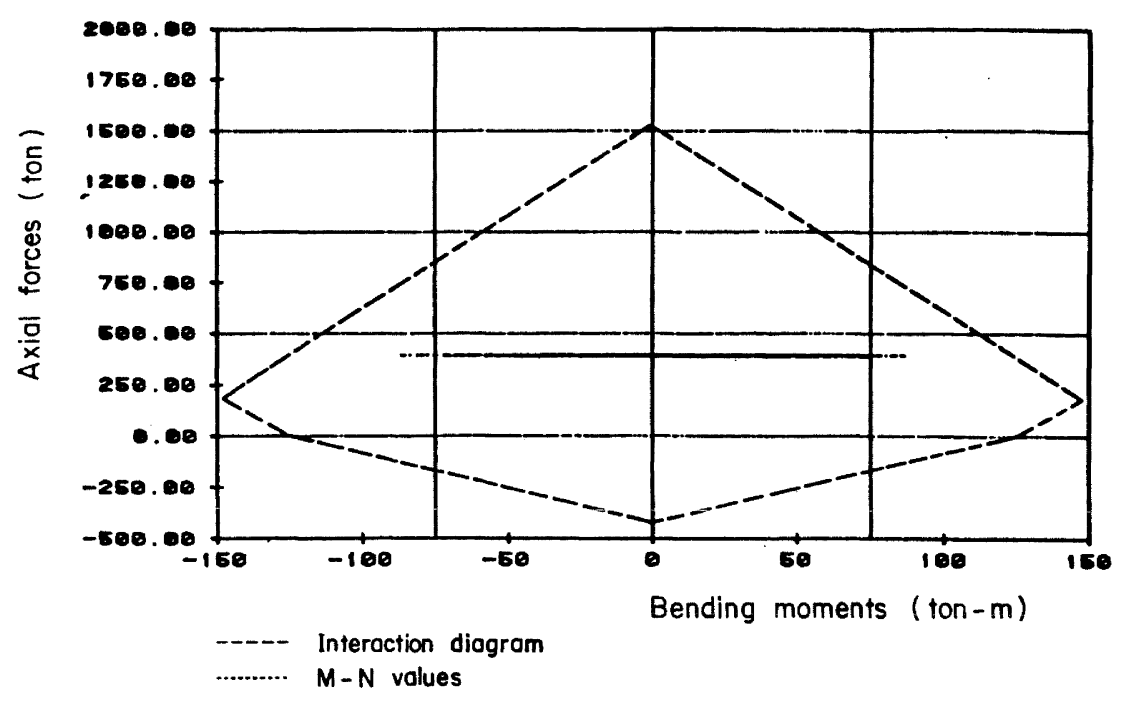

FIG. 17 - M-N VALUES, COLUMN SECTION 23 (REF. 8)

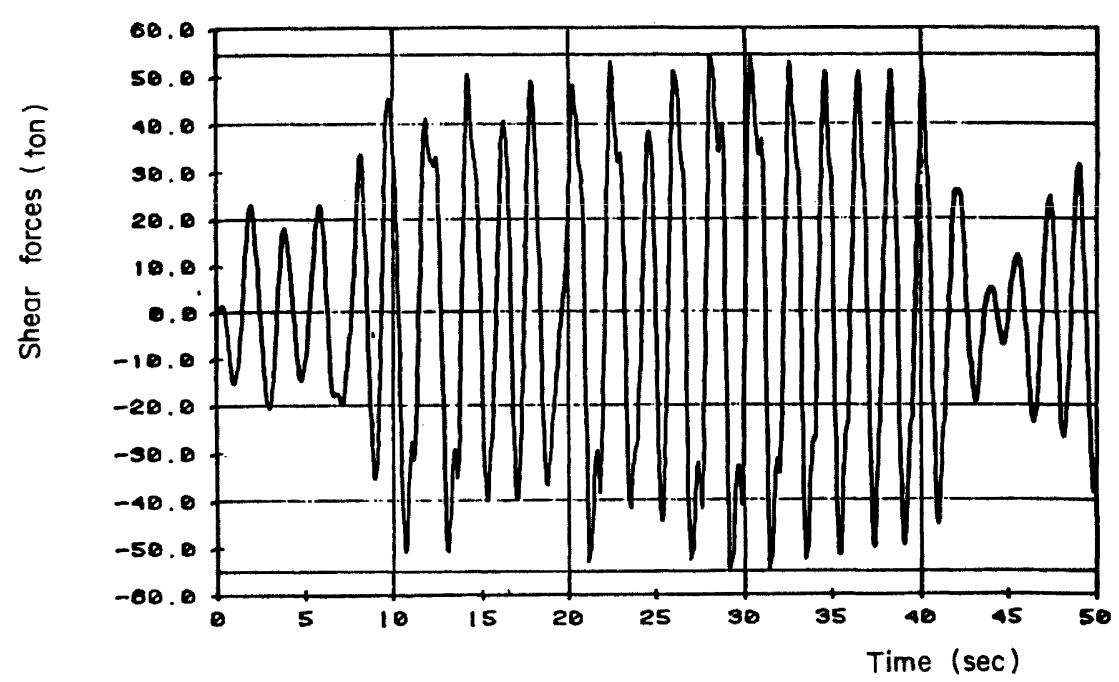

FIG. 18 - TIME HISTORY OF SHEAR FORCE, COLUMN SECTION 23, INCLUDING GIRDER YIELDING 
Local ductility demands (curvatures)

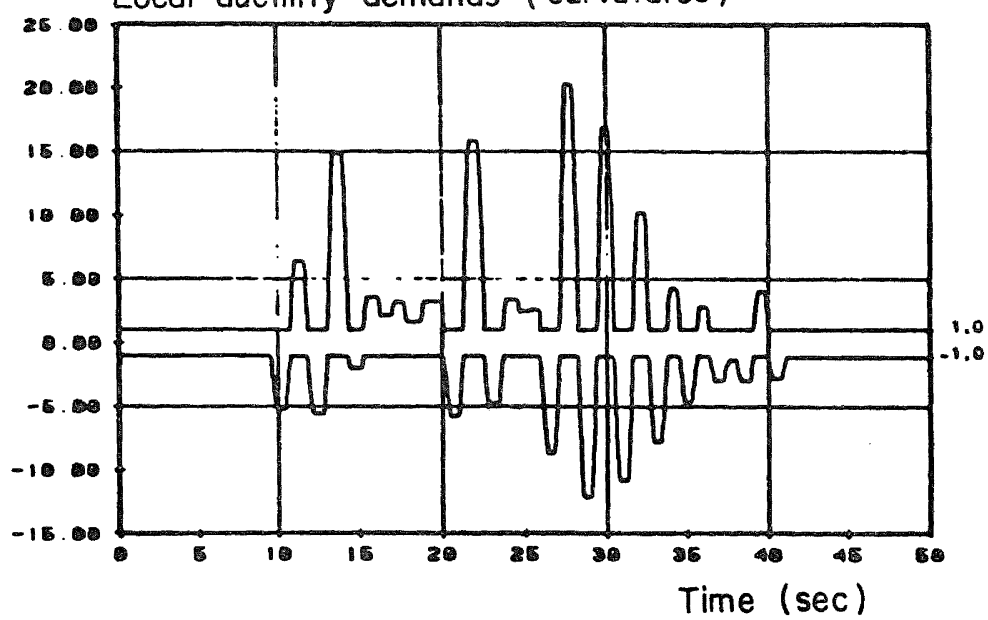

FIG. 19 - LOCAL DUCTILITY DEMANDS, BEAM SECTION $1, \ell_{p}=0.5 \mathrm{~d}$ (REF. 8)

Local ductility demands (curvatures)

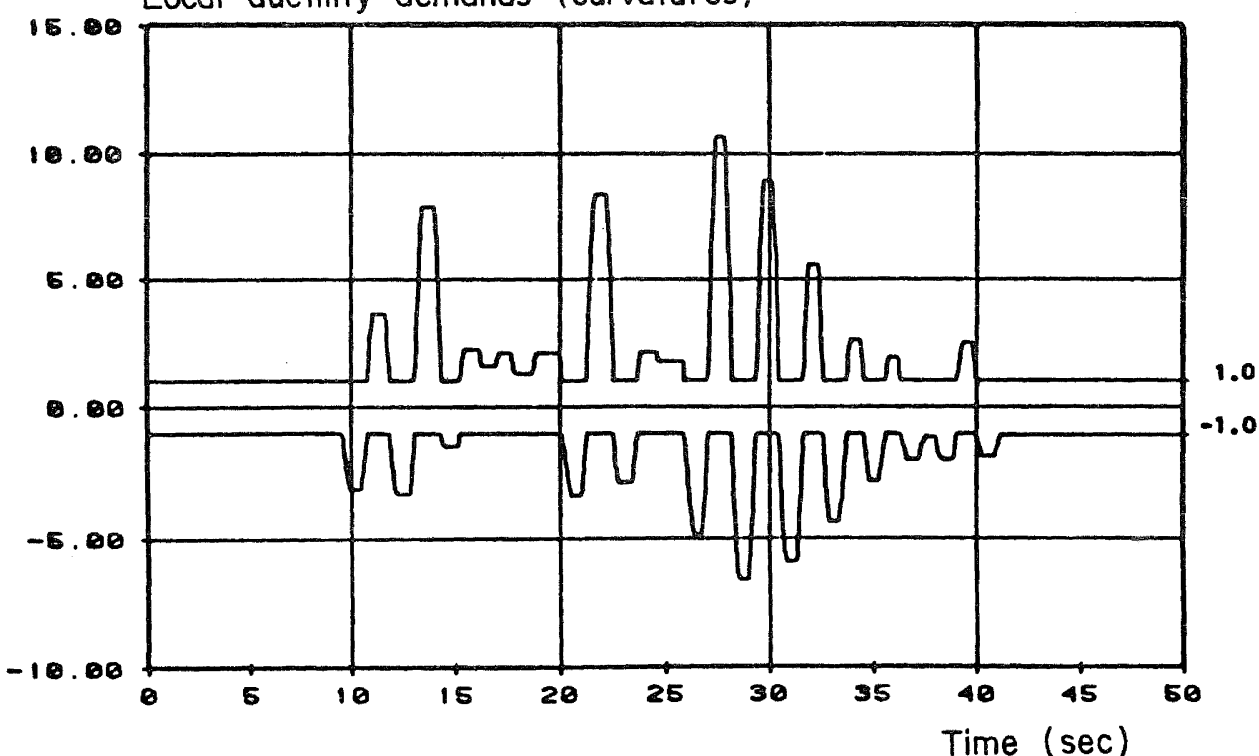

FIG. 20 - LOCAI DUCTILITY DEMANDS, BEAM SECTION $1, \ell_{p}=1 d$ (REF. 8)

The extension of the region of the structure affected by nonlinear behaviour is very large, as inferred from Fig. 21 which shows the sequence of formation of plastic hinges. Unfortunately, the information available to the writer did not suffice to find out how many hinges were active simultaneously.

In summary, the foregoing studies show very good qualitative agreement between predicted response and observed behaviour. This degree of success may at least partly be due to the simplicity and regularity of the system studied. Unfortunately, not much can be said regarding quantitative agreement, perhaps excluding the observa- tions about absence of diagonal cracking when the calculated shear forces are much smaller than the calculated capacities. Quantitative comparisons between predicted local ductility demands and observed local damage will only be feasible after we create banks of similar information based on the results of laboratory tests. In order to make quantitative comparisons between global or local predicted responses with the corresponding real life values, we should have adequate instrumental records. Hence the need for ambitious programs of installation of instrument arrays in complex structures, designed to record strains, deformations, displacements and accelerations produced by high intens- 


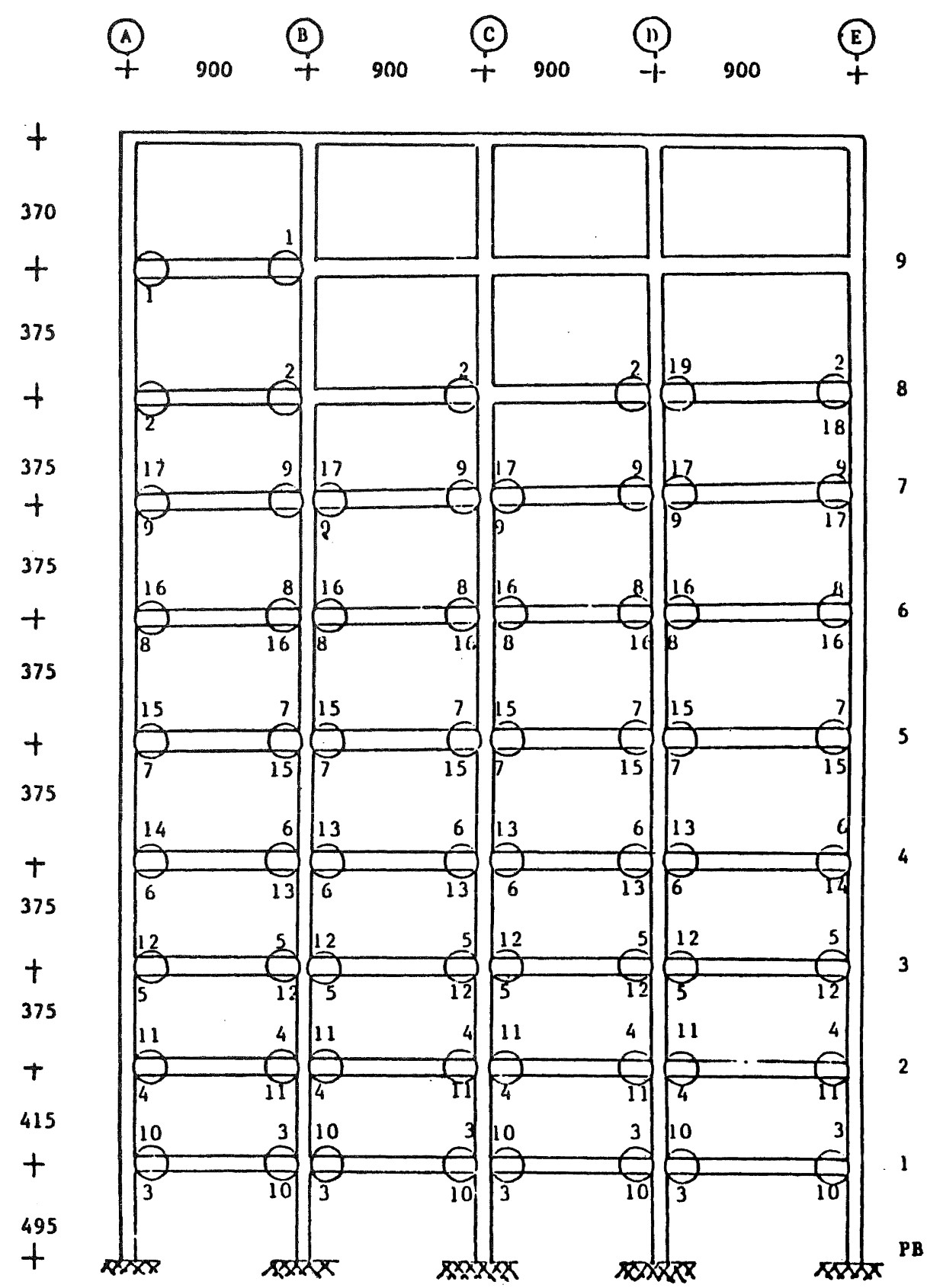

FIG. 21 - SEQUENCE OF APPEARANCE OF PLASTIC HINGES, STC BUILDING (REF. 8)

ity earthquakes at several locations, members and sections.

\section{RELATION BETWEEN OBSERVED DAMAGE AND SAFETY FACTORS OF INDIVIDUAL MEMBERS}

Despite the great value of detailed studies of nonlinear dynamic response for understanding the seismic behaviour of actual structures, the modelling and computational efforts they demand are as a rule large enough to preclude their generalized application to make comparisons between predicted response and observed

behaviour. Therefore, attempts at relating observations about the behaviour of actual systems to the adequacy of the design and construction requirements applied, have also included comparisons between nominal safety factors at given sections or members and the corresponding local behaviour.

The following is a summary of a study presented in Ref. 8 covering six structures, each designed and built in accordance either with the 1966 Mexico City building code (C66) or with its revision of 1976 (C76).

Under the assumption that compliance with the 1985 Mexico City emergency code (E85) would be a good indicator of adequate safety with respect to an earthquake similar to that of september 1985, the response of the mentioned structures to such an earthquake was estimated by means 
of a modal linear analysis for an excitation represented by the design response spectra specified by $\mathrm{NE} 85$. The ratios of the forces obtained in this manner to the nominal available strengths at the corresponding critical sections, obtained in terms of nominal material properties and cross section dimensions of members, are called in the sequel action/strength ratios (ASR) and their relation to the type and level of damage is studied.

The most relevant properties of the buildings studied and the damage suffered by them are summarized in Appendix A. From this information and from the details supplied in Ref. 8, the following conclusions are reached.

a) Studies of the response of linear models do not lead to reliable estimates of response of nonlinear systems, in particular where large nonlinearities result from severe excitations. At most, linear models may provide qualitative information as to the most vulnerable sections of these systems. However, they fail to predict the behaviour of individual members after the internal forces acting on them suffer sudden increases resulting from stress redistribution associated with brittle failure of other members.

b) A well known principle in earthquake engineering is confirmed anew: use of higher safety factors for brittle failure modes as compared to those applied to ductile failure modes may be as important as adopting adequate base shear coefficients. A positive confirmation of this principle is found in the adequate behaviour of columns of buildings $B 2$ and $B$ in Appendix A, while a negative confirmation is provided by failure of the foundation of building B 1, where the safety factor with respect to story shears was higher than that with respect to pushing-in or pulling-out of friction piles.

c) Details regarding placement of longitudinal reinforcement and degree of confinement provided by transverse reinforcement in columns significantly contribute to restrict damage produced by large alternating deformations.

d) Reinforcement of slab-to-column connections, as well as transverse reinforcement of the ribs of waffle slabs ought to be substantially improved.

\section{BEHAVIOUR OF FOUNDATIONS}

This section is based on Ref. 9, which contains quantitative information about design criteria and safety factors for a set of 11 buildings with moderate or severe damage associated to deficient foundation performance. The sample includes building Bl of Appendix $A$, which collapsed as a consequence of insufficient capacity of the foundation with respect to overturning:
The design and construction of foundations in the soft soil area in Mexico City poses unusual problems, as a consequence of the low shear strength of the clay, its high compressibility, the occurrence of regional settlement of the ground surface in the Valley of Mexico and the frequency and intensity of earthquakes. The low strength and high compressibility of clays lead to extensive use of solutions such as shallow or deep raft foundations and combinations of them with several types of pointbearing and friction piles (Fig. 22). The occurrence of regional settlement provokes the emersion of foundations supported on deep stiff layers and the overloading of point bearing piles and piers by negative friction.

Shallow footing foundations are used only for lightweight structures. Consequently, their behaviour during the 1985 earthquake was satisfactory as a rule, with the exception of those cases with obvious constructive deficiencies. However, many instances of differential settlements on structures with shallow foundations were observed, resulting from their interaction with adjacent, heavier structures. In most cases, the earthquake only accentuated a process that had started before, under the action of permanent loads.

Some shallow raft foundations showed substantial non-uniform settlements, leading to tilting of the building. In general, deficient behaviour of foundations of this type can be ascribed to excessive bearing pressure for vertical loads (implying excessive settlements and low safety factor with respect to shear failure) and initial tilting resulting from load eccentricities, soil heterogeneities and pumping sustained for long time intervals in near-by excavations.

In compensated foundations part of the weight transmitted from the structure to the soil layers supporting it is compensated by eliminating the weight of the soil excavated in order to build the foundation structure. In general, the latter is a hollow box constituted by the reinforced concrete slabs at its top and bottom, the retaining walls around it and a twodimensional grid of girders, stiffening it (Fig. 22). Often, the hollow box includes also the space used as a basement. The bottom slab lies usually several meters below the ground surface. According to the portion of the total weight of the structure that is compensated, it can be considered to be total or partial compensation, or even overcompensation.

The causes of ill behaviour of compensated foundations are similar to those for shallow foundations. Particularly significant were the instances of excessive net pressures transmitted to the soil, and the consequently large settlements produced by permanent loads. The superposition of excessive vertical stresses with high cyclic shear stresses may give rise to substantial non-linear strains, which in turn result in large residual strains, and therefore large settlements (9). This may 


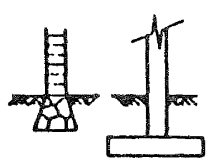

FOOTINGS

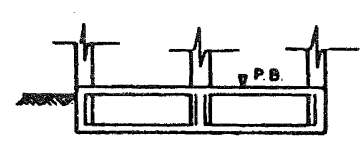

SHALLOW RAFT

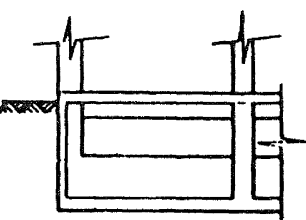

COMPENSATED FOUNDATION

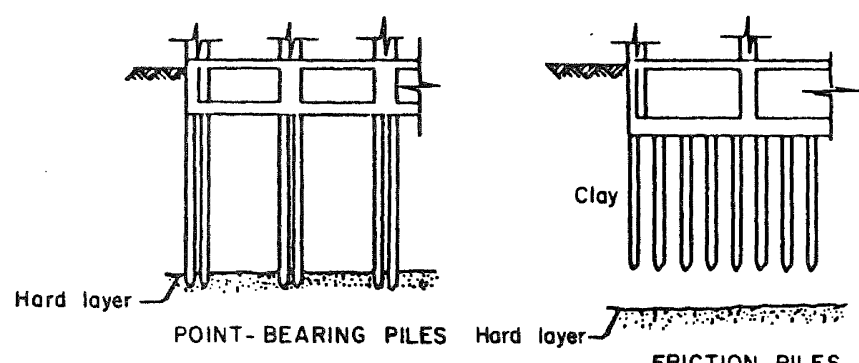

FRICTION PILES

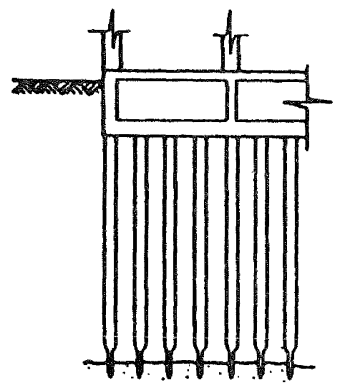

PENETRATING-POINT PILES

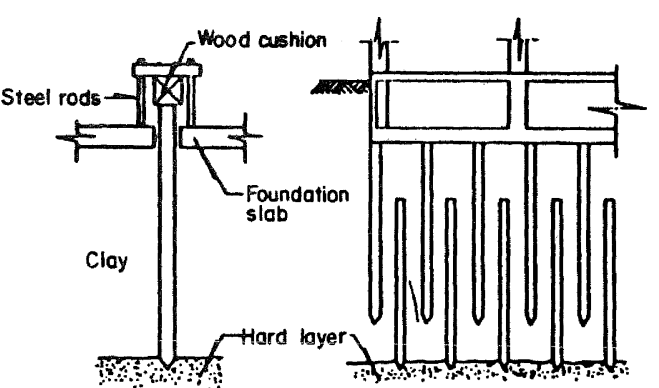

CONTROL PILE

OVERLAPPING PILES

FIG. 22 - TYPES OF FOUNDATIONS USED IN THE LAKE ZONE OF MEXICO CITY (REF. 9)

explain the cases of very large vertical settlements in several buildings, some of which were not slender enough as to make their foundations sensitive to overturning moment problems. An unforeseen concept adding to the problem in most of the cases studied is the leaking of water into the hollow foundation box, thus increasing the weight of the building.

The behaviour of foundations on pointbearing piles was in general satisfactory, although in many such cases the soil next to the periphery of the construction suffered significant settlement. However, evidence is available about much more serious problems that may affect foundations of this type. The most important of them are the cases of crushing of concrete at the head of piles, produced by the combination of axial load bending moment. The latter is produced by the seismic lateral forces and may turn to be extremely high in thoses cases where the head of the pile has emerged out from the soil surface, as the latter follows the process of regional settlement.

A small number of buildings founded on point-bearing piles resulted with tilting displacements after the earthquake. In some cases this effect was caused by penetration of piles into the hard layer supporting them, and in a few other instances the problem was ascribed to struct- ural failure of the wooden piles that were used about 40 years ago.

Friction piles are ordinarily used in combination with partially compensated foundations. Two forms of deficient performance were identified: a) sudden settlement of heavy constructions, with large dimensions in plan, where the net additional loads transmitted to the soilpiles system were higher than allowed by the current code of practice for foundation design and b) permanent tilting, including one case of collapse, associated with overturning of slender structures. Specialists in the design of foundations of this type in Mexico City agree on considering that our understanding of the behaviour of those systems is far from satisfactory. Serious doubts remain with regard to how vertical and lateral stresses are transmitted to the soil through the piles and the foundation slab, as well as about the interaction between both systems in an overall failure mechanism. On the other hand, it is very likely that bond strength at the interface between soil and piles deteriorated in many cases during the earthquake, but this phenomenon is not needed to explain the bad performance of the cases studied in detail in Ref. 9.

A common denominator of the instances of inadequate performance of foundations is their not having complied with criteria 
and specifications generally accepted before the earthquake. Nevertheless, this does not mean that compliance with those criteria is tantamount to satisfactory performance. On the contrary, the earthquake has brought to the surface the need for substantially improving our knowledge about the behaviour of soft soils subjected to high cyclic stresses. Similarly, large research efforts must be devoted to understanding the phenomena of loss of bond of friction piles subjected to cyclic loads. These two problems are the matter of ongoing research programs in Mexico and abroad. The study of other important problems, such as the combined participation of foundation rafts and friction piles in resisting vertical loads and overturning moments, is still to start.

\section{NONLINEAR TORSIONAL RESPONSE}

As shown in Table 3, 15 percent of the buildings that suffered collapse or severe damage were branded as possessing pronounced asymmetry in stiffness and 42 percent of the former group of buildings were located at block corners. Many of these were reinforced concrete frame buildings with plain brick masonry walls, acting either as infills or as shear walls, throughout the whole of their faces next to the boundaries with the adjoining plots of land. Thus, the lateral-force resistant structure of one such building consists of two systems of conventional rigid frames in two orthogonal directions, plus two rigid diaphragms, covering the full height and the full width of the building, at its two edges not facing the street. In many cases the damage pattern strongly suggested that high amplitude torsional vibrations had played an important role. Because it had been common practice, starting right after the 1957 earthquake, to take into account torsional response in accordance with a linear analysis, including both dynamic amplification of static eccentricity and accidental eccentricity, it was speculated that very high torsional vibrations, significantly higher than those preaicted by the linear theory, might have taken place.

A systematic study of the torsional response of non-linear systems is now underway. The first stage has concentrated on elastoplastic single-story systems, with a plan similar to that shown in Fig. $23(10)$. The lateral strength is supplied by three shear elements with elastoplastic behaviour. The centre of stiffness, CS, is assumed to coincide with the centroid of the plan area, while the centre of mass, $\mathrm{CM}$, lies a distance $e_{s}$ away from $i t$. This distance is the conventional static eccentricity, herein called "stiffness eccentricity", in order to distinguish it from the "resistance eccentricity", $e_{r}$ which is the distance between the centroid of the resistances of the shear elements and the centre of mass.

A set of structures was chosen, each characterized by a value of $e_{s}$, ranging from 0 to $0.4 \mathrm{~b}$, where $b$ is the width of the structure, parallel to the eccentricity. Each structure was designed in accordance with the 1976 code and the strengths of the elements at the ends were increased so as to obtain predetermined values of $e_{r}$. In order to account for uncertainties about $e_{s}$ and $e_{r}$, for each of their values two assumptions were made regarding the actual location of the centre of mass at distances of $\pm 0 . l_{b}$ from its nominal value.

Each structure defined as described above was subjected to several singlecomponent strong-motion time histories parallel to the direction of the shear elements. Its response, including torsional oscillations, was obtained by step-by-step integration. The maximum ductility demand at anyone of the shear elements was compared to the value corresponding to a symmetric system with the same natural periods in translation and torsion as the asymmetric structure, and designed for the same

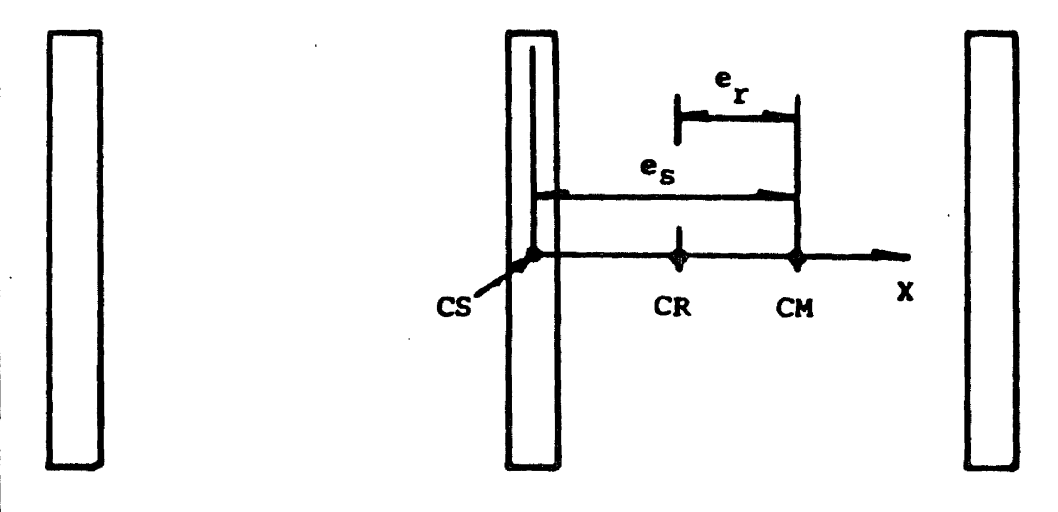




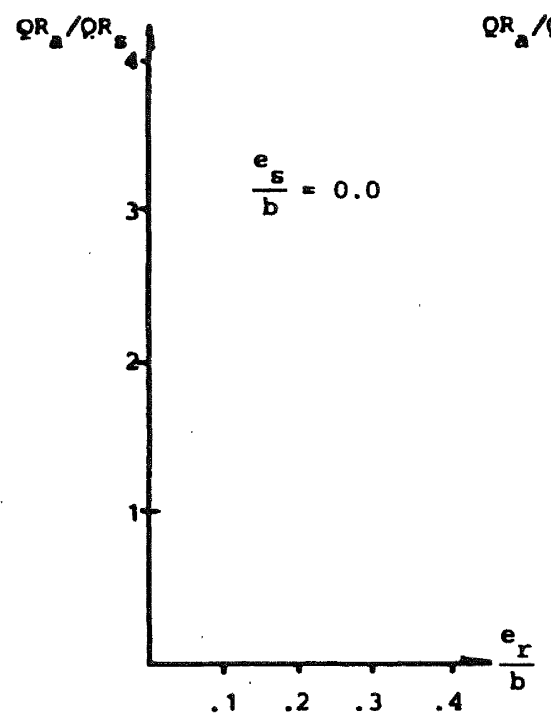

(a)

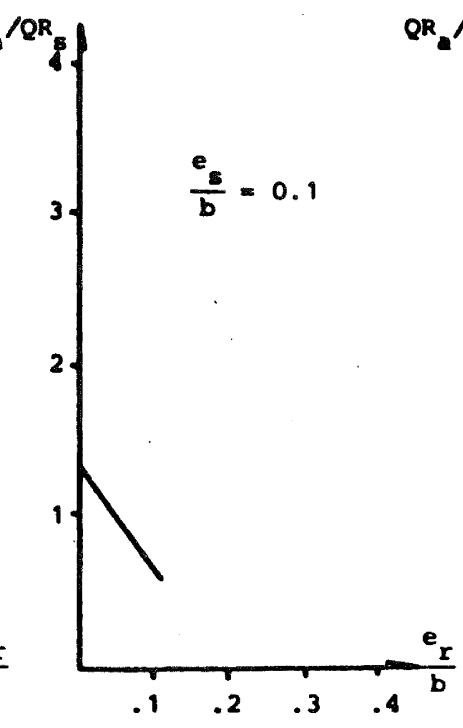

(b)

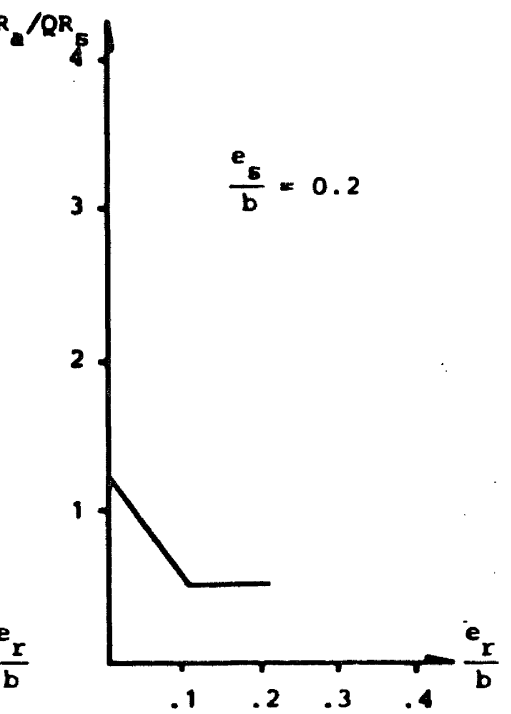

(c)

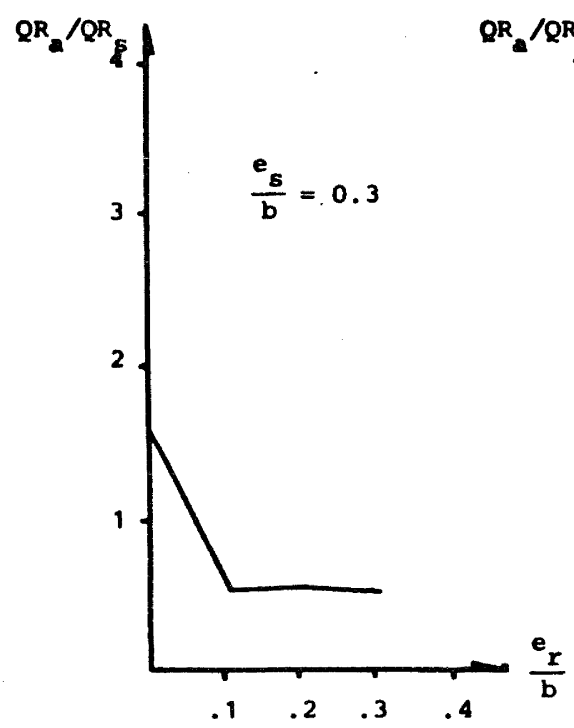

(d)

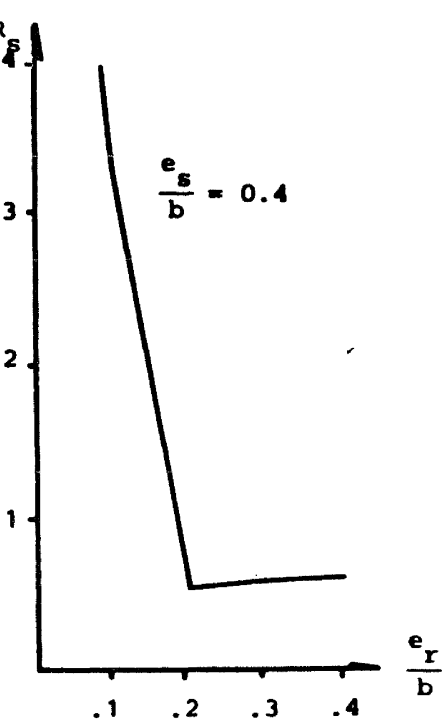

(e)

FIG. 24 - DUCTILITY DEMANDS IN ECCENTRIC SYSTEMS. T $=0.5 \mathrm{sec}$ (REF. 10)

response spectrum. Typical results for the EW components of the SCT record of 19 September 1985 are depicted in Figs. 24-26, which show ratios of the ductility demands mentioned above the translational periods (equal to the corresponding torsional periods) of $0.5,1.0$ and $1.5 \mathrm{sec}$, for different combinations of $e_{s}$ and $e_{r}$. As the figures consistently show, having resistance eccentricities much smaller than stiffness eccentricities may lead to excessive ductility demands. The last revision of Mexico City building code accounts for this problem by putting a lower bound to $e$ as a function of $e_{s}$ (described in detail below).
DISCONTINUITIES IN STRENGTH AND STIFFNESS: WEAK FIRST STORY

When the 1976 code was written, it was known by many engineers that sharp discontinuities in strength and stiffness along the height of buildings might drastically

affect the distribution of ductility

demands at stories. Even though very

little quantitative information was available concerning that distribution for particular cases, it was clear that a nonuniform distribution of safety factors throughout a building would prevent the dissipation of kinetic energy by hysteretic behaviour of those members with the largest 


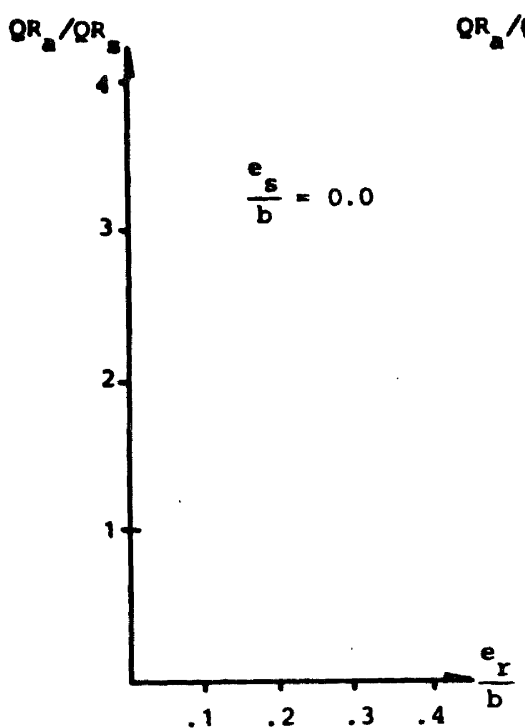

(a)

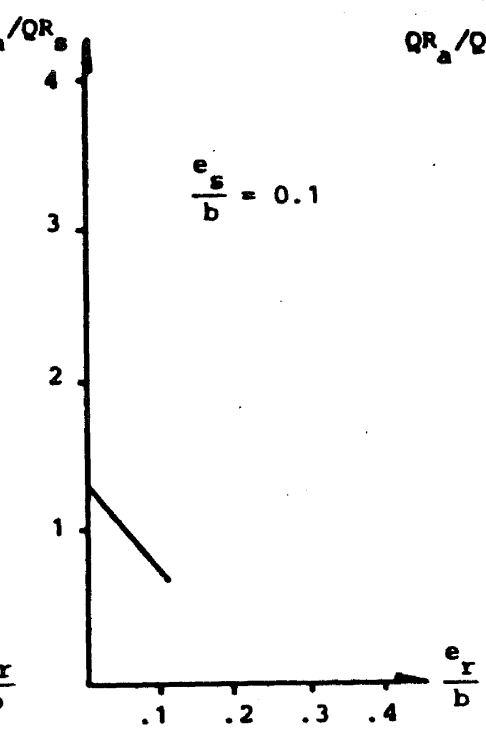

(b)

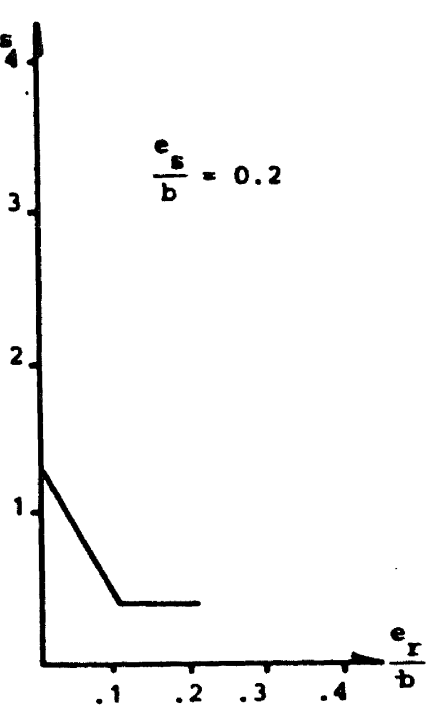

(c)

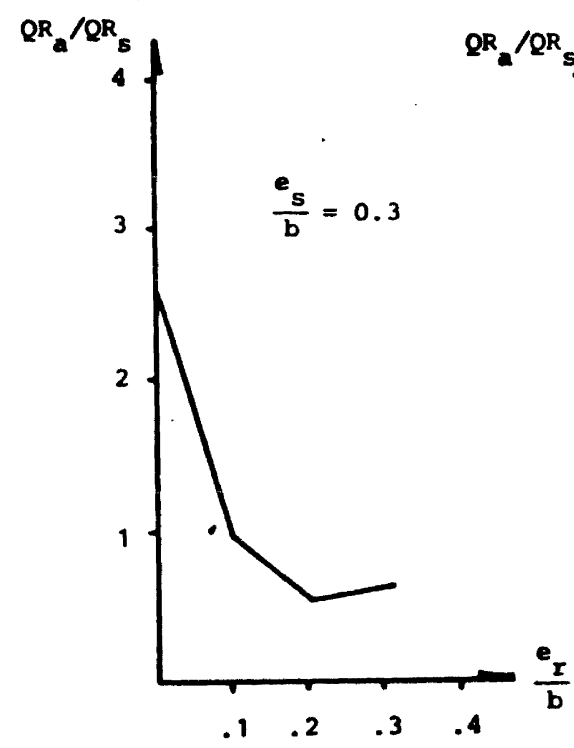

(d)

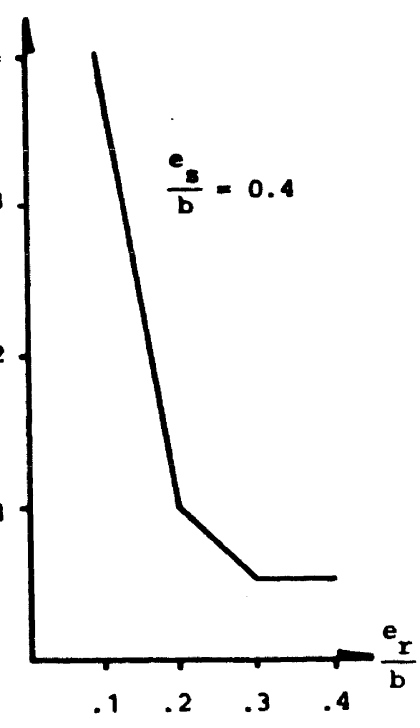

(e)

FIG. 25 - DUCTILITY DEMANDS IN ECCENTRIC SYSTEMS. T $=1.0 \mathrm{sec}$ (REF. 10)

safety factors, at the expense of forcing the required dissipation of energy to be concentrated at the members with the smallest safety factors and, consequently, to give rise to excessively large ductility demands at the latter members. Therefore, the 1976 code states as a condition for applying high reductions, based on ductile behaviour, to the linear response spectra or lateral force coefficients, that the safety factor at any given story should not be lower by more than a given percentage than the average of those safety

factors for all the stories. The percentage was set at 20 for high ductility structures, for which a reduction factor of $1 / 6$ could be applied to linear response design values, and 35 for ordinary frame structures, to which corresponded a factor of $1 / 4$.

The most dangerous cases of sharp discontinuities in strength and stiffness are buildings with a free, and therefore weak, first story. Many buildings of such a class are found in Mexico City, mainly among those used as dwelling units in the most densely built areas, because the ground floor story is used as parking space while the upper stories contain the apartments. A large percentage of those buildings did not comply with the requirements of the 1976 code relative to uniformity of safety factors, either because they were built before that code was enforced or because the engineers who designed their 


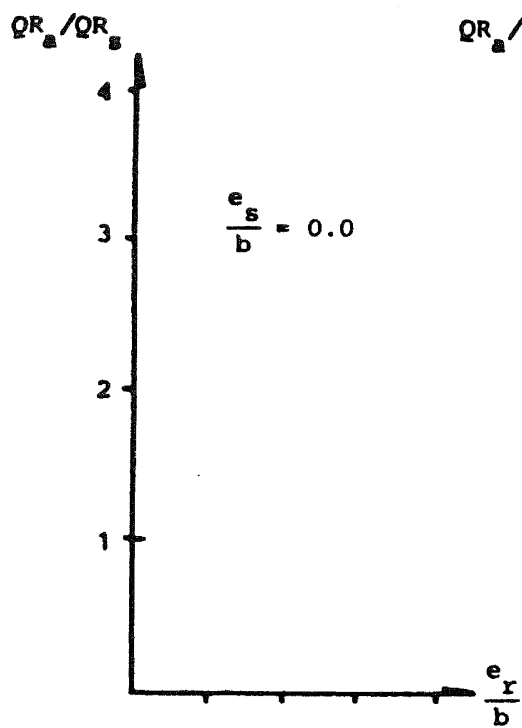

$\begin{array}{llll}.1 & .2 & . & .\end{array}$

(a)

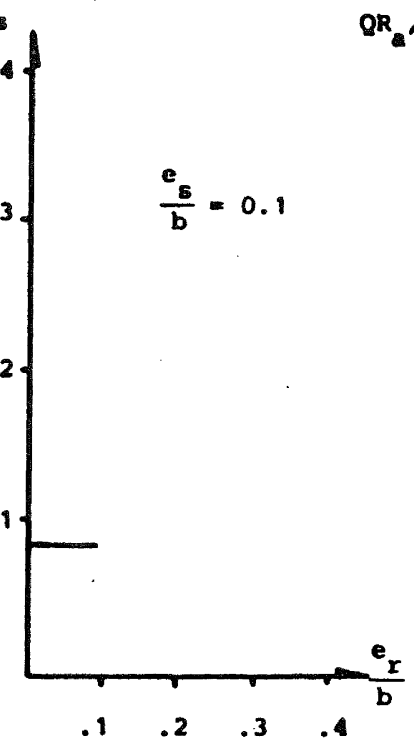

(b)

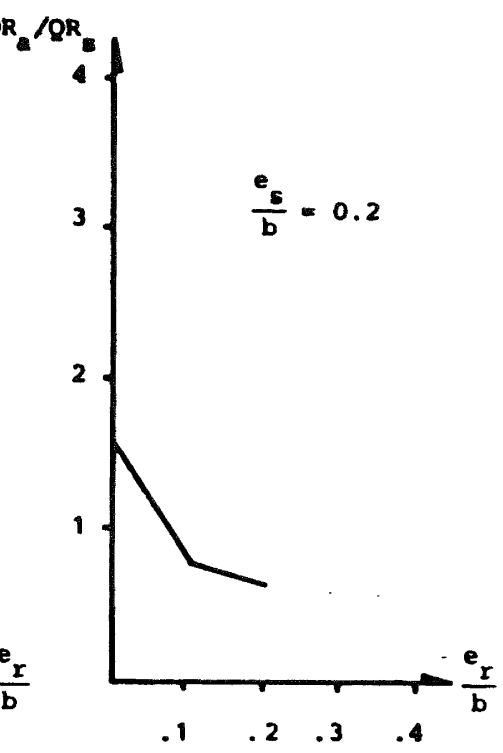

(c)

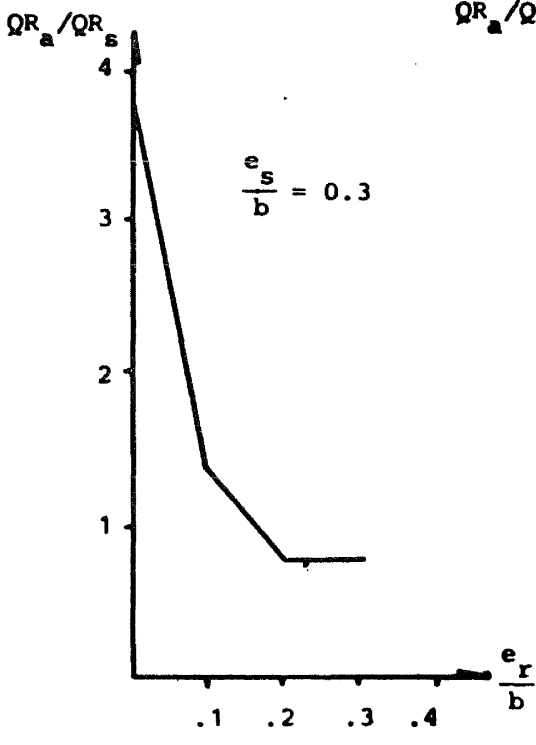

(d)

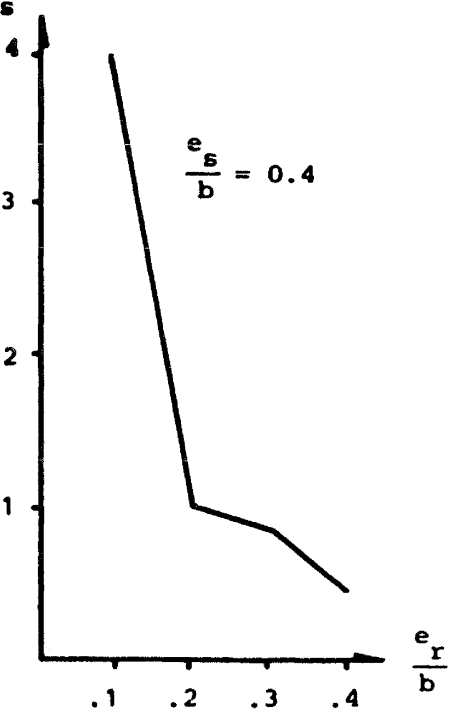

(e)

FIG. 26 - DUCTILITY DEMANDS IN ECCENTRIC SYSTEMS. T $=1.5 \mathrm{sec}$ (REF. 10)

structures were not sufficiently informed about the implications of non-uniformity of safety factors on the nonlinear dynamic response of complex systems.

Eight percent of the buildings which collapsed or suffered severe damage in

September 1985 possessed a free first story. It was not clear whether the failures should be ascribed to unfavourable concentrations of ductility demands accentuated by sharp variations of safety factors or, simply, they could be explained by the low values of those safety factors at the first story, irrespectively of their values at other stories. Trying to find general answers to this question, a theoretical program on the dynamic nonlinear response of systems with weak first story was undertaken. The program includes two parts.

The first is a systematic study of a large number of two-degrees-of-freedom shear systems, the properties of which are chosen so as to reproduce the linear dynamic response of the fundamental mode of multidegree shear systems, representative of tall buildings (11). The second part emphasizes the details of the time histories of response of a set of five-story and twelve-story frame systems (12).

The systems studied in the first part were designed in accordance with the emergency code of 1985, with a safety 
factor of unity, and were subjected to the EW component of the SCT record. Three 2dof systems were chosen, equivalent to buildings with 7,12 and 25 stories, and fundamental periods of $0.7,1.4$ and 2.0 sec, respectively. Among other cases, a set of elastoplastic structures was defined so that in all members of the set the story stiffnesses were proportional to the story safety factors (Fig. 27). The absolute values of the stiffnesses were determined so as to produce the required periods, but some members of this set do not satisfy the specifications about maximum allowable story deformations. According to Fig. 27, ductility demands at the first story are very sensitive to the ratio of safety factors in the upper and lower portions of the building, as well as to its initial natural period for small deformations. There exists a critical range of the ratios of the safety factors for which the effect is largest.

Another set of 2-dof systems was defined to represent the cases of buildings which are designed as frame systems with uniform safety factors along their height, but which are built so that the infill walls are not adequately isolated from the structure, as specified in the project. A structure in these conditions having free first story, will remain with the strength and stiffness in that story as given by

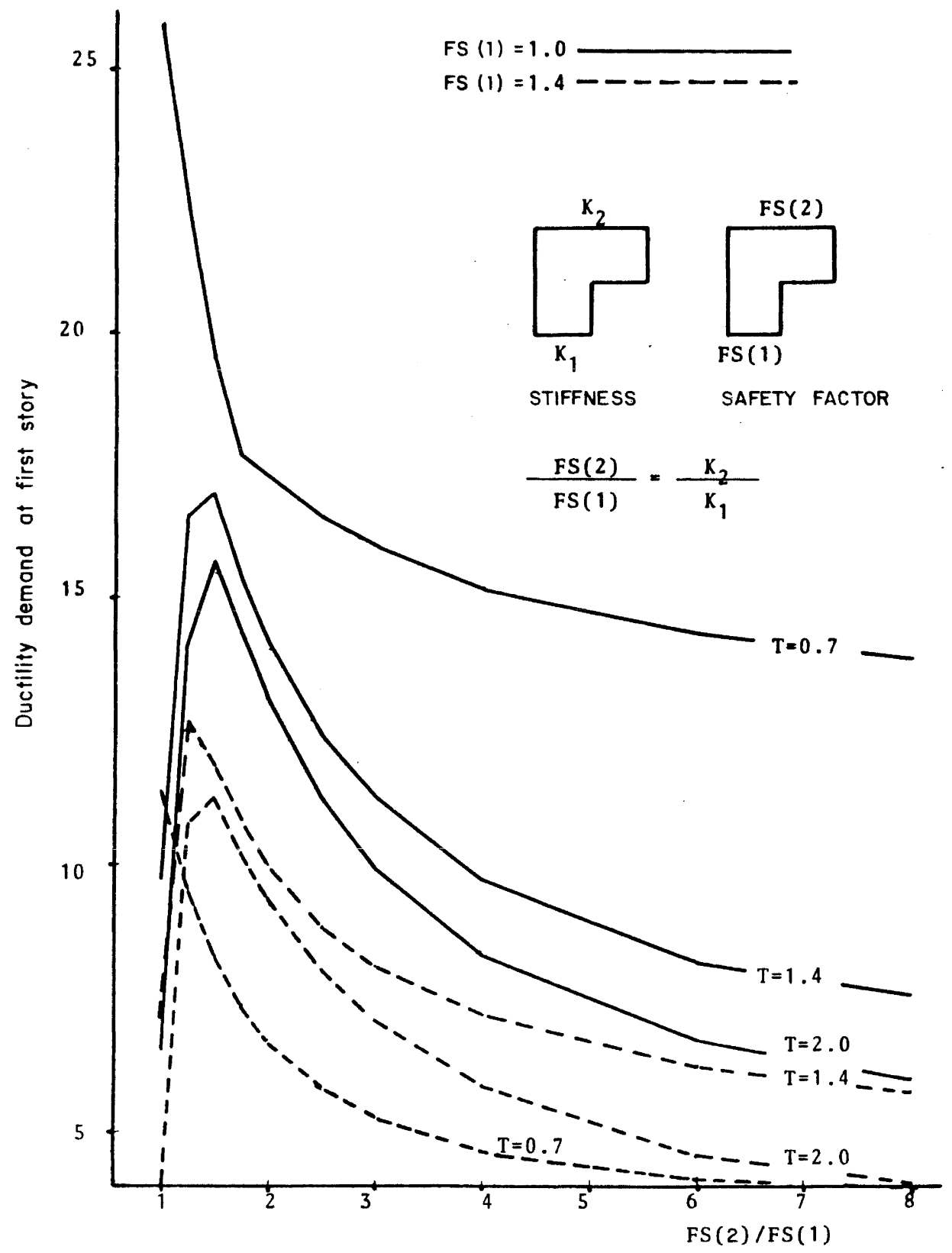

FIG. 27 - DUCTILITY DEMANDS FOR CONSTANT NATURAL PERIODS 
the original design, but at the upper stories both properties will have values larger than what the project requires. In order to study these cases, the original systems were defined as possessing uniform safety factors and two types of variation of stiffnesses (Fig. 28). Then stiffnesses and safety factors were increased by constant amounts at all stories except the first, so that the ratio of the increment of the stiffness to the first-story stiffness was equal to that of the increment of the safety factor to its value at the first story. As a result, the natural periods are modified as shown in Fig. 28, and the linear lateral displacements of the first story suffer slight variations, as shown in Fig. 29. After all this was done, the equivalent elastoplastic 2-dof systems were defined and their non-linear responses calculated, neglecting $\mathrm{P}$-delta effects. Some results are shown in Fig. 30. Qualitatively, these results are similar to those in Fig. 27.

Figs. 31 and 32 show the sensitivity of the response to P-delta and stiffness degradation effects. Fig. 31 corresponds to uniform systems and Fig. 32 to some where the stiffnesses and safety factors in the upper stories have been multiplied by 3. The horizontal axis represents the safety factor at the first story and the vertical axis represents its lateral displacement. Stiffness degradation was represented by Takeda's model and, as Fig. 31 shows, it can be a determining factor in controlling the response of some systems with significant P-delta effects. These results call attention to the large

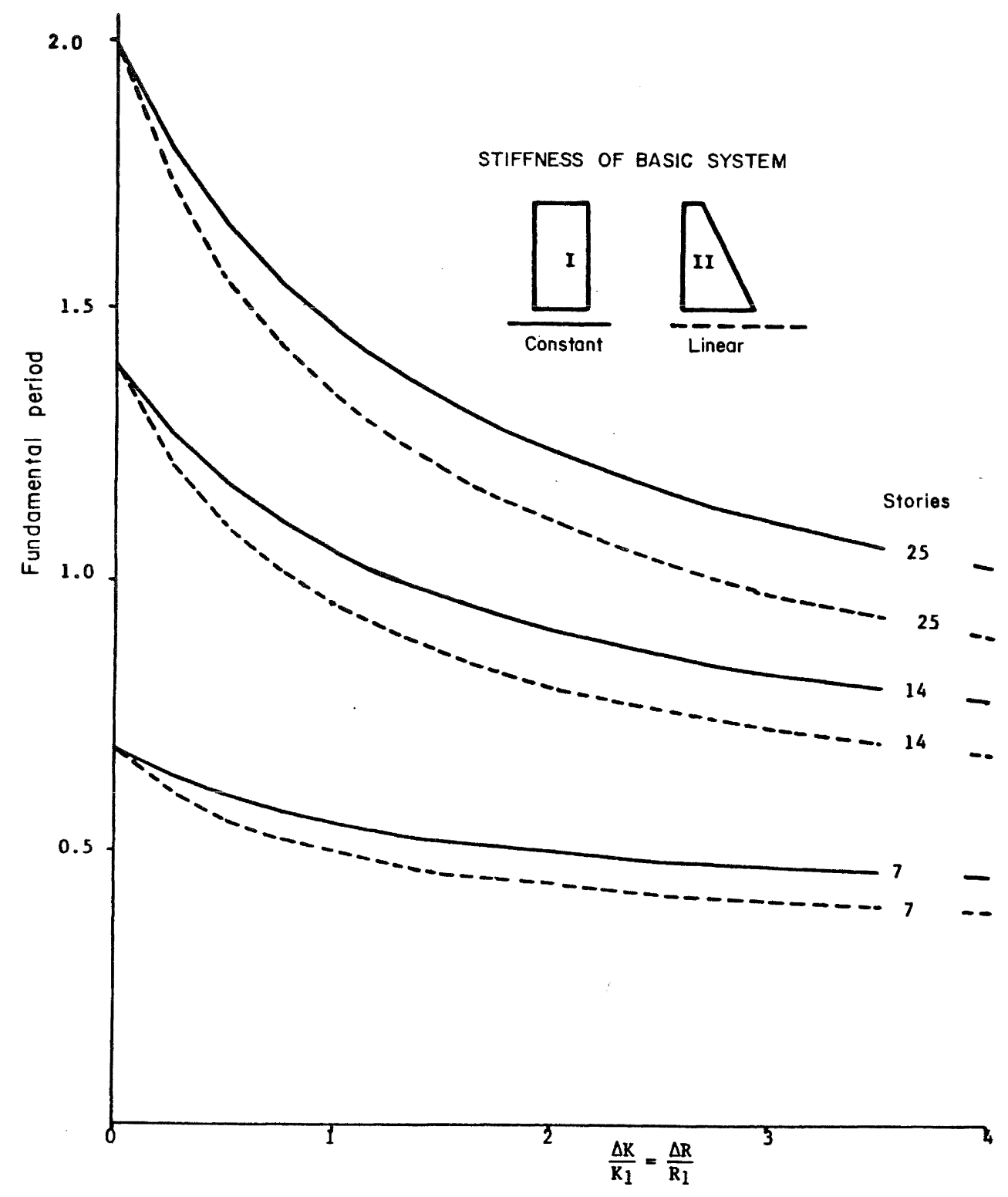

FIG. 28 - VARIATION OF NATURAL PERIODS WITH $\Delta \mathrm{k} / \mathrm{k}_{1}$ 


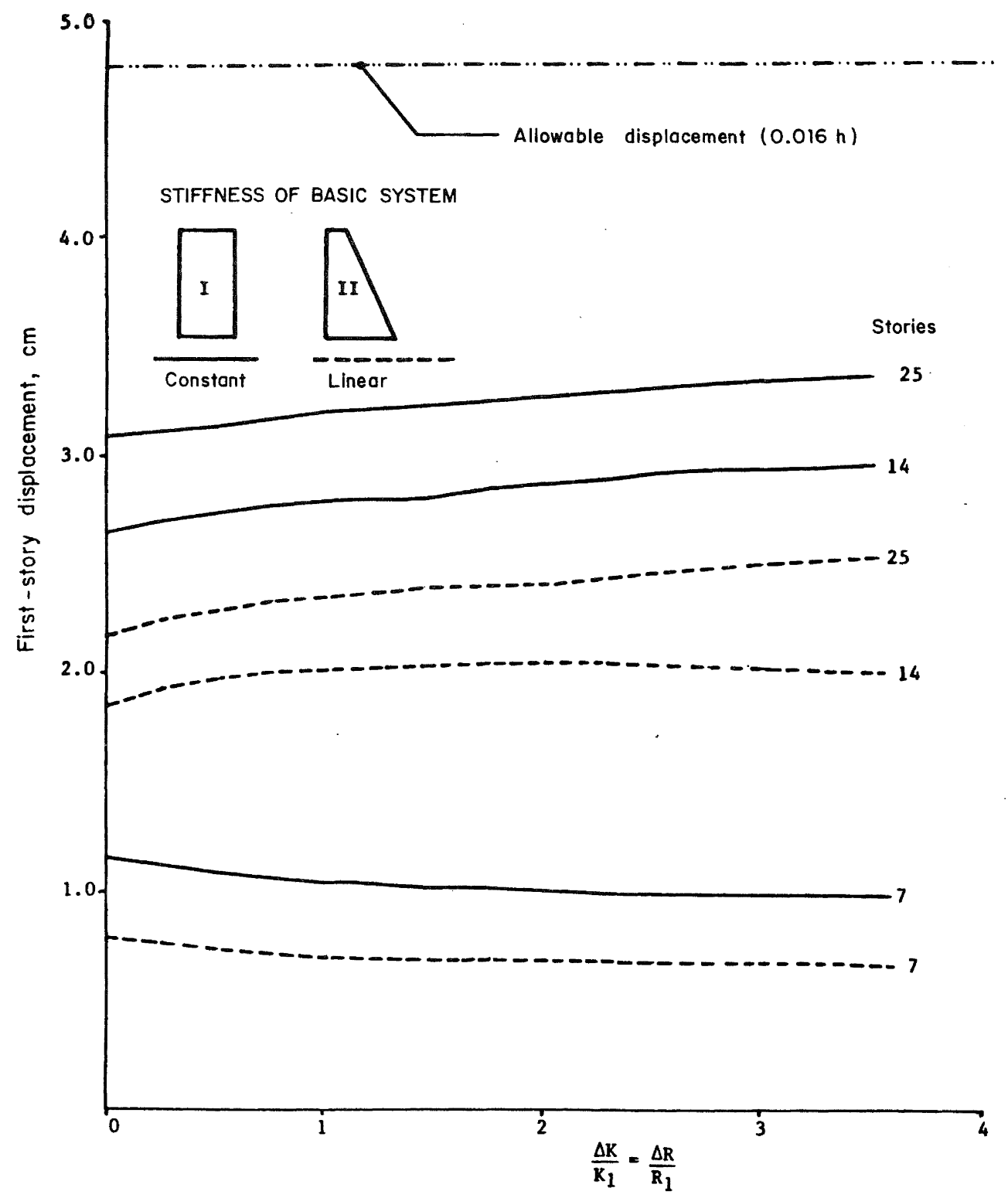

FIG. 29 - VARIATION OF LINEAR RESPONSE WITH $\Delta \mathrm{k} / \mathrm{k}_{1}$

uncertainties involved in the prediction of the dynamic response of real structures, in particular to the need for a systematic study of their force-displacement properties under the action of large-amplitude alternating loads.

The complexity of the interactions involved in the problem can be grasped from Figs. 33-35, taken from Ref, 12, which correspond to the second part of the research program mentioned above. Figs. 33 and 34 correspond to five-mass systems, with fundamental natural periods of 0.63 and $2.0 \mathrm{sec}$, respectively, and Fig. 35 corresponds to a twelve-mass system. For $\mathrm{T}=0.63 \mathrm{sec}$, the response of the uniform system is greater than that of the system with stronger and stiffer upper floors; the reverse is true for $\mathrm{T}=2.0 \mathrm{sec}$. Fig. 33 shows that the response of the uniform system with $T=0.63 \mathrm{sec}$ has a clearly defined dominant period of $2.2 \mathrm{sec}$, which practically coincides with the dominant period of the excitation. On the other hand, the response of the non-uniform system shows that frequencies higher than those of the excitation significantly contribute to the response. The explanation of these discrepancies seems clear: the uniform system softens as it responds, and the softening involves both the first story and the upper ones, thus leading to tuning of its response with the excitation, while the non-uniform system, with stronger upper floors, softens (significantly) only 


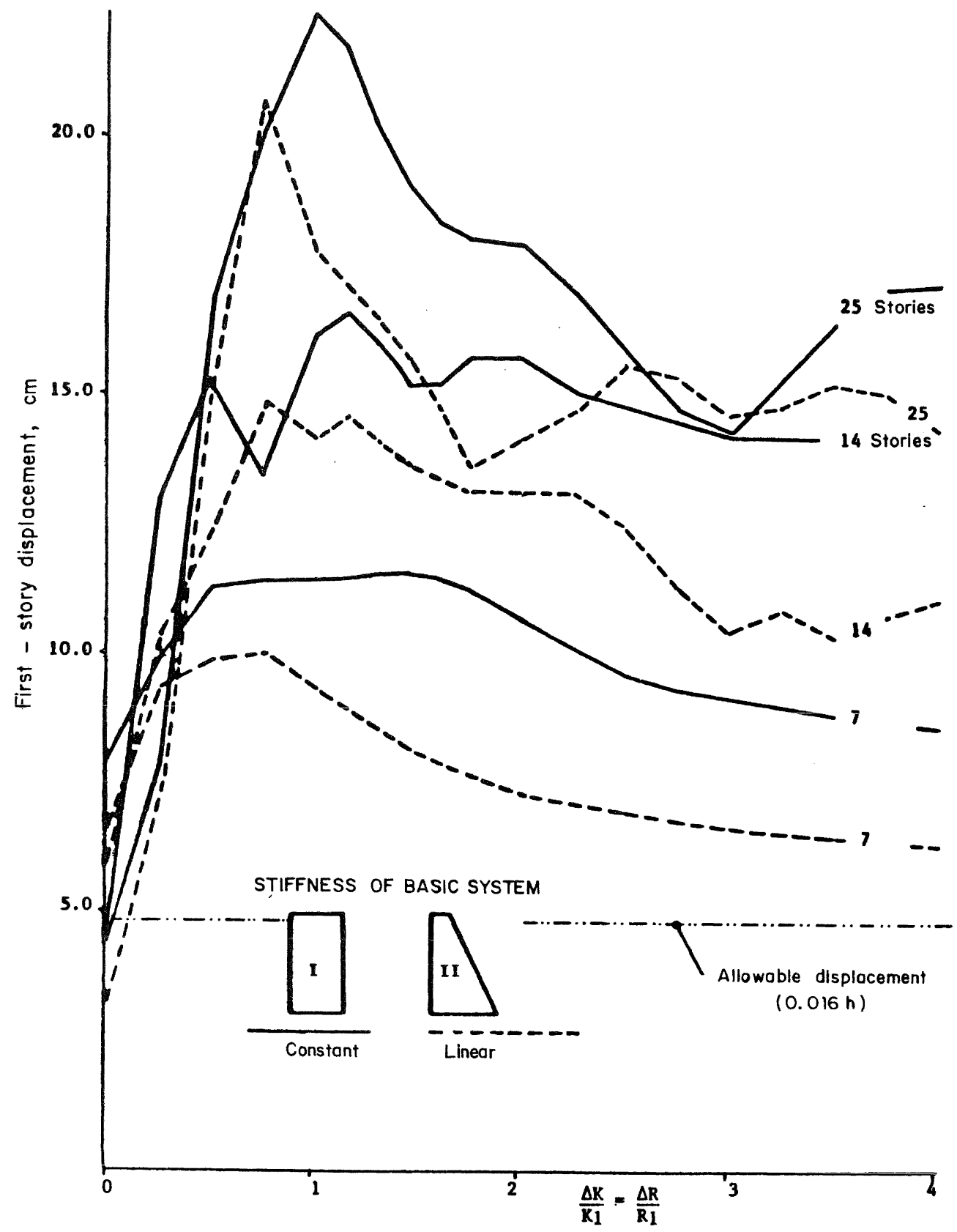

FIG. 30 - STRUCTURAL RESPONSE WITH MODIFIED NATURAL PERIOD

at the first story, but that softening is not enough to lengthen sufficiently the effective period of the system so as to tune its response with the excitation. The opposite effect is observed in Figs. 34 and 35 , for systems with inital period equal to $2 \mathrm{sec}$ and $1.4 \mathrm{sec}$, respectively: the systems which are stronger at their upper stories respond with the same period as that of the excitation, and therefore the displacements of their first floors are large, while the systems which are weaker at the upper stories respond with dominant periods longer than that of the excitation and, therefore, with smaller amplitudes.

\section{SOIL-STRUCTURE INTERACTION}

Many buildings failed at their upper stories rather than at their bases as a consequence of colliding with their neighbours; but many cases of failure at the upper portions of buildings could not be ascribed to pounding, and the conjecture arose that the rocking response produced by soil-structure interaction at the foundation of tall buildings had been respons- 


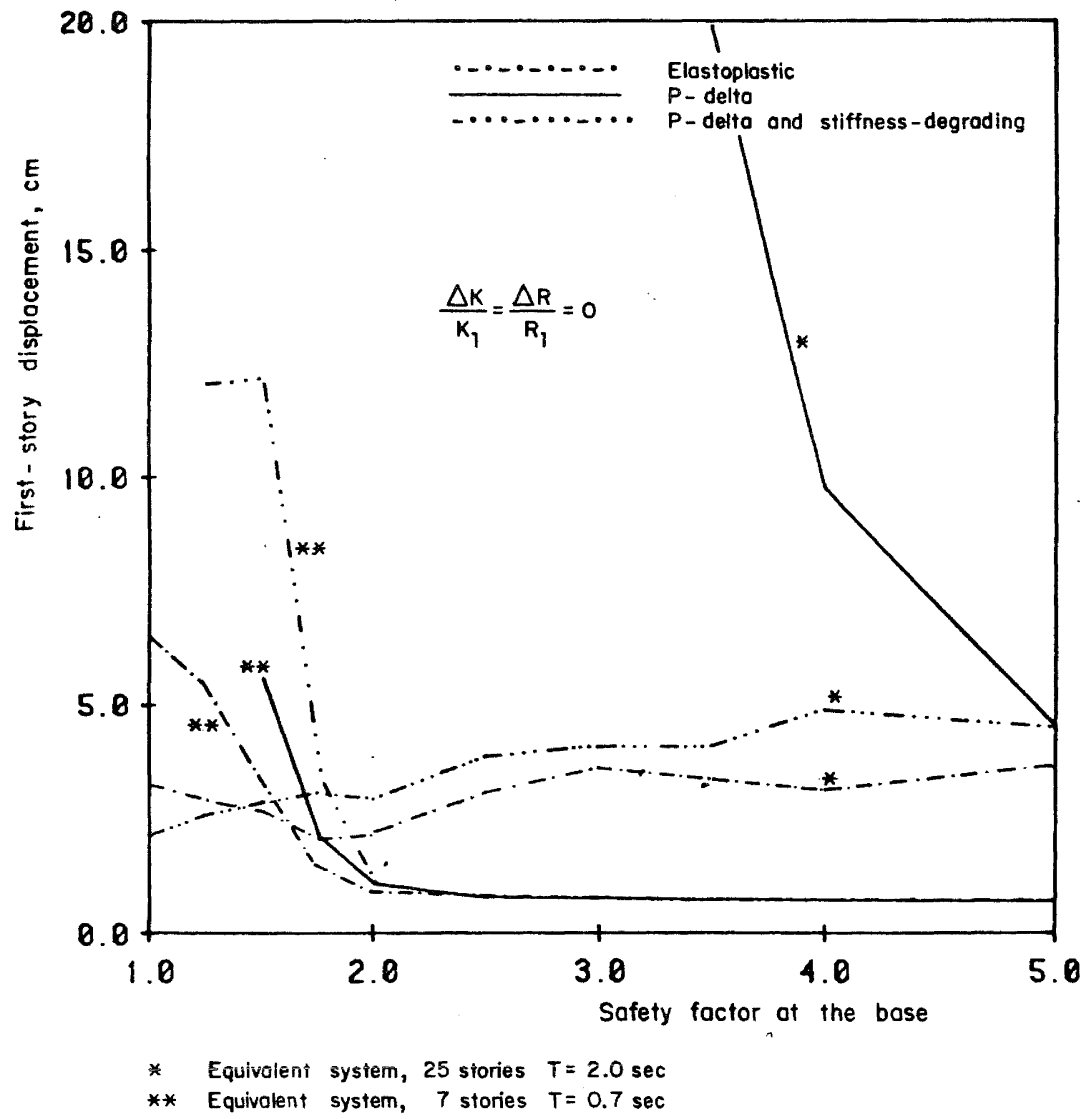

FIG. 31 - INFLUENCE OF P-DELTA AND STIFFNESS-DEGRADING EFFECTS

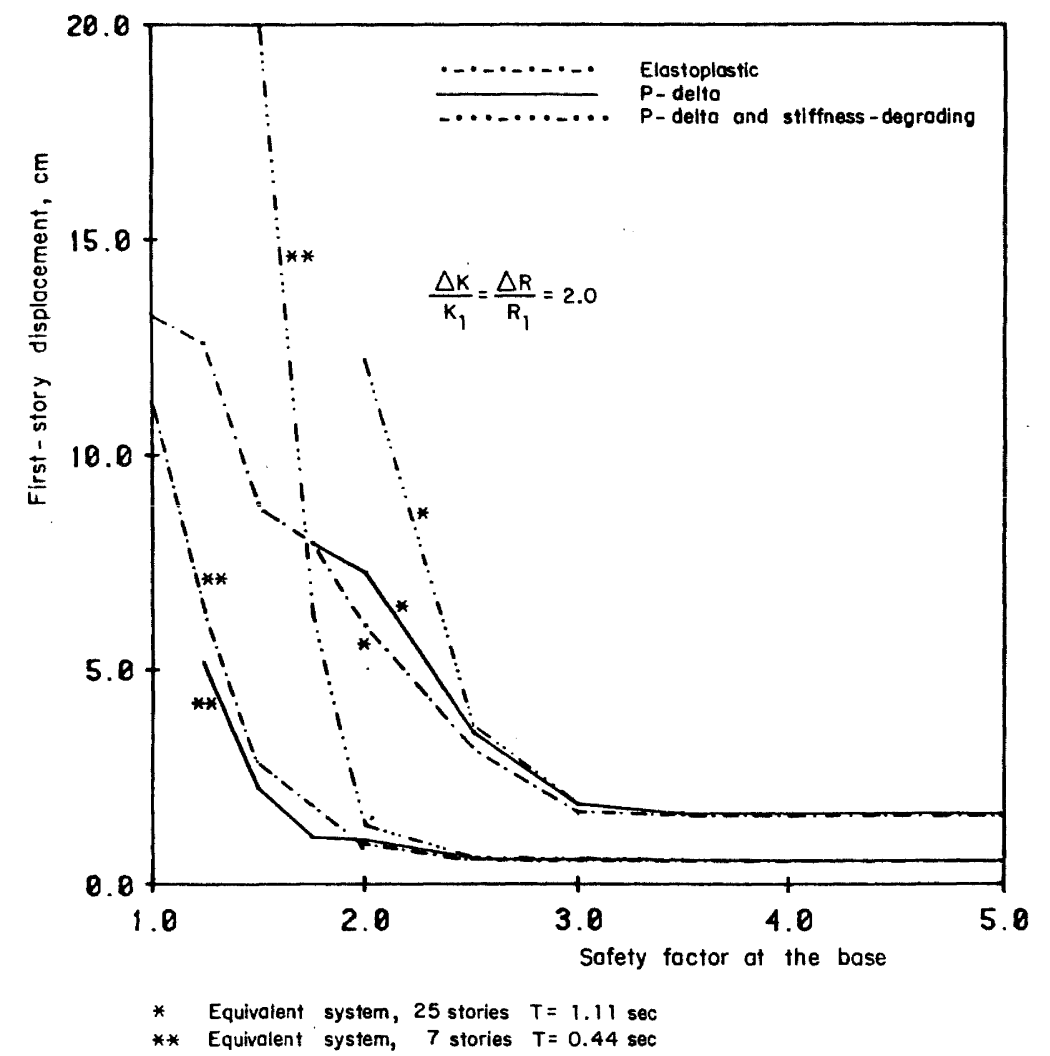

FIG. 32 - INFLUENCE OF P-DELTA AND STIFFNESS-DEGRADING EFFECTS 

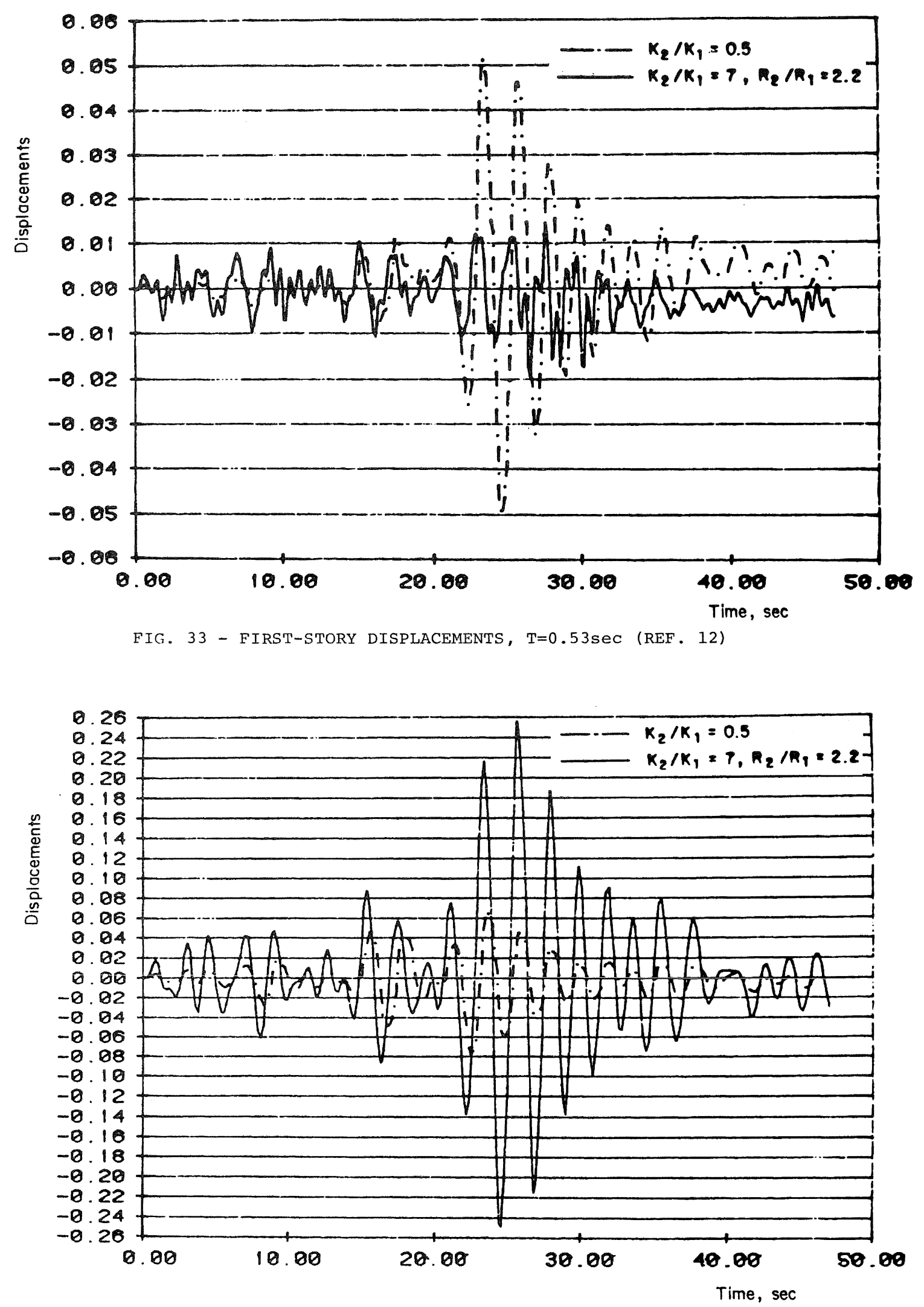

FIG. 34 - FIRST-STORY DISPLACEMENT, T=2.0 sec (REF. 12) 

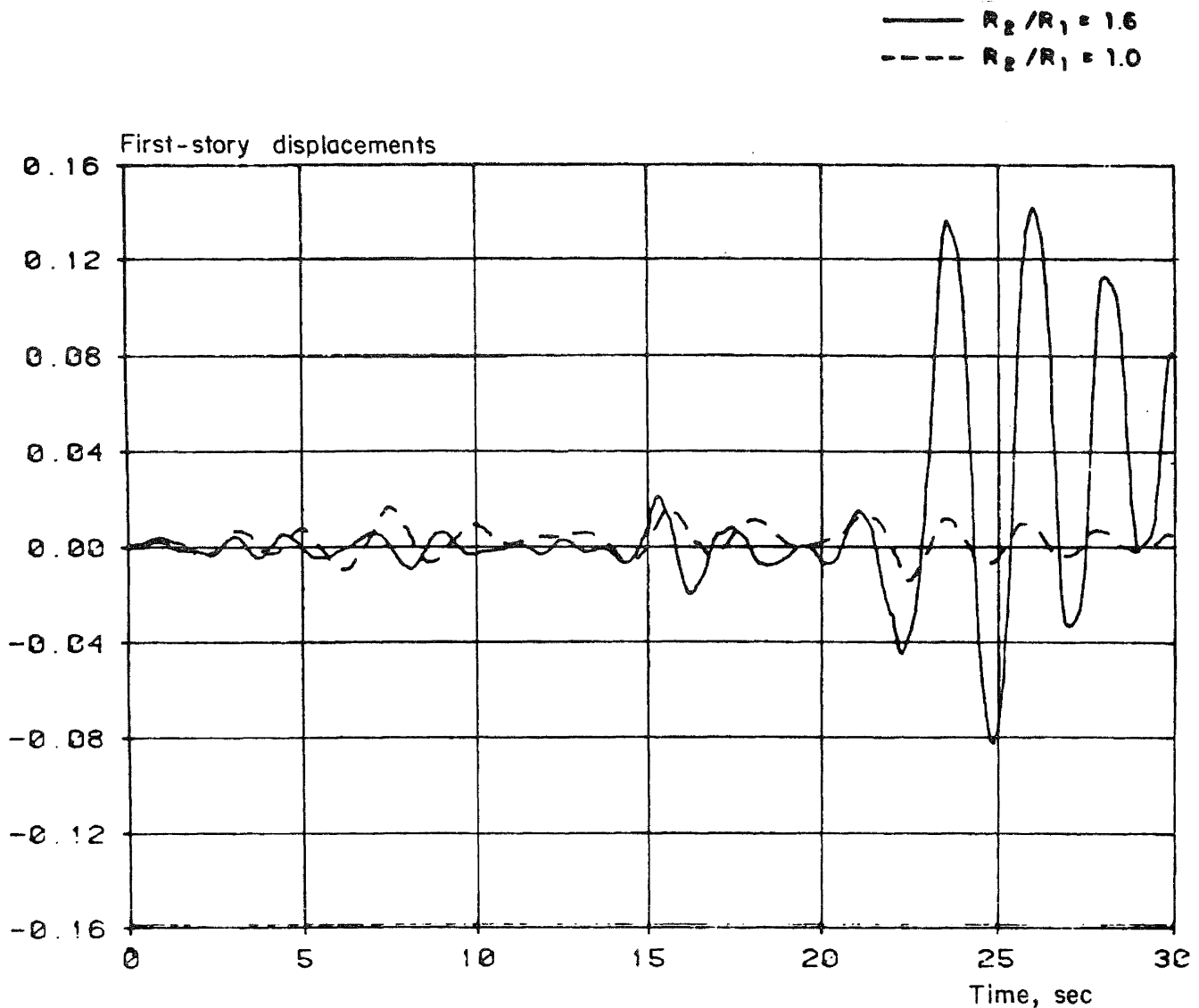

FIG. 35 - FIRST-STORY DISPLACEMENT, T=1.4sec (REF. 12)

ible for excessive accelerations and ductility demands at their tops. Aiming at confirming or rejecting this assumption, a parametric study was carried out on the step-by-step dynamic response of a set of elastoplastic shear-beam systems with dimensions, masses and natural periods lying in the ranges of those found in usual buildings in Mexico City.

The variables studies include number of stories $(10,15,20)$, fundamental period assuming rigid base $(1,1.5,2 \mathrm{sec})$, and forms of variation of stiffnesses along the height of the buildings (constant, linearly decreasing towards the top). The mass per unit height of building was kept constant in all cases, and the height-to-width ratio was always taken as 3 . The design lateral forces were those specified by the emergency code of 1985 for buildings with ductility

factor equal to 4 to be located on the soft soil area. The forces were obtained by means of a conventional modal analysis, assuming rigid base. The safety factor for story shears was also taken as a variable; in some cases it was taken as constant along the building height, while in others it increased systematically towards the top, so as to represent the conditions in real buildings, where the dimensions of some elements contributing to the lateral strength do not decrease as fast as the design shears.
The excitation studied was the EW component of the SCT record of September 19, 1985. Therefore, all systems considered had fundamental periods (neglecting soil-structure interaction) shorter than or equal to the dominant period of the ground motion $(2 \mathrm{sec})$. The dynamic stiffness of the soil, including the contribution of friction piles, was estimated following two alternate approaches $(13,14)$. Some results are shown in Figs. 36-39, for natural periods of 1 and $2 \mathrm{sec}$ and two different values of the safety factors. Figs. 36 to 38 show ductility demands for the conditions of rigid base and for two different assumptions regarding the dynamic stiffness of the foundation. Fig. 39 shows the ratios of the ductility demands including the effects of soil-structure interaction to those corresponding to rigid-base systems.

The following conclusions were reached, including some results not shown in Figs. 36 to 39 :

a) In general, the ratio of ductilities with flexible and with rigid bases grows towards the top. At the top, it is greater than unity.

b) Ductility demands decrease towards the top. At the top, they never reach excessive values. 


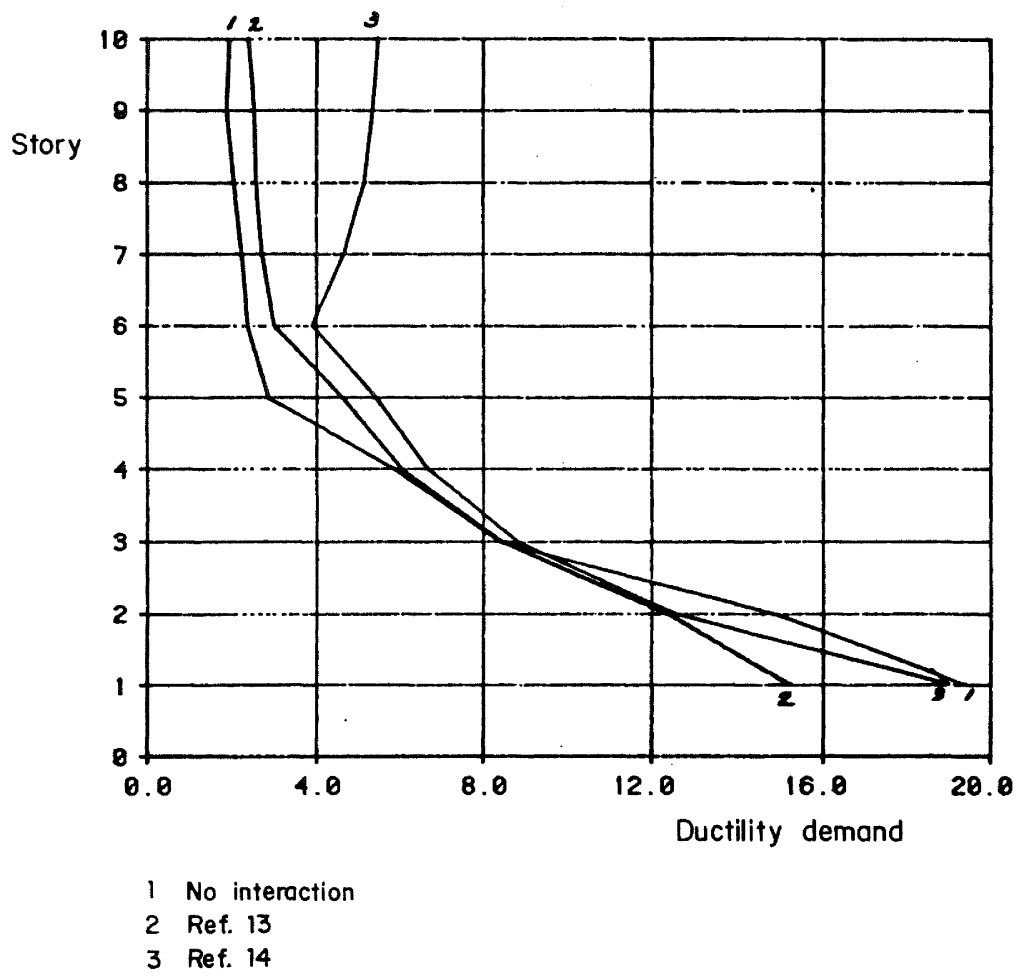

FIG. 36 - DUCTILITY DEMANDS IN SYSTEMS WITH SOIL-STRUCTURE INTERACTION. $\mathrm{T}=1.0$ sec, $\mathrm{K}$ constant, $\mathrm{F}_{\mathrm{S}}=1$

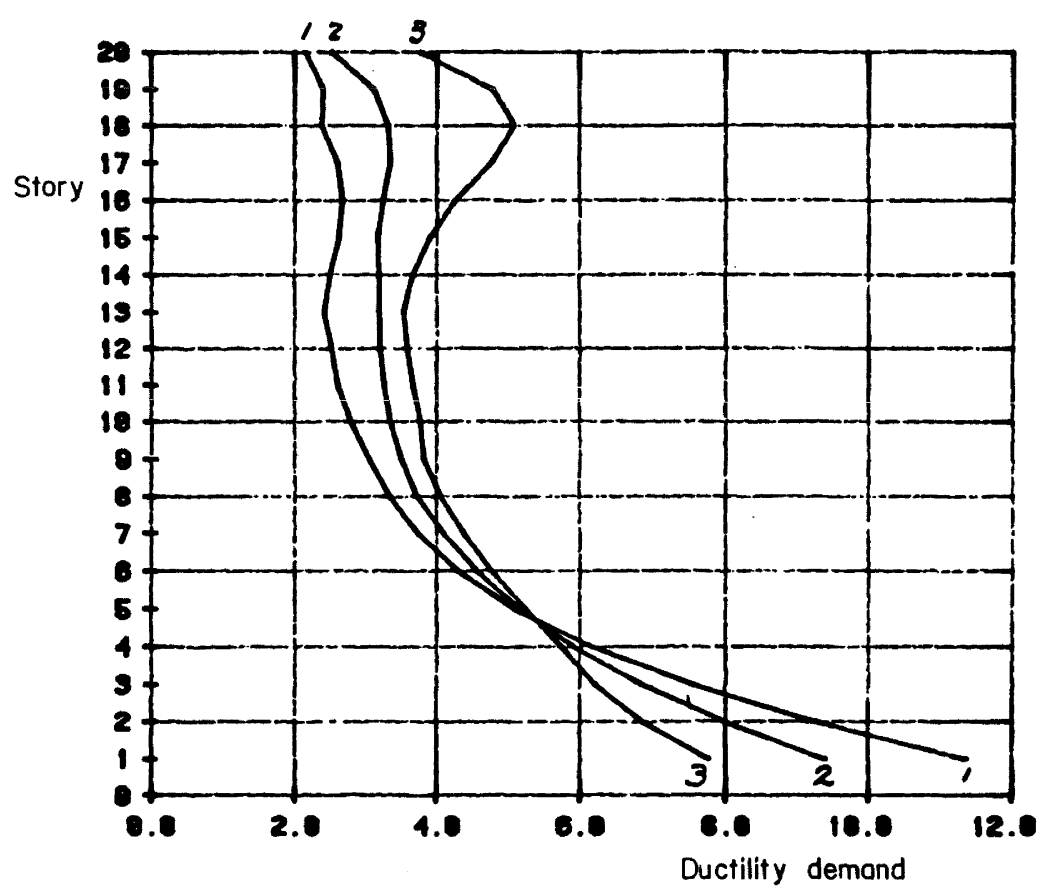

FIG. 37 - DUCTILITY DEMANDS IN SYSTEMS WITH SOIL-STRUCTURE INTERACTION. $\mathrm{T}=2.0 \mathrm{sec}, \mathrm{K}$ linear, $\mathrm{F}_{\mathrm{S}}=1$ 


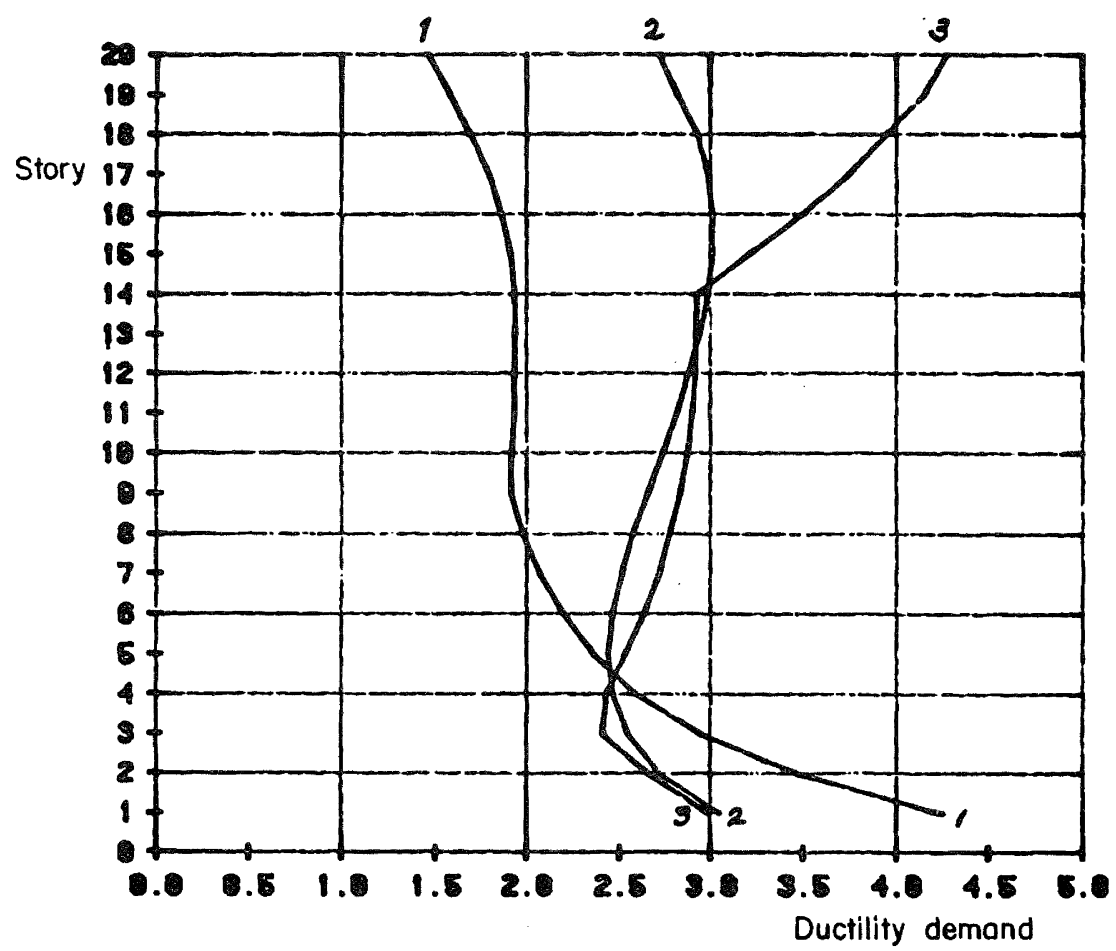

FIG. 38 - DUCTILITY DEMANDS IN SYSTEMS WITH SOIL-STRUCTURE INTERACTION $\mathrm{T}=2.0$ sec, $\mathrm{K}$ constant, $\mathrm{F}_{\mathrm{S}}=1.5$

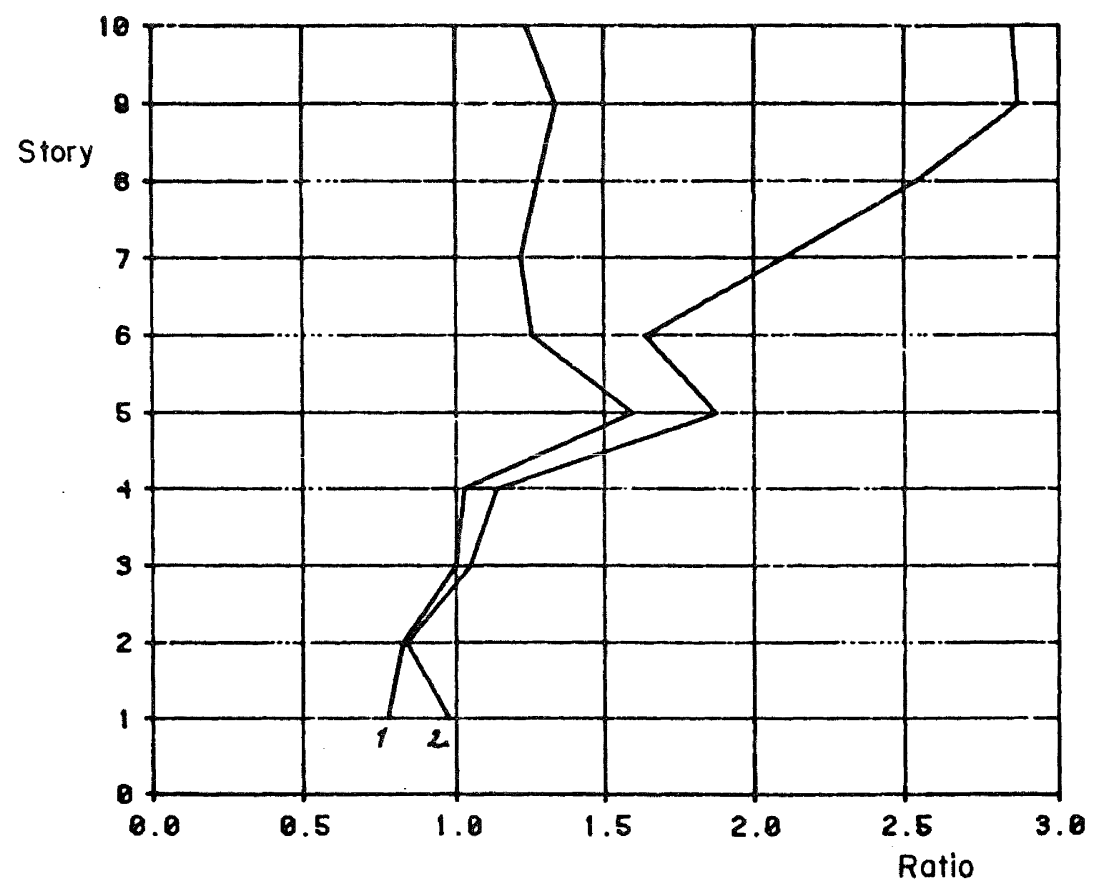

FIG. 39 - RATIO OF DUCTILITY DEMANIS WITH SOIL-STRUCTURE INTERACTION TO DUCTILITY DEMANDS WITHOUT INTERACTION. T=1.0 sec, $\mathrm{K}$ constant, $F_{S}=1$ 
c) For short natural periods, the influence of soil-structure interaction is more pronounced for buildings with stiffnesses decreasing towards the top. For long natural periods, that influence is more pronounced for buildings with constant stiffness.

d) Soil-structure interaction may lead to excessive ductilities at the lowest stories of short-period buildings.

The results of the foregoing conclusions were obtained for natural periods not longer than the dominant ground period. According to them, soil-structure interaction must be discarded as a major cause of failure at the upper stories of buildings, and the likelihood of alternate reasons must be investigated.

\section{TILTING STRUCTURES}

A large number of buildings in Mexico City tilt as a consequence of both load eccentricities at their foundations and random variations in the compressibility of the soil. It is therefore important to assess the significance of tilting on the dynamic response of builaings. If a building with symmetric load-deformation curves for lateral excitation tilts at an angle $\alpha$, its lateral capacity in terms of baseshear coefficient will be decreased by that amount in the direction of tilting but will be increased by the same amount in the opposite direction. The results will be a structure with asymmetric loaddeflection curves. Stimulated by the need to make a decision about strengthening of a building that resulted with residual tilting after the 1985 earthquakes, several simple elastoplastic systems with asymmetric load-deflection curves were analyzed for non-linear response under base excitation (15). Fig. 40 shows the ductility demands for a set of systems with natural period equal to 2 sec, with a nominal base shear capacity of 0.10 . The excitation was the EW component of the SCT record of 1985 and an ensemble of simulations of the same component. The horizontal axis represents degrees of asymmetry, that is, differences between the lateral capacities in two opposite directions. For the case considered, it takes tilting angles of 0.01 to increase the expected ductility demands from 4 to more than 20. Obviously, this effect could not be ignored during the revision of the chapter on seismic design of Mexico City code.

\section{BUILDING CODE}

The committee which formulated the Emergency code of 1985 remained in charge of making a more detailed and careful revision of the previous documents and drafted a revised code. For this purpose, research along different lines was promoted, funds were obtained, projects were started and the results have been made available to those responsible for the different code chapters as they come out. Although many doubts remain and many lessons are still to be digested, the revised documents were turned over to engineers associations for comments from their members. Comments were analyzed and incorporated when adequate, and the final version was issued in June 1987. It was legalized shortly after that.

The revision was not restricted to engineering aspects only, but was much wider than that. Regarding the topics related with structural safety, important changes were introduced in the chapters dealing among other things with the defini-

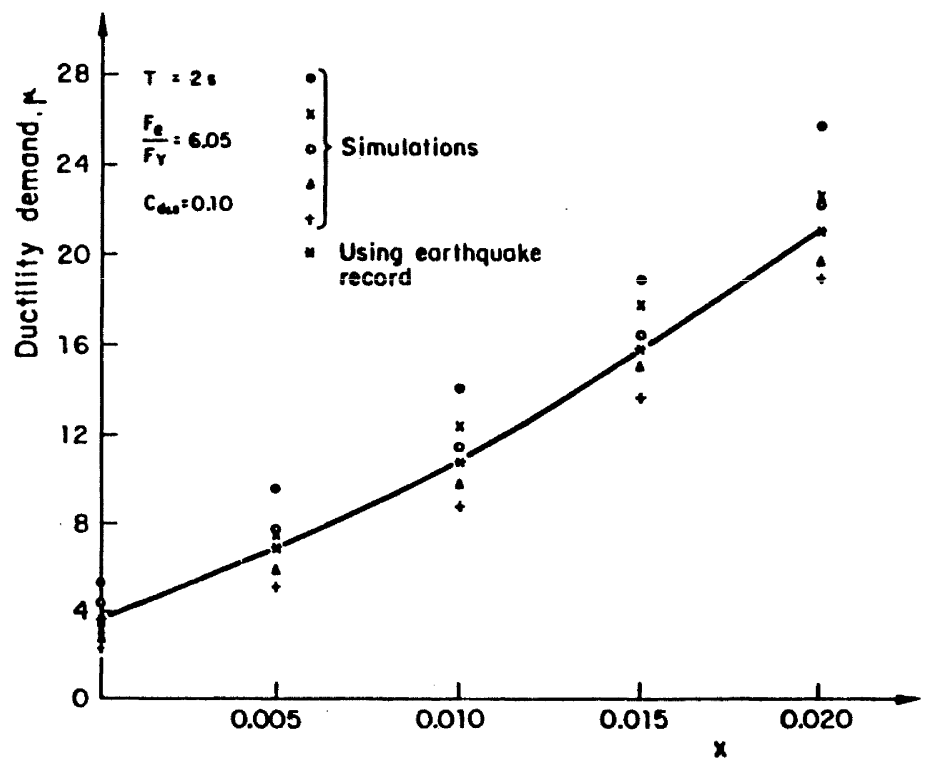

FIG. 40 - DUCTILITY DEMANDS IN SYSTEMS WITH ASYMMETRIC RESISTANCE (REF. 15) 
tion of loads, the design requirements for the various kinds of materials and structural members, the quality assurance regulations and the specific criteria for seismic analysis and design. The comments that follow refer only to the latter criteria, although occasionally they marginally touch others.

As compared with the 1976 code, the 1987 revision includes, as the 1985 Emergency Code, higher design intensities; stricter criteria for detailing structural members and connections, thus improving their capacity to sustain large alternating deformations; stricter criteria for quality control of materials, in particular concrete, and for field supervision; more clearly defined responsibilities concernino maintenance and changes of use of buildings, etc. The following are some of the most important changes to the chapter on seismic design.

\section{Classification of constructions}

For the purpose of the previous regulations relative to structural safety, constructions were classified into three groups: Group A covered very important structures, the failure of which would most likely cost many lives or large material or cultural losses, group B included ordinary office and apartment buildings and group $C$ comprised provisional structures and those whose failure would have only minor consequences. In the present version, group $\mathrm{C}$ disappears and group $B$ is split in two, according to the importance of the structures; sub-group BI includes those constructions taller than $30 \mathrm{~m}$ or larger than $6000 \mathrm{~m}^{2}$ in area to be built in the firm ground or transition zones as well as those taller than $15 \mathrm{~m}$ or larger than $3000 \mathrm{~m}^{2}$ in the lake zone, and sub-group B2 includes the rest in the former group $B$. Constructions in group $A$ are to be designed for seismic base shear coefficients 50 percent higher than those in group B. Constructions in group $A$ and in sub-group B1 are required to have, in addition to a general director of the work, a co-director responsible for structural safety, whose overall responsibility includes the structural design, including the foundation; the execution of excavation, foundation and structure; the quality control of materials and construction procedures, as well as all structural safety concepts involved in the project and execution of non-structural elements.

\section{Seismic Analysis}

As in the previous version, the code permits two versions of static analysis (one ignores the fundamental natural period and the other allows reductions of the base shear coefficient on the basis of Schwarz-quotient estimates of that period) for structures lower than $60 \mathrm{~m}$, and a simplified method for structures lower than $13 \mathrm{~m}$ satisfying certain additional requirements. It demands a dynamic analysis for all other cases.

\section{Microzoning}

obtained in Ref. 7 suggested that throughout the area initially covered by the ancient Aztec city intensities were significantly lower than outside it, and that, on the other hand, in certain parts of zones II and III (transition and soft, respectively) the intensity had been significantly higher than in the rest of those zones, both in 1985 and in 1957 and 1979 . It was not considered adequate raising the design coefficients at these areas of higher intensities with respect to the rest of zone III, on account of the many factors (higher seismic coefficients, lower strength reduction factors, more strict requirements for given reduction factor related with nonlinear response) which were already contributing to raise the strengths of structures designed in accordance with the new code. In view of the lack of sufficient theoretical confirmation it was not deemed adequate specifying lower design coefficients for the lower intensity area mentioned above. However, the findings in Ref. 7 led to specifying that zone III be extended to cover some areas which strictly according to the characteristics of local soil conditions should be included in $\mathrm{z}$ one II. The reason for this increase in intensities is probably the occurrence of local amplification effects not predicted by the simple uni-dimensional wave propogation model.

The fact that intensities were higher in certain portions of zone III (see Fig. 7) was reflected in the new optional Appendix to the technical regulations complementary to the code, which permits reducing the ordinates of the acceleration response spectra in terms of the local value of the fundamental period of the soil, at any point in zones II and III, excluding the highest intensity sub-zone in Fig. 9.

\section{Response Spectra}

The new design spectra resulted from an envelope to the spectra produced by the maximum magnitudes likely to be generated at the various seismic sources near Mexico City. They are also based on a calibration of the performance of structures with different capacities during the 1985 earthquakes. For structures on the newly defined zone III, the maximum ordinates of the acceleration response spectra for linear systems were raised by 67 percent, those for zone II were raised by 60 percent, both with respect to the 1976 version (Fig. 5), while those for zone I were not modified. Thus the new values are $0.40 \mathrm{~g}, 0.32 \mathrm{~g}$ and $0.16 \mathrm{~g}$. The plateaus similar to those shown in Fig. 5 now extend from 0.2 to $0.6 \mathrm{sec}$ for zone $I$, from 0.3 to $1.5 \mathrm{sec}$ for zone II and from 0.6 to $3.9 \mathrm{sec}$ for zone III. As before, the width of each of these plateaus intends to cover concepts such as uncertainties about computed periods, both of the structure and of the ground, or the influence of soilstructure interaction. The optional appendix mentioned above was added, where the use of narrower response spectra is permitted, based on local values of dominant ground period, and assuming that soilstructure interaction will be explicitly 
accounted for in the dynamic analysis.

\section{Strength reduction factors}

Factors similar to those proposed in the emergency code were maintained, aiming at penalizing the strengths associated with brittle failure modes.

\section{Regularity}

One of the main lessons of the earthquake is that irregular structures are much more sensitive to the uncertainties attached to the simplifications inherent in conventional methods of structural analysis. Therefore, a set of conditions are stipulated in order to brand a structure as regular. Other structures are penalized in the sections dealing with allowable base-shear reduction factors.

Regularity requirements include, for instance, the following:

a) The plan must be "nearly" symmetric in plan with respect to each of two orthogonal axes. This symmetry applies to masses as well as to distributions of strength and stiffness.

b) The ratios of height to width and of length to width must be smaller than 2.5 .

c) The plan must not have protruding or entering portions larger in any direction than 20 percent of the building dimension parallel to that direction. Similar restrictions apply to the dimensions of voids in the plan of floor slabs. In addition, these voids must not introduce excessive asymmetries and their position in plan must not vary from floor to floor.

d) Floor and roof systems must be stiff and strong enough as to transmit seismic forces to the resisting elements.

e) The mass and the area of a given floor must lie within 70 and 100 percent of the corresponding value for the floor immediately below it. This restriction does not apply to the floor at the top.

f) All columns are restricted at all floors in two orthogonal directions by horizontal diaphragms as well as by girders or flat slabs.

g) The lateral strength of a given story must not exceed twice the value of the story below it.

h) The torsional eccentricity must not exceed at any story one tenth of the width of the building in that story in the direction parallel to the eccentricity.

\section{Seismic behaviour factors}

These correspond to the former "ductility factors", $Q$, of the 1976 code. Their designation has been changed in order to emphasize that they do not only account for the ability of the materials and structural members considered to develop ductile behaviour, but also for a number of other concepts, such as degradation of strength and/or stiffness, and the uncertainties tied to the prediction of the response and failure mechanisms of given structures. These factors serve to compute numbers ' $Q^{\prime}$, by which the ordinates of the design spectra for linear response can be divided in order to obtain design spectra that account for non-linear response. The larger are the mentioned factors, the larger are the reductions that may be applied to the linear spectra. (For natural periods shorter than $\mathrm{T}_{\mathrm{a}}$, the left extreme of the interval of constant ordinates of design spectra similar to those in Fig. $5, Q^{\prime}$ varies linearly from 1 at $T=0$ to $Q^{\prime}=Q$ at $\mathrm{T}=\mathrm{T}_{\mathrm{a}}$; for $\mathrm{T}$ greater than $\mathrm{T}_{\mathrm{a}}, \mathrm{Q}^{\prime}=\mathrm{Q}$.) In the previous code, the largest allowable "ductility factor" was 6 . In the present one, the largest allowable "seismic behaviour factor" is 4, and its applicability is restricted to structures complying with most of the requirements previously imposed for $Q=6$. In addition, the values of $Q^{\prime}$ must be reduced by 20 percent for systems not satisfying the regularity conditions described above.

In the 1987 code, $Q$ may be taken as 4 for the design of buildings satisfying the following requirements:

a) Their lateral strength is supplied by steel or reinforced concrete frames or by combinations of these types of elements with braced frames or shear walls, but the frames alone are strong enough to resist 50 percent of the specified lateral force. (The previous number for $Q=4$ is 25 percent.)

b) The stiffness of in-fill walls connected to the structure must be included in the analysis, but their resistance can be taken into account only if those walls are built with solid units.

c) The sum of the contributions of frames, braces and reinforced concrete shear walls to lateral strength, neglecting the contribution of masonry walls, must not be less than 80 percent of the specified lateral force. (This restriction accounts for the higher vulnerability of masonry walls to degradation by the action of alternating loads.)

d) The minimum ratio of available lateral resistance to acting shear force at any given story is not smaller in more than 20 percent than the average of those ratios for all the stories. similar restriction, with the same upper bound, was specified in the 1976 code for $Q=6$. For $Q=4$, the upper bound was 35 percent, but, as stated above, it was often violated. This restriction aims at preventing the occurrence of excessive ductility demands at the base of buildings with weak first story.) 
e) Details of reinforced concrete and steel members and connections are those specified in the corresponding chapters of the building code for high ductility members. They are similar to those formerly specified for $\mathrm{Q}=6$.

If requirements $b, c$ and $e$ are satisfied, but not the others, $Q$ must be taken as 3. The same value applies to flat slabs and other frames satisfying the mentioned requirements. Flat slabs must satisfy the design requirements specified in the chapter on reinforced concrete structures.

Lower value of $Q$ apply to other structures.

\section{Torsional eccentricities}

The results of the studies on nonlinear torsional response of one-story systems led to some significant changes in the criteria to evaluate torsional effects. Two types of torsional eccentricities at any given story are considered: the conventional "stiffness eccentricity, $e_{s}$ ", which is the distance between the centroid of the stiffnesses in the direction perpendicular to the eccentricity and the line of action of the shear force at the story of interest; and the newly defined "resistance eccentricity, $e_{r} "$, which is similar to the former, but with the word "stiffnesses" replaced by "resistances". From the mentioned results it is concluded that if $Q$ is taken as 3 , the restriction must be imposed that the strengths of the structural members must be such that $e_{r}$ and $e_{s}$ have the same sign and $e_{r}$ is at least as large as $e_{s}-0.2 b$, where $b$ is the dimension of the story of interest, in the direction parallel to the eccentricity. For $Q>3$, the condition that $e_{r}$ and $e_{s}$ have the same sign is kept, but the lower bound to $e_{r}$ is changed to $e_{s}-0.1 b$.

Previous studies on linear torsional response of single-story systems served to obtain the amplification factor of 1.5 , applied to static eccentricities in order to obtain dynamic eccentricities (16). However, there are cases, such as that of a symmetric tower located in asymmetric position on top of a lower body, where the static eccentricity is zero and the dynamic eccentricity is finite. Obviously, those cases cannot be handled by means of an amplification factors. In the lack of sufficient dynamic response results, it is specified that the design torsional eccentricity at a given story cannot be taken as smaller than half of the maximum static torsional eccentricity at any story below and that the design torsional moment at that story cannot be smaller than half of the maximum calculated for any story above that of interest.

\section{Asymmetric force-deflection curves and tilting structures}

The results in Fig. 40 are qualitatively taken into account by requiring that the resistance reduction factors for the design of members of structures with asymmetric force-deflection curves be divided by the quantity $1+2.5 \mathrm{~d} Q$, where $d$ is the absolute value of the difference of the shear force coefficients resisted by the structure in two opposite directions.

For the purpose of verifying the safety of existing structures, the influence of initial tilting on decreasing the lateral resistance in one direction and increasing it in the opposite is taken into account by requiring that the design lateral forces applicable to ordinary conditions be multiplied by $1+5 Q f$, if $f$ is greater than 0.01 , where $f$ is the tilt angle.

\section{Minimum design shear}

The chapter on dynamic analysis specified that the base shear must not be taken as smaller than 80 percent of the product of the weight of the building by the ordinate of the linear response spectrum divided by $Q^{\prime}$. This restriction aims at protecting structures in the face of the very large uncertainties attached to the prediction of dynamic response of real systems.

\section{Existing structures}

All structures belonging to group $A$ that do not comply with the emergency code or with the present code must be strengthened in accordance with the latter. This requirement applies also to structures in group B for which there are doubts concerning safety with respect to failure or serviceability limit states, either because those constructions were seriously damaged in 1985 or for any other reason.

\section{CONCLUDING REMARKS}

Shortly after the main earthquake in 1985 it was known that its intensity had largely exceeded the provisions of the current building code, but also that many cases of collapse or severe damage would have been avoided had very little additional effort been spent in detailing and quality control. The requirements of the 1987 building code are a testimony to this lesson, previously taught many times in many places, but not sufficiently heard or remembered.

Besides confirming previous lessons, the earthquake raised new questions and stressed others formerly asked concerning the ability of engineers to predict the response of complex systems. Questions along this line range from those arising from our imperfect knowledge about the behaviour of structural members and systems under alternating loads to the influence of irregularities in the distribution of masses, stiffnesses and safety factors on the distribution of ductility demands. On one hand, some results of the dynamic response studies presented in this paper show that the mentioned response may be extremely sensitive to the variation of parameters of mechanical behaviour about which we have little knowledge; on the other, the conditions under which a complex system 
subjected to severe dynamic excitation ceases to respond without collapse are not understood, and therefore our efforts to make estimates of safety with respect to collapse in probabilistic terms have to include a large uncertainty reflecting our ignorance. We hope that much will be learned about the dynamic mechanical properties of buildings after the results of ongoing studies on the calibration of observed behaviour of specific buildings with respect to their predicted response are available, but we regret that the absence of strong motion instruments capable of measuring accelerations and deformations at several locations of buildings has deprived us of the possibility of making studies on identification of the properties of building systems under contions of large cyclic deformations.

Our systematic studies on the nonlinear dynamic response of irregular buildings are showing that predicting the distribution of local ductility demands on those buildings is hindered by uncertainties much larger than previously recognized. Although some trends have been identified regarding the influence of torsional eccentricities and sharp variations in safety factors related to storey shears, sufficiently wide parametric studies are still to be carried out, including models other than shear systems. The progress of studies trying to assess the influence of P-delta effects, stiffness and strength degradation and soil-structure interaction is even slower.

Local variations in ground motion intensity presented a pattern much more complicated than conventional amplification models predict. Complexities arise partly because of small-scale local heterogeneities and partly because of the contribution of wave-trains other than those considered by one-dimensional models. A program underway includes formulating a three-dimensional model of the valley of Mexico and obtaining calculated motions at different points on the ground surface for different wavetrains. The results of those studies will serve to refine the microzonation maps proposed in the latest building code.

\section{ACKNOWLEDGEISENT}

Much of the information used in this paper is based on extensive work carried out by several colleagues of the author, who have generously supplied him with published reports or preliminary drafts. To them all I wish to extend my deepest thankfulness, in particular to J. Avila, G. Ayala, R. Gómez, J. Iglesias, R. Melí, M.J. Mendoza and S.E. Ruiz. The Collaboration of $\mathrm{J}$. López and $\mathrm{E}$. Mendoza in some of the structural response studies here presented is also deeply recognized.

\section{REFERENCES}

1. Esteva, L., "The practice of earthquake engineering in Mexico City and its revision in the light of the observations from the 1985 earthquakes", Proc. 3rd U.S. National Conference on Earthquake Engineering, Charleston (1986).
2. Rascón, O.A. and Muñoz, C., "Análisis sismico de tuberias enterradas", Institute of Engineering, UNAM, Report 494 (1986).

3. Meli, R. and Rosenblueth, E., "The 1985 Earthquake causes and effects in Mexico City", Concrete International, ACI, Detroit, Mich. 6 (5), 12 .

4. Meli, R. and Miranca, E., "Evaluación de los efectos de los sismos de septiembre de 1985 en los edificios de la ciudad de México, Parte I. Evaluación de daños", Institute of Engineering, UNAM, Mexico City (1986)

5. Singh, S.K., Mena, E. and Castro, R., "Some aspects of source characteristic of the 19 September 1985, Michoacan Earthquake and ground motion amplification in and near Mexico City from strong motion data", Submitted for publication in the Bulletin of the Seismological Society of America (1986).

6. Mena, E., Carmona, C., Delgado, R. Alcántara, L. and Domínguez, O., "Catálogo de acelerogramas procesados del sismo del 19 de septiembre de 1985 . Parte I: Ciudad de México", Institute of Engineering, UNAM, Report 497, Mexico City (1986).

7. Iglesias, J., "Estudio de las intensidades del sismo del 19 de septiembre en la ciudad de Mexico", Universidad Autónoma, Metropolitana,' Mexico City (1987).

8. Avila, J., "Evaluation of the behaviour of buildings damaged during the september 1985 earthquakes". Work in progress at Institute of Engineering, UNAM, Mexico City (1987)

9. Mendoza, M.J. and Auvinet, G., "Comportamiento de cimentaciones de edificios en la ciudad de México durante el sismo del 19 de septiembre de 1985", Insitute of Engineering, UNAM, Mexico City (1987)

10. Gómez, R., Ayala, G. and Jaramillo, D., "Respuesta sísmica de edificios asimetricos", Institute of Engineering, UNAM, Mexico City (1987).

11. Esteva, L., and Lopez, J., "Respuesta sismica de edificios de cortante coñ planta baja debil", Report on work in progress, Institute of Engineering, UNAM, Mexicot City (1987)

12. Diederich, R. and Ruiz, S.E., "Influencia de un piso bajo débil en la seguridad sismica de edificios", Institute of Engineering, UNAM, Mexico City (1987).

13. Novak, M., "Vertical vibration of floating piles", Journal of the Engineering Mechanics Division, ASCE, 103, EMI (Feb. 1977), 153-168.

14. "Reglamento do Construcciones para el Distrito Federal, Normas Técnicas Complementarias para Diseño por Sismo", Mexico City (1987)

15. Ruiz, S.E., Rosenblueth, E., and 
Diederich, R., "Ductility demands of structures with asymmetric resistance" personal communication from work in progress at Institute of Engineering, UNAM, Mexico City (1987).

16. Rosenblueth, E., and Elorduy, J., "Responses of linear systems to certain transient disturbances", Proc. Fourth World Conference on Earthquake Engineering., Santiago, Chile (1969) 1, A-1, 185-196.

APPENDIX A. PROPERTIES OF SEVERAL BUILDINGS AND DESCRIPTION OF DAMAGE

\section{B 1: Zacatecas}

Height: nine stories and a two-story appendage

Date of construction: 1970

Type: reinforced concrete beams and columns, combined with a system of confined-masonry load-bearing walls.

Building code, $C_{\mathrm{s}}: \mathrm{C} 66,0.06$

Foundation: partial compensation of weight, combined with friction piles, $22 \mathrm{~m}$ long

Failure mode: overturning as rigid body, by failure of foundation.

Comments: ASR values for tension and compression forces on piles are around unity for $\mathrm{C}_{\mathrm{S}}=0.06$. The safety factor with respect to story shears is larger than that with respect to overturning.

\section{B2: Izazaga}

Height: eleven stories above ground, a basement and a two-story appendage.

Date of construction: 1971

Type: waffle-slabs and columns, infill walls isolated from structural frames

Building code, $\mathrm{C}_{\mathrm{S}}: \mathrm{C} 66,0.06$

Reinforcement details:

a) adequate transverse reinforcement in columns

b) poor slab-to-column connection

c) poor transverse reinforcement in slab ribs

Foundation: point bearing piles

Damage:

a) floor system: diagonal cracking of slab ribs

concrete crushing at slabcolumn connections

b) columns: only slight damage

Comments: For E 85 loads, typical values of ASR for bending moments on columns ranged between 1.06 and 1.83, while the corresponding ASR for shear forces ranged between 0.24 and 1.21. Damage was typically slight or insignificant on columns, perhaps as a result of having much larger safety factors with respect to shear forces than to bending moments.

\section{B3: Medicos Militares}

Height: seven stories above ground, a basement and a two-story appendage.

Date of construction: 1968

Type: waffle-slab and columns, with lightmasonry diaphragms and reinforced concrete cross-bracing in one direction; brick masonry core at shaft for elevators and stairway.

Reinforcement details:

a) poor anchorage of reinforced concrete braces

b) shallow beams embedded in waffle slabs; poor transverse reinforcement

c) poor details in columns: bar bundles, scarce transverse reinforcement.

Foundation: totally compensated, no piles Damage:

a) concentrated in ground floor

b) extensive damage of floor system

c) diagonal tension failure of several columns

d) destruction of masonry core

e) concrete crushing at slab-column connection

Comments: No clear relation was found between ASR values and damage in columns, except that damage was much less pronounced at those sections where the safety factor for shear was much larger than that with respect to bending moment

\section{B: Guaymas-Chapultepec}

Height: twelve stories above ground, a basement and a two-story appendage

Date of construction: 1981

Type: waffle-slabs and columns, corner building, braced masonry panels on frames adjacent to neighbouring plots of land, reinforced concrete core at shaft for elevators and stairway

Building code, $\mathrm{C}_{\mathrm{S}}: \mathrm{C} 76,0.066$ and 0.12 , in longitudinal and transverse directions, respectively

Reinforcement details:

a) poor anchorage of reinforced concrete braces

b) low steel ratios in columns

c) poor concrete confinement in columns

d) too little waffle-slab reinforcement across column-section

e) scarce transverse reinforcement in slab ribs

Foundation: partially compensated, friction piles

Damage:

a) yielding of slab in transverse direction

b) settlement of reinforced concrete core 
c) generalized failure of columns

d) total destruction of several wall panels, floor system panels

Comments:

a) damage is much greater than predicted on the basis of ASR values for bending moments and shear forces

b) generalized failure of columns may be ascribed to the lack of adequate concrete confinement, or to sudden changes in their state of stress resulting from settlement of reinforced concrete core

B5: Añil-Churubusco

Height: ten stories above ground, a basement and a three-story appendage

Date of construction: 1975

Type: flat slabs and columns, masonry walls along two parallel edges, brick masonry core

Building code, $\mathrm{C}_{\mathrm{s}}$ : $\mathrm{C} 66,0.08$

Reinforcement details:

a) shallow beam embedded in slab

b) high steel ratios, but bars in bundles of 4

c) insufficient confinement in concrete core

d) insufficient reinforcement at slabto-column connections

Foundation: partial compensation, friction piles

Damage:

Damage is substantially more severe in the direction perpendicular to the masonry walls. Maximum damage occurred at eighth story, which corresponds to maximum computed deformations. Diagonal cracks in columns, in the weakest direction of the building. Extensive damage in slabs, mainly in floors 5 to 7 . Large settlement of masonry shaft. Average building settlement: $50 \mathrm{~cm}$

Comments: Diagonal cracking occurred at sections where ASR values for shear were greater than unity and greater than ASR values for bending moment. This is observed both in columns and walls.

\section{B6: Xochicalco}

Height: eight stories and a two-story appendage

Date of construction: 1979

Type: flat slabs and columns, masonry walls along two parallel edges, high intensity of masonry shear walls at all stories, with the exception of ground floor, which is free of walls in one direction

Building code, $\mathrm{C}$ : $\mathrm{C} 76,0.6$ in weak direction, 0.12 in diréction parallel to edge walls

Reinforcement details:

a) shallow beam embedded in slab

b) good slab-to-column connections c) columns with adequate longitudinal and transverse confinement, with exceptions

d) insufficient transverse reinforcement at slab ribs

Foundation: partial compensation, friction piles

\section{Damage:}

Severe damage at ground floor. At upper stories, no damage in direction parallel to edge walls, but walls in the perpendicular direction are severely damaged in the first few lowest stories.

Comments: A close look at the reported ASR values and at the corresponding descriptions of damage show that at the second story columns with ASR in bending moment slightly greater than unity and with ASR in shear smaller than unity suffered no damage, while columns in the ground floor story with similar ASR values, suffered significant damage. 